\title{
The Consumption of Mortality
}

\author{
BY
}

Michael J. Miller, B.A.S.

A Thesis submitted to

The Faculty of Graduate Studies

in partial fulfilment of the requirements for the degree of

\section{Master of Architecture}

Carleton University

Ottawa, Ontario

September 12, 2005

(C) Copyright

2005, Michael J. Miller 


\section{Abstract}

Cemeteries are disappearing from the landscape of the modern city due to society's ambivalence towards death and dying. This thesis challenges this discomfort and reintroduces the cemetery into the city by revitalizing the role of rituals, including communal food rituals in funeral ceremonies. When examining different religions from around the world, we realize that many cultures use food symbolically in their death rituals. A notable example of such a relationship is the Christian celebration of Easter. There are other examples of ancient and modern food rituals that are relevant to funeral ceremonies. These food rituals have the ability to transform, structure, and delineate architectural space. Once these food rituals have been interpreted, they have the potential to inform an architectural strategy that can be used to reintegrate cemeteries into the city. An architectural design proposal for Dead Man's Island, in Vancouver, Canada, demonstrates the site's potential for the reintroduction of the cemetery into the landscape of the contemporary city. This is achieved through a proposal for columbaria and related cemetery infrastructure. In its concluding chapters, the thesis structures a 
series of narratives that guide the reader through the architectural intervention in order to introduce and illustrate thresholds that one would experience in the interface of the cemetery and the city. 


\section{Table of Contents}

Introduction...1

Food and Death

1.1 Food, Death and Society...5

1.2 Food and Death Rituals in Ancient Cultures...8

1.3 Food and Death Rituals in Contemporary Culture...12

Section I Endnotes...16

The Cemetery: A Historical Background

2.1 Location...19

2.2 Typology ...21

2.2.1 Undifferentiated...21

2.2.2 Small Family Plots...22

2.2.3 Rural Activity Focus...23

2.2.4 Population Centre...23

2.3 Cemetery Layout \& Planning: Background...25

2.4 Cemetery Layout: Contemporary Concerns...28

Section II Endnotes...31

Case Study

3.1 San Michele Cemetery...34

Section III Endnotes...39 


\section{Table of Contents}

The Contemporary Cemetery

4.1 The Conception of the Hearth and Sacrifice...41

4.2 The Conception of the Eucharist...44

4.3 The Eucharist: A Modern Understanding...47

Section IV Endnotes...50

A Contemporary Cemetery Proposal: Vancouver B.C., Canada

5.1 Historical Analysis of Proposed Site...53

5.2 Process...60

5.3 First Insights...62

5.4 The Narrative of the Deceased...68

5.5 The Narrative of the Deceased's Beloved...73

5.6 The Narrative of the Pedestrian...84

Section V Endnotes...88

Conclusion...90

Drawings: The Manifestation of an Idea...92

Bibliography...103 


\section{Table of Illustrations}

Food and Death

1.1Cartoon of Grim Reaper...4

The Cemetery: A Historical Background

2.1 View of St. James Acres cemetery in Vancouver... 18

Case Study

3.1 Photograph of San Michele Cemetery...33

3.2 Site diagram of extension to San Michele Cemetery...36

3.3 Site diagram of extension to San Michele Cemetery...36

3.4 Aerial view of proposed extension...37

The Contemporary Cemetery

4.1 View inside Brion Family Cemetery...40

A Contemporary Cemetery Proposal: Vancouver B.C., Canada

5.1 Satellite image of downtown Vancouver and Stanley Park...52

5.2 Satellite image of Dead Man's Island...54

5.3 Detail Photograph of Gestural Model: Historical Layering ...61

5.4 Detail Photograph of Gestural Model: Historical

Fragmentation...61

5.5 Conceptual Image: Layering Study...63 


\section{Table of Illustrations}

A Contemporary Cemetery Proposal: Vancouver B.C., Canada

5.6 Conceptual Image: Light Study ...63

5.7 Art work...65

5.8 Conceptual Image: Merge of land and sky study...65

5.9 Conceptual Image: The Deceased...66

5.10 Conceptual Image: Journey $1 \ldots 66$

5.11 Conceptual Image: Journey 2...67

5.12 Conceptual image of courtyard...67

5.13 Conceptual image of interior looking out...67

5.14 Conceptual image looking out of Columbarium...67

5.15 Conceptual image looking inside Columbarium...67

5.16 View of ramp access to island $1 \ldots 68$

5.17 View of ramp access to island $2 \ldots 68$

5.18 View of courtyard looking South East...69

5.19 View of ramp to main structure...69

5.20 View of main structure exiting ramp...69

5.21 View of processional path towards outdoor ceremonial area...70

5.22 View of ramp down to outdoor ceremonial area...70

5.23 Ariel view of outdoor ceremonial area...70

5.24 View of outdoor ceremonial area looking south...70

5.25 View of main entrance...71 


\section{Table of Illustrations}

A Contemporary Cemetery Proposal: Vancouver B.C., Canada

5.26 View after entering main entrance...71

5.27 View of stacks leading into indoor ceremonial area...71

5.28 View of main ceremonial area...71

5.29 View of ramp to main structure... 74

5.30 View of stairs leading toward bridge...74

5.31 View of bridge connecting the island to Stanley Park...74

5.32 View of ramp to main structure with chapel on the right hand side...75

5.33 View of ramp to main structure... 75

5.34 View of processional path towards outdoor ceremonial area...75

5.35 Aerial view of island looking north...75

5.36 Aerial view of the outdoor ceremonial area looking north...76

5.37 View of ramp down to outdoor ceremonial area...76

5.38 View of ramp to main structure...76

5.39 View of ramp to main structure...76

5.40 View after entering main entrance... 78

5.41 View of stacks leading into indoor ceremonial area...78

5.42 View from entrance looking south along main structure...78

5.43 View from corridor looking into ceremonial area...78

5.44 View of main ceremonial area looking south east...79 


\section{Table of Illustrations}

A Contemporary Cemetery Proposal: Vancouver B.C., Canada

5.45 View main ceremonial area looking north east...79

5.46 View of main ceremonial area from mezzanine...79

5.47 View of stairs to second floor...80

5.48 View of main dinning hall... 80

5.49 View of main dinning hall looking north towards main

ceremonial area...80

5.50 View of columbarium east of main structure... 82

5.51 View of entrance for columbarium...82

5.52 View from inside columbarium... 82

5.53 View from floor five inside columbarium...83

5.54 View of niche looking south from columbarium...83

5.55 View from pedestrian path looking east at bridge... 85

5.56 View of pedestrian path leading to bridge...85

5.57 View of path looking south under bridge...85

5.58 View of water garden looking south... 86

5.59 View from path under waterfall...86

5.60 View of path that provides access to park...86

5.61 View from path looking at park...86

5.62 View of ramp to restaurant located in main structure ...87

5.63 View from inside restaurant...87 


\section{Table of Illustrations}

A Contemporary Cemetery Proposal: Vancouver B.C., Canada

5.64 View from path looking at path that connects to

columbarium...87

5.65 View from path below bridge looking north towards Stanley

Park ...87

Drawings: The Manifestation of an Idea

6.1 Site Plan of downtown Vancouver with Dead Man's Island...92

6.2 Site Plan...93

6.3 Main Structure: Sub Floor Plan...94

6.4 Main Structure: Perspective Sub Floor Plan...94

6.5 Main Structure: First Floor Plan...95

6.6 Main Structure: Perspective First Floor Plan...95

6.7 Main Structure: Second Floor Plan...96

6.8 Main Structure: Perspective Second Floor Plan...96

6.9 Main Structure: North East Elevation...97

6.10 Main Structure: North West Elevation...97

6.11 Main Structure: North East Section...98

6.12 Main Structure: North West Section...99

6.13 Columbarium: Sub Floor \& First Floor Plan...100

6.14 Columbarium: Second Floor Plan... 100

6.15 Columbarium: Floor Plan 2...101 
6.16 Columbarium: Floor Plan 3...101

6.17 Columbarium: Floor Plan 4...101

6.18 Columbarium: Floor Plan 5...101

6.19 Columbarium: Floor Plan 6...101

6.20 Columbarium: Floor Plan 7...101

6.21 Columbarium: North East Elevation...102

6.22 Columbarium: North West Elevation...102

6.23 Columbarium: North East Section...103

6.24 Columbarium: North West Section...104 


\section{Introduction}

This thesis explores the important and crucial role of cemeteries in the development of the collective memory of a city. It argues that, in comparison with the past, contemporary cemeteries are becoming places of 'non-place' as result of what Marc Augé calls "supermodernity". Cemeteries within today's city are slowly fading away from its landscape. This is due to contemporary western society's ambivalence towards death. Graveyards are increasingly placed at the periphery of the city, which tends to separate the domains of the living and the dead, or at the very least have a demarcated boundary that manages their interaction. This thesis will address this erasure of the cemetery from the fabric of the city, and demonstrate that cemeteries are not 'non-places', but are living landscapes where the potential dialogue between the living and the dead can continue. In this transformation of the role of the cemetery, food rituals play an important role. This thesis examines the food rituals that are associated with funerary ceremonies, considered one of the base components in death rituals throughout the world. These have the ability to transform, structure, and 
delineate architectural space. Once interpreted, rituals of food in death rituals can be used to inform an architectural language for the re-introduction of cemeteries within a city's landscape. An examination of modern food rituals pertaining to funeral customs along with a discussion of cemeteries, past and present, will be introduced through a case study of the San Michele cemetery and its proposed extension in Venice, Italy. This discussion will illustrate and support the potential for columbaria on Dead Man's Island in the city of Vancouver, British Columbia, Canada. Finally this thesis will draw conclusions about how western society views death and its practices, as well as how the landscape of the living can be re-conceived and transformed to include the presence of the dead. 


\section{Introduction Endnotes}

${ }^{1}$ Marc Augé, Non-Places. Introduction to an Anthropology Of Supermodernity (N.Y: Verso, 1992) 78. 


\section{Food and Death}

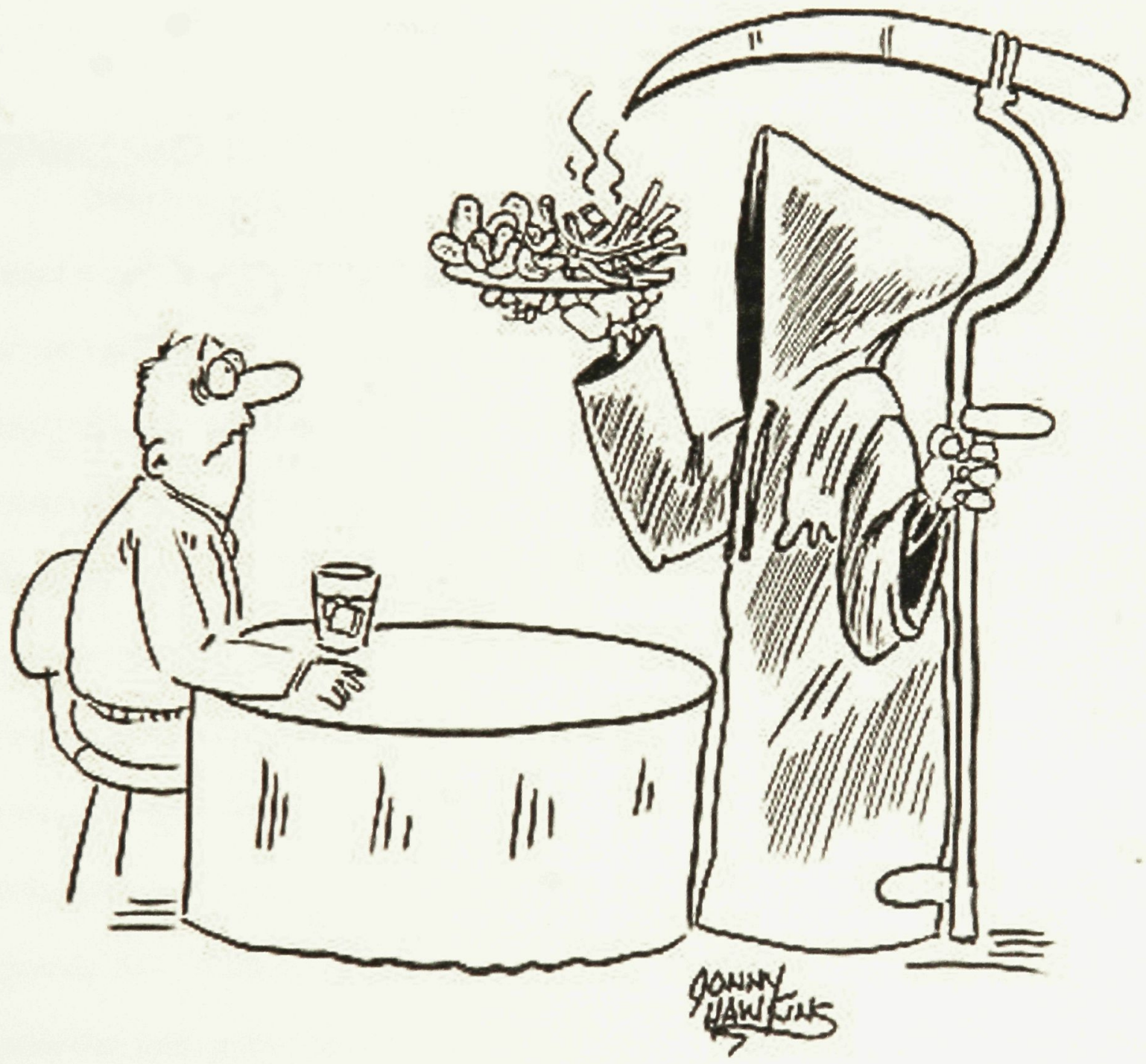

Fig. $1.1<$ http://www.cartoonstock.com/directory/f/french_fries.asp> 


\section{Food, Death and Society}

\section{ONE.ONE}

When one suggests a relationship between food and death, people tend to react either by denying that such a link exists or by conjuring up morbid images of rotting corpses and cannibalistic rituals. I counter this instinctive aversion by arguing that the relationship between food and death is primordial, and that it continues to be manifested today through our everyday rituals and practices. However, modern mass culture has blurred these linkages to a point where society no longer sees a direct relationship between these fundamental elements. The spectacle of death is no longer important, it is only whispered in a modern mass culture that has done all it can to distance itself from not only the animals it eats but also the placement of its deceased. In this chapter I will explore the relationship between food and death rituals, and illustrate their essential role within the fabric of society. I will also examine food and eating through a wider lens, taking it beyond its common definition as a commercial 
resource that is "technologically mediated, manipulated, and reconstructed to suit the narrow objectives of utilitarianism and market efficiency." 2

Food rituals are a basic part of human existence, because, to put it bluntly, we need to eat in order to live. At first glance, this fact seems so obvious that one may question why it needs to be explicitly stated. However, when one examines the statement more closely, it becomes apparent that the necessity to nourish oneself by consuming food is a basic determinant of social interactions and rituals. This is so because during an individual's lifetime, a great deal of time and effort is devoted to the preparation and consumption of food. The necessity of basic nourishment imposes structures on society by, for example, delineating specific times of the day during which meals are consumed. Society has come to rely on this structure, and its daily repetition creates a cycle of rebirth, as with each new day there is a renewed need for nourishment. In the 1960s and 1970s, Levi-Strauss and Mary Douglass stressed the role of food as a signifier, classifier and identity builder. ${ }^{3}$ People imbue particular foods with deep-seated meaning and emotion, regardless of whether they are involved in its production or its consumption. Through food, status is negotiated and social boundaries are drawn. Food can connect or break social hierarchies and draw lines between men and women, and masculinity and femininity. ${ }^{4}$

When I discuss food or eating in the context of rituals, I am referring to anything one can ingest. This consumption can be both literal: eating a pig roasting over an open fire, licking a lollipop, drinking a café latte at Starbucks, and figurative: using animals as symbolic medium for sacrificial and non- 
sacrificial rituals. As French anthropologist and philosopher Roland Barthes once said, food is not only a "collection of products that can be used, but also at the same time a system of communication, a body of images, a protocol of usages, situations, and behaviour." In this way, food becomes more than just nutrients necessary for survival, it begins to shape how one experiences the world. It has been said "the history of man is only intelligible in the context of his history of food. ${ }^{n}$

It is not difficult to find cultural examples where food rituals are carried out in conjunction with death rituals. In most, if not all cultures, there exists a variation of the food and death relationship. In many societies, food bridges the threshold between the worlds of the living and the dead through symbolic rituals embedded in the very fabric of most religious and non-religious based communities. 


\section{Food and Death Rituals in Ancient Cultures}

\section{ONE.TWO}

During feasts in the past death was remembered because food is life, "and such a concrete, certain but temporary joy." ${ }^{7}$ During banqueting ceremonies, entertainment reminded diners that life is short and we should seize the occasion to "eat, drink and be merry." After their deaths, ancient Greeks were often laid out on couches for the funeral ceremony, perhaps on the very beds on which they had once dined. When a meal was completed in ancient Egypt an individual was asked to carry a "skeleton or a wooden image of a corpse in a coffin (among the guests), reminding all that they were all mortal." ${ }^{9}$ Roman and early Christian funeral monuments portrayed Paradise as a banquet, exhibiting the deceased feasting with friends in the hereafter. Christian poetry often portrayed death as a wedding banquet, in other words, as a "solemn but triumphant procession into the dining hall, beyond the threshold of which lies bliss for the soul as bride of the Beloved." ${ }^{10}$ 
The Christian celebration of Easter illustrates the relationship between food and death rituals. For Christians the feast of Easter celebrates Christ's resurrection from the dead, a ritual that is revisited every Sunday during communion. In communion, the Last Supper is re-enacted, and bread and wine are consumed to symbolize God's ability to be transparent and be fully embraceable in their lives. According to the historian Bede the name "Easter" came from the dawn goddess Eostre, who rises in the East and whose name echoes this fact. Easter is a spring dawning, after Jesus' suffering and death, and after the long fast of Lent and the cold of winter; therefore, its physical signs are light and fertile renewal." ${ }^{11}$ In determining the Sunday on which Easter falls, astronomers make reference to the date of the full moon. Thus, "the feast deliberately embraces sun and moon, week and month, and is central to the Christian year. In tune with this, the fertile Easter hare, as representative of the moon, brings eggs, each bearing a little sun as its yolk, and the fragile shell of each inviting initiation and new life, a breaking out of the tomb." ${ }^{12}$

Similarly, in Hellenistic times there were gods that were associated with light: Helios, Ahura Mazda, Mithras, and Osiris. Osiris received sacrifices of black or variegated cocks because he was known as a dying and rising god who knew both the underworld and the light of the sun. ${ }^{13}$ The cock was an important symbol in terms of the mysteries surrounding immortality. To the Greek god of healing, Asclepius, the cock was sacred, and its mythology encapsulated dying and the restoring to life. ${ }^{14}$ The philosopher Socrates was known to have asked for the sacrifice of a cock on his behalf in honour of Asclepius on his deathbed; 
for Socrates believed he was not dying, but awakening to a more bountiful existence. ${ }^{15}$ Hermes, the Greek god, had a great deal in common with cocks. His similarities included "winged, intensely masculine and phallic nature; his role as psychopomp or leader of the souls across the boundary separating life from death" ${ }^{16}$ In ancient Greece it was also customary to leave a jug of olive oil in the deceased's tomb, as a considerate and respectful offering that was viewed as being useful to the dead in the hereafter. ${ }^{17}$ So sacred was food for the Greeks that the ultimate crime that could be committed by a host was the murder of one of his guests at the dinner table. A dinner guest was deemed to be under the protection of the host, and once under his roof guests were vulnerable, trusting, and dependant. ${ }^{18}$

In ancient Roman times people were accustomed to making a day out of visiting the burial places of their family member and friends, and caring for their graves. For them there was something festive about visiting a gravesite to commemorate a relative's death. Perhaps it was the journey out of Rome, while carrying provisions for their meal that ensured the sense of procession and celebration. ${ }^{19}$ During this time the family of the deceased would sit, enjoy the "bucolic surroundings, and picnic. There was also a sense, more or less explicitly believed in, that when friends and relatives ate together at or above graves they were somehow including the dead people in the party, cheering them up, warming them with love and remembrance, and even sharing food with them: people made libations of wine and left food for the dead." 20 
The Sepulchrum Eurysacis, or tomb of Eurysaces, at Rome's Porta Maggiore takes a more individualistic approach to the food and the rituals of death using architecture as a medium. Scholars have interpreted the form of this architecture as replicating some kind of measuring instrument and the upper portion of circular voids are openings that lead to where the bread was baked. ${ }^{21}$ According to William MacDonald the ashes of Eurysaces' wife, Atistia would have "been placed in a marble bread-basket," while the story was further told in the frieze above the grid/square of the "ovens". ${ }^{22}$ In this example, a semantic doubling is introduced: the story of baking is preserved in the frieze decoration, while, at the same time, the monument entombs the baker and his wife in its stone oven. The absence of bread in the oven-tomb might be symbolic of the ritual of communion. ${ }^{23}$ In general, the overall look of the oven-tomb symbolizes both cremation and cooking; merging two very separate avenues into a single polymorphic entity. 


\section{Food and Death Rituals in Contemporary Culture}

\section{ONE.THREE}

When examining different religions from around the world, we realize that many cultures use food symbolically in their death rituals. Some of the first Christians to receive feast days in remembrance of the dates of their deaths were martyrs. Understanding that death is an initiation into eternity with God, Christians called these days "birthdays," or dies natales in Latin. ${ }^{24}$ In the Christian dogma, the ritual known as the Eucharist, also known as Communion, holds specific aspects that integrate the use of food in conjunction with death. It is a ritual which incorporates a belief that Christ and fellow Christians are united with one another. The first Christians met in private houses, around ordinary tables in dinning rooms, needing only two key ingredients, bread and wine. For Catholic Christians, "the Eucharist is God's gift of himself to humankind; and the ultimate sacramental mystery of love again takes the form of eating and drinking." ${ }^{25}$ In this ritual/ceremony individuals who are present eat consecrated 
bread that must first be broken, and may also drink wine from a single cup. In this ritual, the eating of the bread signifies the one becoming many, and in the drinking of the wine, in sharing it, the many becoming one. Through this, Christ's death and the eternal life he gained through his resurrection are symbolically reenacted. Even in his death Christians believe that Christ remains with them through the sharing of the bread and wine; symbolically, his body and blood. In accomplishing this ritual "a number of great oppositions are articulated and the barriers dividing them collapse: God and humankind; the group and the individual; death and life; spirit and body; then and now; here, elsewhere, and everywhere; eternal and temporal; and even meaning and fact ("this is my body")."26

Halloween provides another example of the connection between food and death rituals in modern Western culture. Halloween is a day that holds deep associations within certain cultures, where it not only marks the ending of autumn and the beginning of winter, but also honours death and the dead. Halloween or "All Hallow's" is believed to have originated from an ancient Celtic feast where food and other propitiations were offered to the spirits and costumed followers of the Druid god Much Olla, who went from house to house asking for contributions. If a donation was made, one was promised blessings, if one failed to give, one would suffer bad crops. ${ }^{27}$ In some cultures, the celebration of Halloween is a precautionary strategy against the dead. By giving food to impersonators of the dead, homeowners are able to satisfy their needs, for the time being, and prevent any mischief-making. This exchange of "sharing food is so essential to human 
fellowship, [whereby] bonds are felt to be created with other worlds by offering its denizens food". ${ }^{28}$ Today Halloween has evolved, especially in North America, into a day for children to dress up in ghoulish costumes begging for treats door to door. Remnants of its origins survive however through the costumes, images and the expression: "Trick or Treat".

It is important to remember however that the linkage between food and death rituals is not limited to Western culture. It can also be found in Eastern traditions and practices. For example, in Japan one does not stick chopsticks upright in a bowl of rice, as this practice is reserved for Buddhist mourners making offerings to their dead. Furthermore, in T'ang China there was a hierarchy of milk products: kumyss, clotted cream, and clarified butter; each product symbolized a stage of the transformation of the soul in Buddhism, with clarified butter representing the ultimate development of the Buddha spirit. The cult of the dead is also one of the forms or expressions of patriotism. ${ }^{29}$ In France, the anniversary of the end of World War I is considered the feast-day of dead soldiers. This is celebrated at every monument to the dead, which are found in every French village no matter how small.

With regard to contemporary society, Parkin states that in twentieth century "we have long become used to the idea of the lives of persons and objects as becoming mutually constituted, not in an organic but in a phenomenological sense through the use of metaphor and through perception" ${ }^{30}$ Rather than conceiving an individual as a static being, identity emerges through social interaction and association with particular material objects. Therefore, 
social interaction with and through material forms can morph subject/object boundaries such that material objects become extensions of the body, and therefore the personification of the deceased. Embodied memories of the dead, which are produced in the actions of the living, emerge as habitual repetitions of bodily interactions that have been developed through prior interactions with the deceased. In this way, the deceased may conceivably continue their presence through the bodies of those who survive them. 


\section{Section I Endnotes}

2 Jeremy Rifkin, Beyond Beef: The Rise and Fall of the Cattle Culture (New York: Penguin Books, 1992) 285.

${ }^{3}$ Peter Scholliers, Food, Drink and Identity: Cooking, Eating and Drinking in Europe (New York: Berg, 2001) 7.

${ }^{4}$ Peter Scholliers, Food, Drink and Identity: Cooking, Eating and Drinking in Europe (New York: Berg, 2001) 202.

${ }^{5}$ Jeremy Rifkin, 233.

${ }^{6}$ Jeremy, Rifkin, 234

${ }^{7}$ Visser Margaret, 156.

${ }^{8}$ Margaret Visser, 156.

${ }^{9}$ Margaret Visser, 156.

${ }^{10}$ Margaret Visser, 156

${ }^{11}$ Margaret Visser, The Way We Are (Toronto: HarperCollins. 1994) 213.

${ }^{12}$ Margaret Visser, 213.

${ }^{13}$ Margaret Visser, Much Depends on Dinner: The Extraordinary History And Mythology, Allure And Obsessions, Perils And Taboos, Of An Ordinary Meal (Toronto: McClelland and Stewart, 1987) 125.

${ }^{14}$ Margaret Visser, 125.

${ }^{15}$ Margaret Visser, 125

${ }^{16}$ Margaret Visser, 125.

${ }^{17}$ Margaret Visser, 249. 
${ }^{18}$ Margaret Visser, The Rituals of Dinner: The Origins, Evolution, Eccentricities, and Meaning Of Table Manners (HarperCollins: Toronto. 1991) 110.

${ }^{19}$ Margaret Visser, The Geometry of Love: Spaces, Time, Mystery, and Meaning in an Ordinary Church (HarperCollins: Toronto, 2000) 49.

${ }^{20}$ Visser, Margaret. 49.

${ }^{21}$ Paulette Singley, "Hard To Swallow: Mortified Geometry And Abject Form," Eating Architecture, Ed. Jamie Horowitz (MIT: Cambridge, Massachusetts, 2004) 342.

${ }^{22}$ Paulette Singley, 342.

${ }^{23}$ Paulette Singley, 344.

${ }^{24}$ Margaret Visser, The Geometry of Love: Spaces, Time, Mystery, and Meaning in an Ordinary Church (HarperCollins: Toronto, 2000) 138.

${ }^{25}$ Margaret Visser, 82.

${ }^{26}$ Margaret Visser, 82.

${ }^{27} \mathrm{http}$ ://altreligion.about.com/library/weekly/aa101502a.htm

${ }^{28}$ Margaret Visser, The Rituals of Dinner: The Origins, Evolution, Eccentricities, and Meaning Of Table Manners (HarperCollins: Toronto. 1991) 108.

${ }^{29}$ Ariès, Philippe, Western Attitudes Toward Death: From the Middle Ages to the Present. Translated by Patricia M. Ranum (Johns Hopkins University Press: London . 1974) 75.

${ }^{30}$ Elizabeth Hallam, Death, Memory \& Material Culture (Berg: NewYork, 2001) 42. 


\section{The Cemetery: A Historical Background}

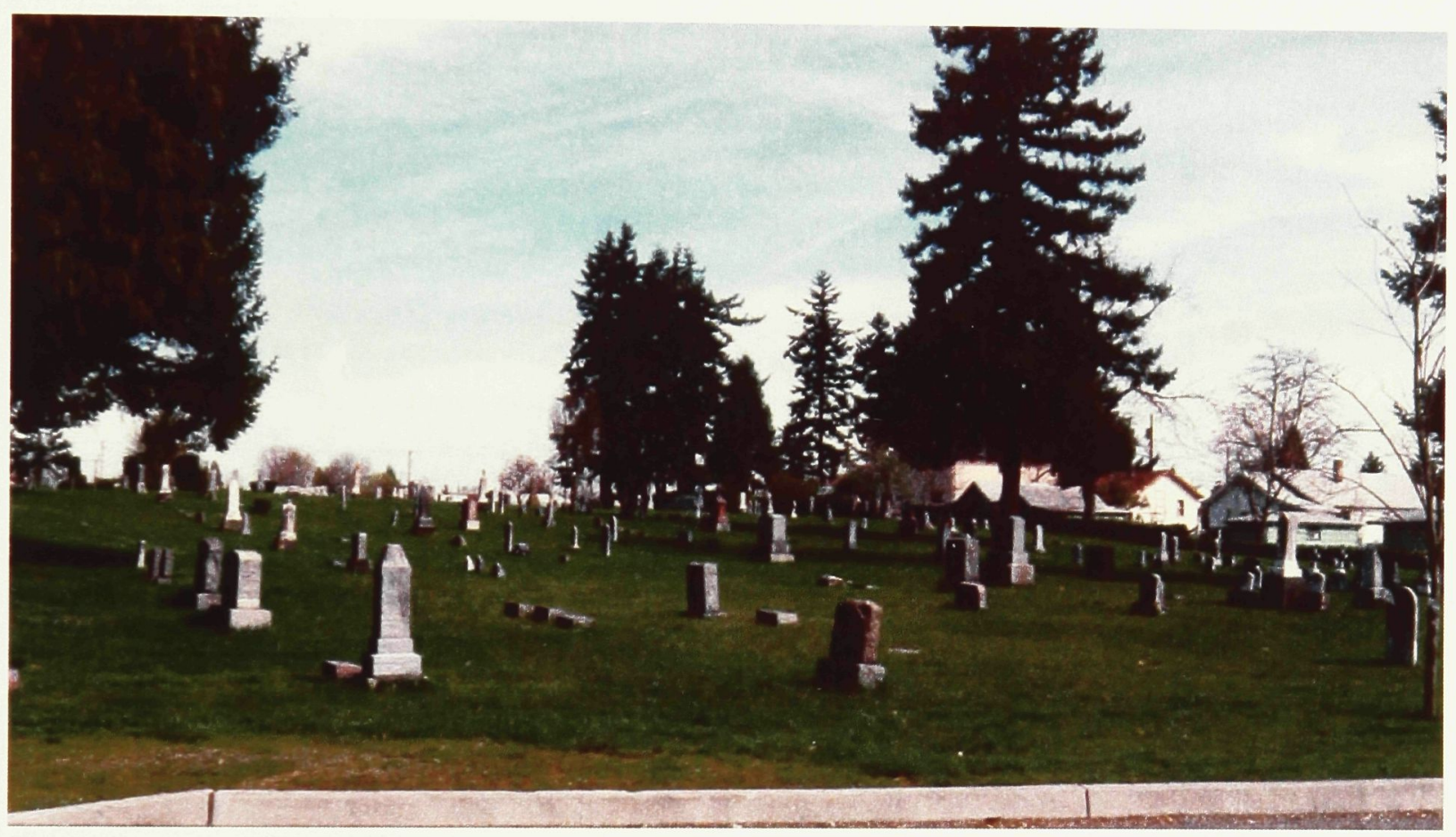

Fig. $2.1<$ http:/www.acc-seattle.com/.../St_James_Acres.htm> View of St. James Acres a cemetery in Vancouver. 


\section{Location}

\section{TWO.ONE}

The word "cemetery" comes from the Greek "koimeterion" or the equivalent Latin "coemeterium", which mean, "to lie down to rest", or "to sleep" ${ }^{31}$ It is impossible to make generalizations about cemeteries, within the context of the past, since local customs play an important role. For example: in ancient Greece as well as Imperial Rome, the dead were often buried in rows along the roadways that lead into cities. The Chinese located their burials by diviners in a similar fashion to the related functions of the city site location whereas the Chilcotin Indians are said to have buried their dead at the location where death occurred. $^{32}$ Thus, there have been numerous methods used to determine the place of burial, some that involved a certain degree of chance, associative orientation or mystical divination.

While the locations of cemeteries can differ from culture to culture, there is an overriding tendency to locate cemeteries on prominent sites such as hilltops or on the slopes of hills. ${ }^{33}$ This choice is likely influenced by the sanitary need for 
appropriate drainage but is equally supported by the spiritual significance of elevated sites as is the case in the Judeo-Christian tradition. 


\section{Typology}

\section{TWO.TWO}

Larry Price suggests in his article, Some Results and Implications of a Cemetery Study, that in the mid-western United States, there is a fourfold classification for cemeteries: 1) undifferentiated; 2) small family plot; 3) rural activity focus; 4) population center. This classification seems to hold true to most of Canada as well. ${ }^{34}$

2.2.1. Undifferentiated - In the Canadian context, undifferentiated burial places are those of voyageurs, lumberman and early settlers who were buried where death occurred. This was usually along early transportation routes, namely rivers. A few piled rocks, short boards, or even a small cross might have marked these sites. ${ }^{35}$ Due to their decay over time, many of these markers are not visible today. In a few instances theses markers have survived, such as those burial sites along the Madawaska, Petawawa, and Bonnechere Rivers; however, one must go by canoe to see them. ${ }^{36}$ 
2.2.2. Small family plots - Although some of these cemeteries may now be surrounded by urban developments, they were originally located on individual farms in rural areas, as is the case with the Billings family cemetery at Billings Bridge in Ottawa. ${ }^{37}$ These types of plots are usually scattered, and generally range in size from five to twenty burials. Most are now overgrown by brush, and are often inaccessible by road.

To explain the existence of small family plots, one can look at Price's basic observations, and draw conclusions:

1. The main means of transportation was horse or oxen-drawn wagons; thus mobility was restricted;

2. Most early settlers were usually poor and could not afford to be transported and buried in a larger, centrally located cemetery;

3. Early settlers were self-sufficient, and developed a strong sense of attachment to the land and it was expected that the family members would be buried on their own land.

As a side note, in some societies the family attachment to land combined with the institution of burial also seems to aggravate population pressure on land. For example, "in pre-Communist China, family graves placed on family agricultural land meant that about two per cent of the arable land in the North China Plain, and as much as ten per cent in some areas, was thus kept out of agricultural production". ${ }^{38}$ There was a change in the means of transportation and a new sense of distance, which resulted from the rise of the automotive industry. This, coupled with changes of rural population structure that reflected 
urbanization processes, led to the abandonment of many cemeteries in isolated areas. ${ }^{39}$ Small family plots were no longer needed and burials began to take place in larger communal plots, which were located near roads or road junctions. $^{40}$

2.2.3. Rural activity focus - Price suggests that this third type of cemetery occurs at a node of rural activity, such as a church, school, or road junction. Generally these cemeteries receive fewer burials than larger highly maintained population-centre type cemeteries. The reasons for this are as follows: firstly, the increased number of people leaving rural areas for urban centres has an inversely proportional relationship to the number of burials in those areas. ${ }^{41}$ Secondly, new types of social orientations are occurring, as a result of technologies like the automobile and television. ${ }^{42}$ Attachments and relationships to older local cemeteries may have been weakened. Rural schools and churches, which used to act as focal points, are now being closed down and demolished, due to the need for larger, more centralized institutions in urban communities. ${ }^{43}$ The closing of some of these rural churches has meant that the cemetery, and its original adjacent association with the community, has also been abandoned.

Finally, one can note that "there is a definite tendency for people to bury their dead where there have been burials in the recent past, and where the cemetery is maintained. As a result most [recent] burials have been in the larger cemeteries near population centres". ${ }^{44}$

2.2.4. Population Centre - This is the fourth type of cemetery, and it is associated with increased urban developments in villages, towns, or cities. ${ }^{45}$ 
Within villages and towns some cemeteries still exist; however, they may be on the margins of these developments, and/or be located next to churches or schools. If these developments experience sudden growth, cemeteries that were once on the periphery may later become surrounded, and provide a buffer zone between different zones within the city. As a result, these spaces may act as "open space" for the residents in the immediate surroundings, and may in time become filled up so that they become inactive. ${ }^{46}$

Price suggests that the status of a cemetery can be categorized as active or inactive. Additionally, Knight in his paper, Cemeteries as Living Landscapes, also suggests a third category: incipiently dormant: ${ }^{47}$

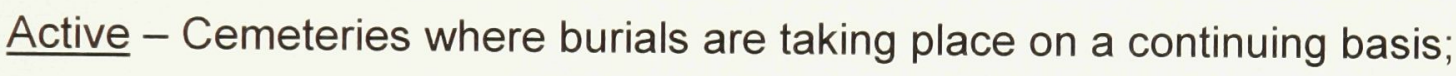
Incipiently dormant - Cemeteries that are for the most part dormant, with the occasional burial;

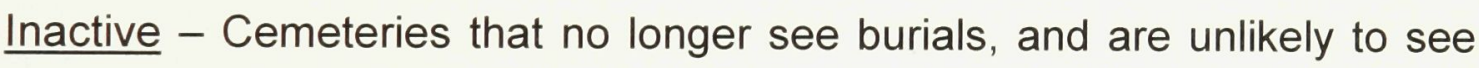
any in the future; these cemeteries may be improperly tended to.

In reference to inactive cemeteries, it would be a tragedy if all the information stored on the decaying stones were not recorded. Cemeteries are a reflection of culture, and communicate not only settlement patterns, but also the history of the community in the surrounding region. 


\section{Cemetery Layout \& Planning: Background}

\section{TWO.THREE}

There are several ways in which cemeteries in their layout, reflect their surrounding social environment. Firstly, there are "good" or "bad" neighbourhoods in many cemeteries, just as in their related towns or cities. ${ }^{48}$ Socially prominent families of a community are generally clustered together and are usually on the higher slopes, just as the more expensive houses in urban developments are often similarly located. ${ }^{49}$ Knight also reveals that "it is an easy task to read the names off the gravestones and not their spatial distribution, and then draw preliminary conclusions which can usually later be supported by interviews or documentary research". 50

Secondly, gravestones can reveal much about a family's status within the community. Kephart, in an article called Status after Death, noted "traditionally, class distinctions within the cemetery were based on size of the lot and size of memorial or mausoleum. Historically, the rich man's grave was marked by a 
large memorial or mausoleum, the poor man's by a small head or footstone, or perhaps by the absence of a stone" ${ }^{51}$ Young also has similar conclusions: "grave markers...can reflect the wealth and prestige of the buyer, and very likely a whole family" ${ }^{52}$ Knight suggests three uses for grave markers: recording the fact of a former life of a person; representing, especially with mausoleums and larger statues, a striving for immortality; allowing a means by which a private family experience with death is shared with the public. ${ }^{53}$

Thirdly, cemeteries reflect their cultural surroundings in that there may be "a real segregation" of a group that is kept out of the grounds. Knight observes that in some older Anglo-Canadian cemeteries along the St Lawrence River in Eastern Ontario there have been segregated burials of Irish and Germans in the Catholic cemetery of Cormac. Knight's research reveals other instances:

"In one united Church cemetery along the St. Lawrence, in which all the names were of Scottish origin, my wife and I found a case where a Scot had married and English girl and they had been buried off to one side away from everyone else. Were they banished in life as in death?! In yet another instance, in the cemetery in Earltown, Nova Scotia, there is an interesting case of a real segregation by clan membership due to rivalries that predate movement to Canada. The Sutherlands and Mackays did not see "eye to eye" when in the Parish of Rogart, Sutherlandshire, Scotland, and after their movement to Nova Scotia around 1818, they maintained their "social distance" even in death, for the Sutherlands are buried in one section of the cemetery and the Mackays in another - with the neutral "cider" Macdonalds (who owned a cider mill) being buried in a buffer zone between them."

It has also been noted that in some societies, in Britain for example, the bodies of suicides and murders are often buried on the north side of 
churchyards. If one refers to the burial of Ophelia in Shakespeare's Hamlet, one can see that it is presumed that the north side of churchyards is seen as unsanctified ground. ${ }^{55}$ In the play, one of the priests announces: "her death was doubtful" and that Ophelia should be buried in "ground unsanctified", meaning that she may have killed herself, and should be buried next to the suicides and away from the holy ground of the general public. 


\section{Cemetery Layout: Contemporary Concerns}

\section{TWO.FOUR}

In determining the overall structure of cemeteries, class distinction, religion, national heritage, and even race, play a decisive factor in their growth and spatial arrangements. ${ }^{56}$ This was especially true in the late 1800's and early 1900 's. In contemporary society, this seems to be less of a concern, and the development of cemeteries is primarily driven by modern economics. For example, in modern cemeteries it is more cost effective to have stones that are flush with the ground, to ease the maintenance of the grounds by lawnmowers. For J.B. Jackson, in his article The Vanishing Epitaph: From Monument to Place, the erasure of the monument of death from our landscapes is not only due to concerns for economy and time, but also due to the changing attitudes towards death. ${ }^{57}$ The pastoral open landscape of the new "memorial garden", he holds, possesses no symbolic reminders of the fate that awaits us all. The removal of monuments from these landscapes may symbolize a negation, if only 
subconsciously, of the inevitable, and a rejection of death's permanence. ${ }^{58}$ Knight supports this view, and suggests that the blandness of gravestones inscriptions today (often simply "In Memory of"), may conclude that such a memorial statement could be anywhere. ${ }^{59}$

With the ever-increasing pressures for valuable agricultural or recreational land, high-density urban developments need to examine new burial methods. Cremations offer some relief to this problem, since ashes can be strewn or deposited in urns or small structures that allow for more density with less space. However, in a multi-cultural context, more cremation is not always a viable solution since this practice goes against the religious principles of certain groups. Alternatives such as high-rise mausoleums provide another solution to the increasing need for body placement in congested urban areas.

High-rise mausoleums are not a new idea. Examples now exist in several countries including Italy, Japan, and the United States. In Nashville, Tennessee, there is a ten story, air-conditioned, structure that can hold up to 65,000 bodies with an adjacent less-deluxe mausoleum that can accommodate $63,500 .{ }^{60}$ With regard to space, one can look at the area of a high-rise structure and compare it to the conventional placement of bodies for burial. The two high-rise mausoleums of Nashville, which house 128,500 bodies, will occupy a mere 14 acres, while burial in the conventional system would take up to 129 acres. ${ }^{61}$ With respect to addressing the concerns related to body placement in very dense urban areas, the San Michele cemetery in Venice, Italy, has undertaken a series of initiatives 
to tackle this challenge. In order to understand San Michele's continuing concerns with body placement, one must look at its overall history. 


\section{Section II Endnotes}

${ }^{31}$ David Knight, $\underline{\text { Cemeteries as Living Landscapes. (Ontario Genealogical }}$

Society Ottawa Branch: Ottawa, 1973) 5.

${ }^{32}$ Knight. 7.

${ }^{33}$ Knight. 7.

${ }^{34}$ Larry Price, "Some Results and Implications of a Cemetery Study".

Professional Geographer. 201-207.

${ }^{35}$ David Knight, Cemeteries as Living Landscapes. (Ontario Genealogical Society, Ottawa Branch: Ottawa, 1973) 8.

${ }^{36}$ Knight. 8.

${ }^{37}$ Knight. 9.

${ }^{38}$ Sopher, David. Geography of Religions (N.J.: Prentice-Hall, 1967) 32.

${ }^{39}$ Knight, David B. Cemeteries as Living Landscapes. (Ontario Genealogical Society, Ottawa Branch: Ottawa, 1973) 11.

40 Knight. 11.

41 Knight. 11.

42 Knight. 11.

${ }^{43}$ Knight. 11.

${ }^{44}$ Larry Price, "Some Results and Implications of a Cemetery Study".

Professional Geographer . 205.

${ }^{45}$ David Knight, Cemeteries as Living Landscapes (Ontario Genealogical

Society, Ottawa Branch: Ottawa, 1973) 12. 
${ }^{46}$ Knight. 12.

${ }^{47}$ Knight. 13.

${ }^{48}$ Knight. 14.

${ }^{49}$ Knight. 15.

${ }^{50}$ Knight. 15.

${ }^{51}$ Kephart, W. "Status After Death”. American Sociological Review. 642.

${ }^{52}$ Young, F. "Graveyards and Social Structure." Rural Sociology. 447.

${ }^{53}$ David Knight, Cemeteries as Living Landscapes (Ontario Genealogical Society, Ottawa Branch Ottawa 1973) 17.

${ }^{54}$ Knight. 15.

${ }^{55}$ Knight. 16.

${ }^{56}$ Knight. 16.

57 J.B. Jackson, "The Vanishing Epitaph: From Monument to Place", Landscape. 22-26.

${ }^{58}$ Jackson. 24.

${ }^{59}$ Knight, David B. Cemeteries as Living Landscapes (Ontario Genealogical Society, Ottawa Branch: Ottawa,1973) 21.

${ }^{60}$ Knight. 31.

${ }^{61}$ Knight. 32. 


\subsection{Case Study}

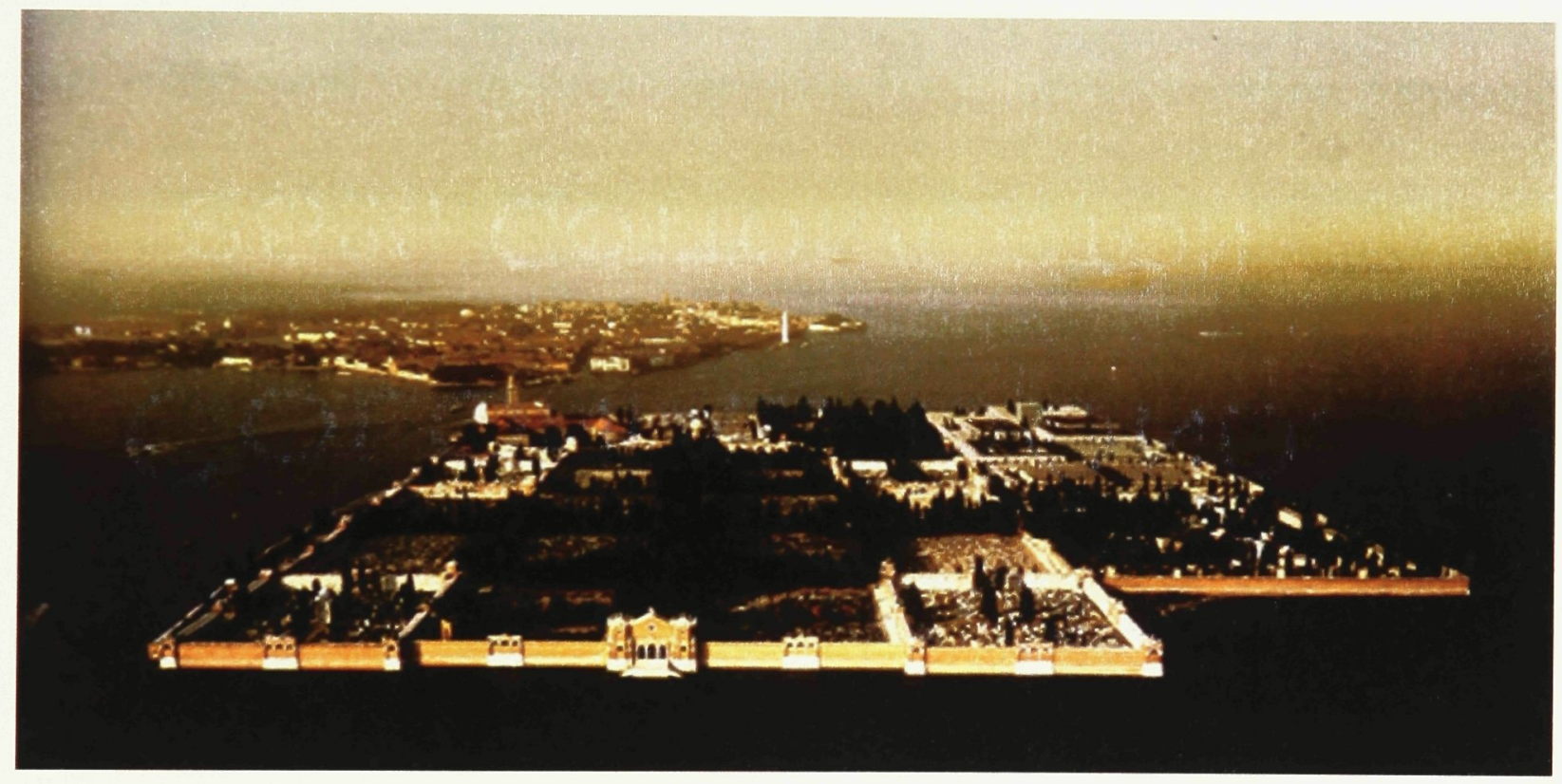

Fig. 3.1 "San Michele Cemetery." Architecture and Urbanism. 402.3 (2004) Aerial photograph of San Michele Cemetery in Venice, Italy. 


\section{San Michele Cemetery}

\section{THREE.ONE}

Located on an island no more than several hundred metres from Venice's north shore, the San Michele cemetery was joined with the island of San Cristoforo in 1835 , and became the first general cemetery that is now the focus of Venetian "civitas" or civic pride. ${ }^{62}$ There has always been a need to continually enlarge the cemetery. The original cemetery of San Cristoforo was completed in 1813, and a mere three years later plans were being drawn to extend the burial ground to include the adjacent island of San Michele, which, at that time, housed a Camaldolese monastery. Between 1835 and 1839, under the direction of Giuseppe Salvadori, the 85 metres of land that separated San Cristoforo from San Michele were reclaimed from the lagoon. Between 1840 and 1860, Annibale Forcellini expanded the island even further by adding a red, brick enclosing wall topped with a pietra d'Istria (white stone) frame. ${ }^{63}$ Further expansions continued into the twentieth century with an addition of a sacca along the eastern wall. 
Following this, in 1975, a second sacca was created on the north-eastern edge to collect mud accumulated from the excavation of canals in Venice. Later, the San Michele cemetery created a policy whereby an individual is buried for twelve years, then cremated and the ashes scattered into a communal sanctified area. Alternatively, the relatives of the departed can pay for the ashes to be transferred into an urn to occupy a spot in one of the many single-storey structures that envelope the cemetery.

By the late 1990's there was still an urgent need for an expansion strategy for the cemetery. The Comunità di Venezia, directed by the mayor of Venice, held an international architectural competition, selecting a winning entry from the London-based firm, David Chipperfield Architects. Construction of the extension will take place in two phases.

The first phase is to be built on the existing sacca located on the northeast corner of the island, and is characterized by physical spaces such as external squares and internal courtyards that reflect an urban quality (Figure $3.2 \& 3.3$ ) ${ }^{64}$ In this phase, two external squares are framed by the smaller, single story internal courtyards, which are formed out of wall tombs. These smaller courtyards differ slightly in size and function, and once they are taken together, they form a sequence of distinct spaces. ${ }^{65}$ Helen Castle, in her article Death in Venice, suggests:

"... each court is to have its own discernible qualities, and thus identity. So, as Chipperfield suggests, you might know the courtyard where your mother is buried by its lemon trees and copper door. This creates a sense of orientation, but more over of place and belonging." 


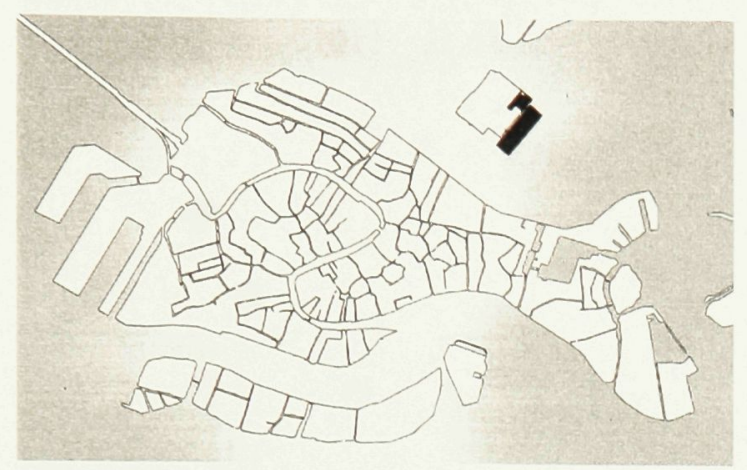

Fig. 3.2 "San Michele Cemetery." Architecture and Urbanism. 402.3 (2004) Site diagram of Venice's proposed extension to San Michele cemetery.

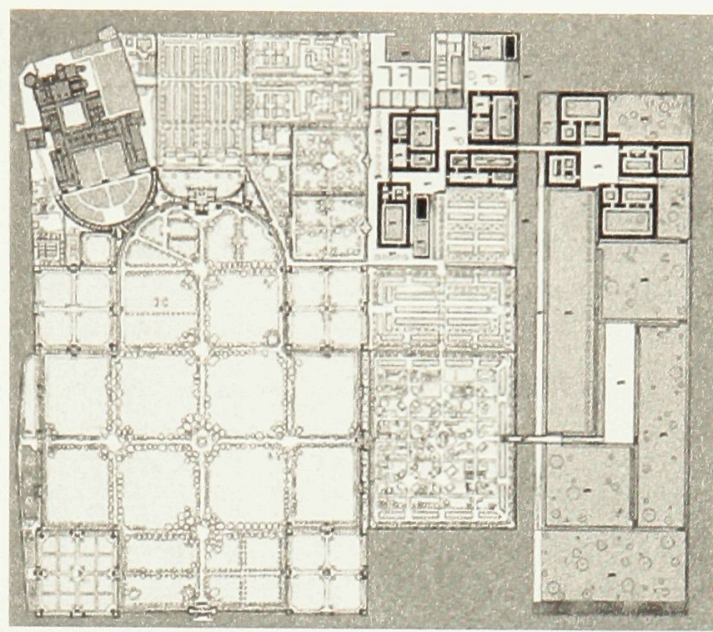

Fig. 3.3 Helen. "Death in Venice: The Spectre of the Tragedy in David Chipperfield's New Extension to San Michele Cemetery." Architectural Design. 70.5 (2000) Proposed extension to San Michele.

In the second phase of construction, Chipperfield Architects will establish garden-like spaces on a new strip of land located on the eastern periphery of the existing island. This new strip will be physically separated from San Michele by a small canal or rio. In this location Chipperfield wants to establish a "critique of the main island" and construct "relationships between walls, gardens, water and views, which are visibly absent in the existing cemetery" ${ }^{67}$ By "readdressing the shortcomings of the old cemetery", Chipperfield thus create gardens both inside and outside the enclosing walls of the tombs. In doing this the lower gardens open to grand vistas from San Michelle to Venice, and vise-versa. This provides not only spectacular views, but also important and needed areas of transition and reflection for the loved ones of the deceased (Figure 3.4). 


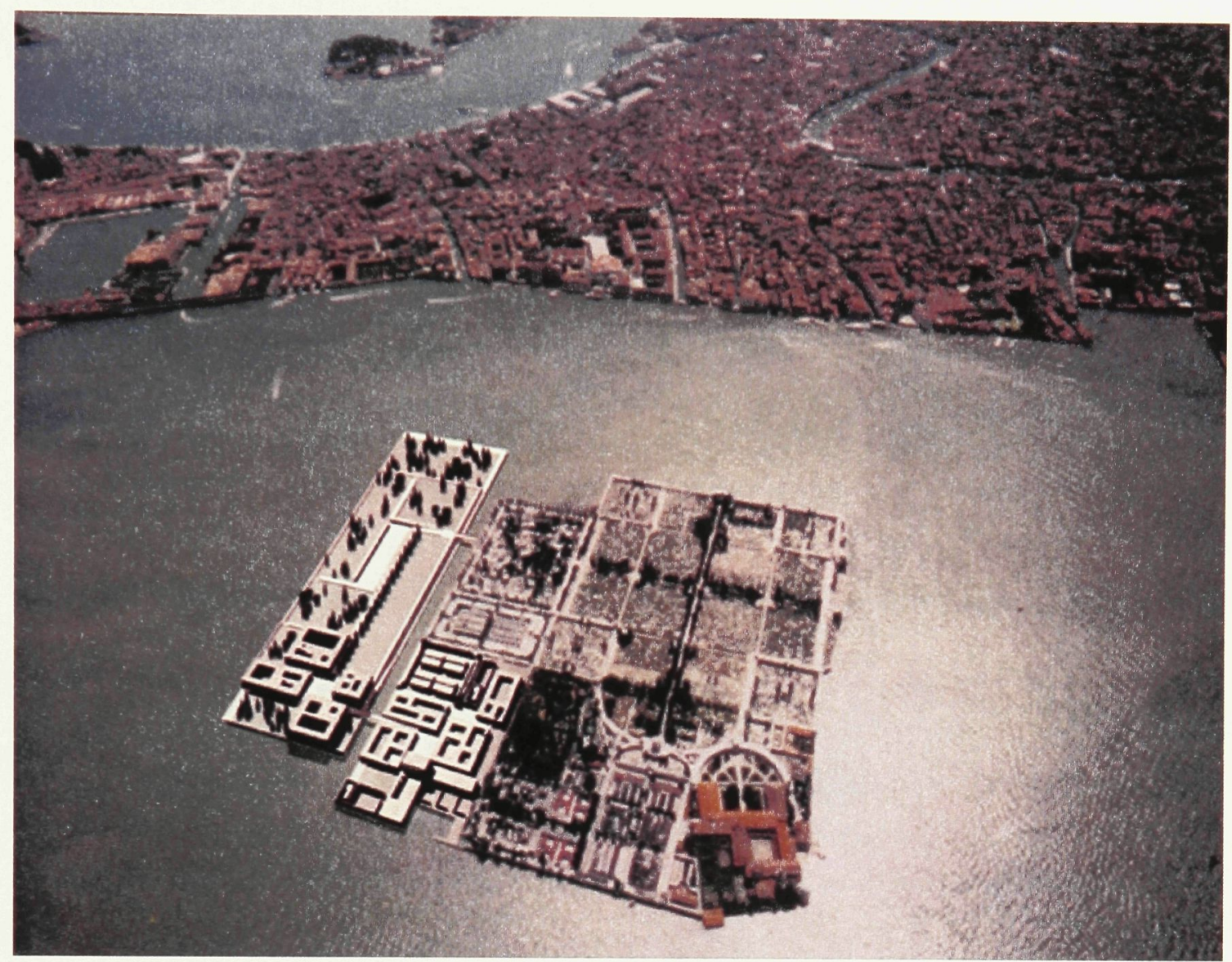

Fig. 3.4 Helen Castle, Architectural Design "Death in Venice: The Spectre of the Tragedy in David Chipperfield's New Extension to San Michele Cemetery," Vol 70.5 (2000) Aerial view of proposed extension.

By constructing higher-density tomb buildings in phase two, it is possible for Chipperfield to appropriate a large amount of open space. When one compares the older sections of San Michele, one notices that many of the tombs are only a single storey, while Chipperfield intends to construct three storey structures. Phase two allows for 16,040 spaces for body placement, while the single-storey mausoleums in phase one allow for an additional 8,941 . $^{68}$ The closely linked structures will also create a "contiguous" and "seamless settlement that reinterprets the urban pattern of calle, campo and cortile (lane ways, squares 
and courtyards) that is so specific to Venice". ${ }^{69}$ Castle's interpretation is as follows:

\begin{abstract}
"Thus by imitating the space between buildings rather than the language of the architecture itself, a skilful interpretation of the essential urban qualities of Venice is captured at San Michele. That same experience of abruptly emerging out of the dark of a corridorlike calle into the sharp golden light of a campo, or entering the cool enclosures of a palazzo's cortile, will be encountered in the new cemetery." 70
\end{abstract}

Chipperfield evokes the strong sense of belonging that people already have for the San Michele cemetery through built forms that reflect Venice's indigenous qualities. He accomplishes this through the abstraction of the contrasting elements of the lightness and darkness of Venice's streets, and then transposes them into the cemetery. San Michele's new addition renews the ability to acquire an architecture of closure at a time when "restitution and reconciliation" are often lacking. ${ }^{71}$

Chipperfield's extension to San Michele is an excellent illustration of how cemeteries play an integral role in the collective memory of a city, and how they can be remoulded to induce a more modern dialogue between the city of the living and the city of the dead. When one looks at the impact of Venice's high urban density, certain conclusions can be drawn. New methods of construction and the reintroduction of the cemetery into the urban fabric must be undertaken, in order solve many of the problems that afflict cities. 


\section{Section III Endnotes}

${ }^{62}$ Helen Castle, "Death in Venice: The Spectre of the Tragedy in David Chipperfield's New Extension to San Michele Cemetery." Architectural Design. 46.

${ }^{63}$ Castle. 47

${ }^{64}$ Castle. 48

${ }^{65}$ Castle. 48.

${ }^{66}$ Castle. 48

${ }^{67}$ David Taylor, "News in Pictures: Chipperfield Takes on Death in Venice." The

Architects Journal. 12.

${ }^{68}$ Helen Castle, "Death in Venice: The Spectre of the Tragedy in David

Chipperfield's New Extension to San Michele Cemetery." Architectural Design. 48.

${ }^{69}$ Castle. 51.

${ }^{70}$ Castle. 51.

${ }^{71}$ Castle. 51. 


\section{The Contemporary Cemetery}

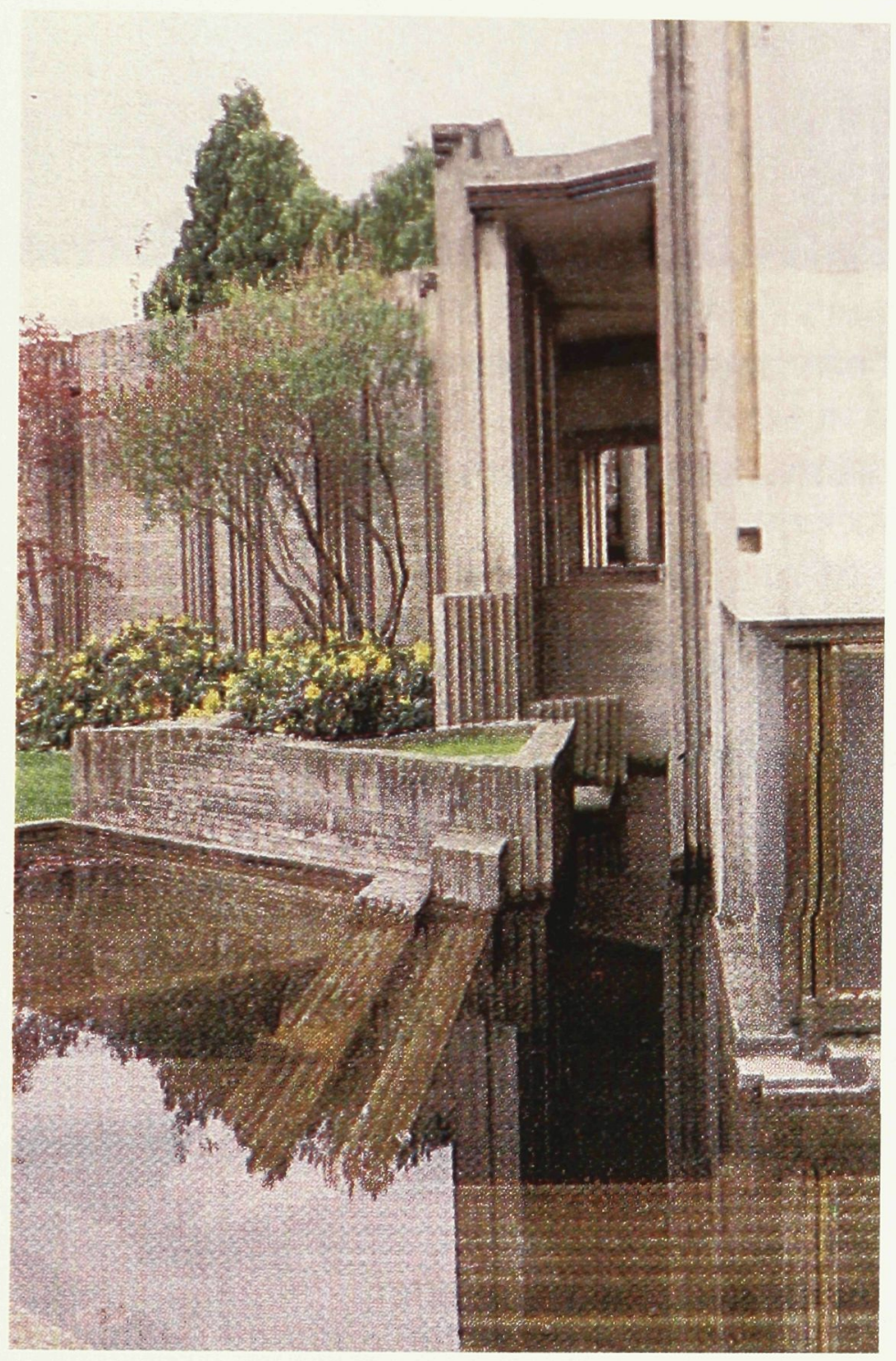

Fig. 4.1 Maria Bottero, Abitare, "Carlo Scarpa: The Brion Family Cemetery, a Poetic Oasis" (n.272, 1963) View inside Brion Family Cemetery. 


\section{The Conception of the Hearth and Sacrifice}

\section{FOUR.ONE}

When one considers the relationships that exist between food and death in the context of architecture, one initially assumes that the individual elements of food, death and architecture are very different and therefore distinct. However, this difference is merely superficial; the elements are, in fact, closely connected. They converge at the "hearth", a theoretical starting point from which everything branches out. Symbolically the starting point of any great civilization is formed around the domestic hearth. The hearth acts a conduit that connects the horizontal plane of the living with the vertical alignment of the dead. This verticality is formalized by tombs and monuments, and is eventually collectivized in a city's public spaces.

In this thesis, the hearth is represented by the dining table, as it is around the dining table that the scene is set. The dearly departed individual is not physically present around the dining table; however, through toasts, prayers, 
feasts for the dead, and empty place settings, we refer to their absence. The table/hearth becomes the reference point of this absence. ${ }^{72}$ It remains a custom to make a setting at the dinner table with the glass turned upside down for an expected guest that does not arrive. During World War II, this same ritual was performed when a pilot's plane failed to return from a mission.

Within our conception of a city the idea of the table is seen in tableaux, in other words, scenes that are made to be seen, and that refer to the absence of a collective someone. ${ }^{73}$ In the past, Civic altars and, later, monuments demarcated the space of this absence.

The hearth is a "primordial centre, a centre that is independent of where it is geometrically posed. Like the templum (open or consecrated space) whose location was determined through the intersection of cardo and decumanus, the hearth is an intersection, a crossing, a point of transaction." ${ }^{74}$ In Roman city planning, a cardo or cardus was a north-south-oriented main street, sometimes called the Cardus Maximus, which served as the centre of economic life in ancient Roman cities. ${ }^{75}$ The decumanus, also known as Decumanus Maximus, is the north-south road that acted as another main street within the city. ${ }^{76}$ Both were derived from the north-south (cardo), and the east-west (cardus) line that the augurs (priest) would draw when making auspices (an omen). ${ }^{77}$ It is at this convergence of inter-dimensional planes that I will address the hearth, also known previously as "altar", from which sacrificial rituals were performed and where food, death and architecture were first entwined. 
In ancient times the altar was the spiritual centre from which sacrificial rituals were performed. This begs the question: why was there a need for a sacrifice? Sacrifice has been a part of all civilizations since humans began to hunt and kill animals for food. It may, in fact, be as old as religion itself. ${ }^{78}$ Sacrificing, which literally makes an object sacred to be consumed, is a means to participate in a cosmic movement from life through death to another form of life. The offering/victim is then eaten, and is shared with both other people and the unseen supernatural forces. The meat is distributed, with some left aside as offerings to the gods; although, sometimes the whole carcass is destroyed (by fire) so that the gods receive all of it (through the ascending smoke) as a gift to please them. ${ }^{79} \mathrm{An}$ inherent part of sacrifice is the initiation of the confrontation of one's mortality, which demands some form of surrender. This surrender establishes or sustains a relationship with the divine through an offering consecrated by its own destruction. Therefore, when one says that they are sacrificing something, it means that they are giving something up in consequence.$^{80}$ In a ritual the offering/victim acts as an intermediary between the sacred and the profane, it mediates and reconciles, and is a kind of hyphen, separating but uniting. ${ }^{81}$ "Its existence allows for the two worlds to be present and inter-penetrable while remaining distinct. ${ }^{82}$ 


\section{The Conception of the Eucharist}

\section{FOUR.TWO}

The concept of sacrifice has roots in Christian tradition through the covenant between the Jews and their God. As a linking device, sacrificial offering was a perfect expression of the tremendous and irreversible connection. Throughout time this ritual has evolved into various forms, because of society's ever-changing values. One of the modern forms of this ritual is the Christian ceremony known as the Eucharist. In The Rituals of Dinner by Margaret Visser, who is a learned writer on rituals that incorporate food, the Christian ritual of the Eucharist is described as follows:

"The ceremony uses every psychological device defined by scholars of ritual. These include notions such as entrainment, formalization, synchronization, tuning, and cognitive structuring, as well as spatial organization and focusing, and perfected ordinary action. Distances both temporal and spatial are collapsed, as ritual contact is made with past, present, and future at once, and as "this place" is united with "everywhere else," including the realm of the supernatural." 83 
In Christianity there still exists an altar, around which all ceremonies are centred, and the sharing of the Eucharist is still the most important ritual. That the altar is used as a table for the Eucharist is symbolic. It references, first of all, the ancient sacrificial altar at the Jewish temple. Over time, Christianity rejected blood sacrifice and the mediating sacrificial victims were no longer needed, because in Jesus' death God himself had become the offering/victim once and for all time. It is the ultimate revelation of God's love that is re-enacted every Sunday and at each Easter Sunday mass, on the day of Christ's resurrection. The altar where the Eucharist is preformed with the bread and wine, symbolizes Jesus' body and blood. In the Eucharist, God enters into the person who eats the consecrated bread and drinks from his cup; the profane becomes sacred and the sacred annihilates the difference between the two. For example, in Rembrandt's painting of the Supper at Emmaus, this moment is illustrated when the breaking of the bread reveals that Jesus is the unknown guest. For human beings this "renewed desire, necessary, simple, ordinary, to be broken and shared, of external matter that becomes internal, and which then turns into the very substance of the eater-that the Christian God of love sacramentally gives himself to human beings. In spatial and temporal terms, always and everywhere become, in the Eucharist, one with here and now." ${ }^{84}$ In this ritual, Christ not only enters the minds of the congregation, but into their bodies as well, thereby breaking the ultimate taboo, as the people share and consume Christ's body and blood. The congregation becomes "one body," as they chant, "through him, with him, and in him. ${ }^{85}$ In this ritual all boundaries are crossed: 
"between individual and group; death and life; spirit and body; meaning fact; beginning, lasting, and ending; old and new; here and elsewhere; eternal and temporal; linear and cyclical time; host and guest; god and humankind. As a meal, the Mass spans all of the meanings of eating at once-from cannibalism to vegetarianism, from complete fusion of the group to utterly individual satisfaction, from the breaking of the most fearful of taboos to the gentlest and most comforting restoration. All this and more is contained, expressed and controlled by ritual: dramatic movement and structure, song, costume, poetry, incense, gesture, and interaction; every one of the five senses is employed in the service of mystical experience. There are also tablecloths and napkins, candles, cups, plates, jugs, and wash basins." 86

The structure of a church refers to things beyond it and provides a setting where spiritual knowledge receives recognition and focal attention, where the altar table is at centre stage. I want this notion reflected in my architecture, allowing the dining table, like the altar, to become the focal point, and thereby influence the overall construction. The shared meal is the central idea of the ritual of the Eucharist, and follows Christ's command: "Do this in memory of me.." ${ }^{87}$ This same type of remembrance is commonly used in modern funerary practices, as evidenced by the common experience of sharing a meal after a funeral. 


\section{The Eucharist: A Modern Understanding}

\section{FOUR.THREE}

In contemporary society the pervasiveness and impact of mass media has increased the importance of certain elements of the cognitive process, namely, sight and hearing, while diminishing the importance of other senses, such as taste. However, in Greek and Latin "taste (gustus, sapor) is a term related etymologically and semantically speaking with the act of acquiring knowledge. ${ }^{88}$ Sapienza, in other words, wisdom, the highest form of knowledge, is related to taste (sapor). This idea is illustrated in an etymology written by Isiodo of Seville:

"The word sapiens (a wise man) is said to be derived from the word sapor (taste) for just as the sense of taste is able to distinguish the flavours of different foods, so to is the wise man able to discern objects and their causes since he recognizes each one as distinct and is able to judge them with an instinct for truth." 89 
Similarly, Tommaso Campanella saw the importance of the tactile dimension (tactus) of taste in his Theologia (1613-1624) where he compares tactus and gustus. The metaphor of taste is used to indicate a peculiar form of instantaneous knowledge. $^{90}$ Thus, taste is, in a sense, an intuitive understanding. This intuitive understanding is developed during the stages of human development, as one develops from early childhood into adulthood.

Savador Dali relates the origin of pleasure in architecture to childhood narcissism. ${ }^{91}$ Objects are experienced and interpreted only from the viewpoint of oral fixation, "The tactile dimension of taste expresses a desire to integrate the outside world into oneself". ${ }^{92}$ This productive interference is based on instinct, just as the incessant oral tasting of childhood is an instinctive part of the cognitive appropriation. ${ }^{93}$ This tangible object of knowledge becomes fact, which is embedded and personified in an artefact. In this way an image is formed, which brings together two realities: the intellectual and the physical. The body becomes the site of reception for these truths. Food and architecture bridge and interconnect these two worlds, and touch the very nature of humans.

Whether in cuisine or architecture, the body is the site of reception for the work, as well as the material existence of the work as an artefact. Thresholds occur within this process of reception. These thresholds create their own spaces and temporal conditions. A piece of work within this process is eaten, ingested and absorbed acquiring knowledge of certain intuitive truths. Duchamp called these spaces and temporal conditions "infra-thin". ${ }^{94}$ We do not distinguish between mind and body, thought and place, but rather experience a discontinuity 
of small spaces of time and moments of space, a series of thresholds are then exposed for the participant to explore and experience. ${ }^{95}$ It is within these thresholds that food and the act of eating create space and shape much of the built environment, indoors and out. During the ritual of eating before and after a funeral one experiences the same thresholds and spaces.

This interpretation of the Eucharistic ritual provides the overarching concept for my architecture, through which I intend to reinsert and redevelop the idea of death and its rituals in food in the modern city. To build on this idea, I will provide an in-depth examination of my chosen site in the following section. Then present a series of narratives that lead the reader through the architecture from three different viewpoints: the pedestrian, one of the deceased's loved ones and, the deceased individual themselves. 


\section{Section IV Endnotes}

${ }^{72}$ Donald Kunze, "The Missing Guest: The Twisted Topology of Hospitality,"

Eating Architecture, Ed. Jamie Horowitz and Paulette Singley (MIT:

Cambridge, Massachusetts, 2004) 171.

${ }^{73}$ Donald Kunze, 171.

${ }^{74}$ Donald Kunze, 173.

${ }^{75}$ http://en.wikipedia.org/wiki/Cardo

${ }^{76} \mathrm{http}: / /$ en.wikipedia.org/wiki/Decumanus_Maximus

${ }^{77} \mathrm{http}: / /$ en.wikipedia.org/wiki/Augur

${ }^{78}$ Margaret Visser, The Rituals of Dinner: The Origins, Evolution, Eccentricities, and Meaning Of Table Manners (HarperCollins: Toronto, 1991) 81.

${ }^{79}$ Margaret Visser. 40.

${ }^{80}$ Margaret Visser. 40.

${ }^{81}$ Margaret Visser. 40.

${ }^{82}$ Dorita Hannah, "Butcher's White: Where the art Market Meets The Meat Market In New York City," Eating Architecture, Ed. Jamie Horowitz and Paulette Singley (MIT: Cambridge, Massachusetts, 2004) 285.

${ }^{83}$ Margaret Visser, The Rituals of Dinner: The Origins, Evolution, Eccentricities, and Meaning Of Table Manners (HarperCollins: Toronto, 1991) 45.

${ }^{84}$ Visser, Margaret. The Geometry of Love: Spaces, Time, Mystery, and Meaning in an Ordinary Church. (HarperCollins: Toronto, 2000) 72. 
${ }^{85}$ Visser, Margaret. The Rituals of Dinner: The Origins, Evolution, Eccentricities, and Meaning Of Table Manners. (HarperCollins: Toronto. 1991) 45.

${ }^{86}$ Visser, Margaret. 45.

${ }^{87}$ Visser, Margaret. The Geometry of Love: Spaces, Time, Mystery, and Meaning in an Ordinary Church. (HarperCollins: Toronto, 2000) 79.

${ }^{88}$ Frascari, Marco. "Semiotica ab Edendo, Taste in Architecture." Journal of Architectural Education. 4.

${ }^{89}$ Frascari. 4.

${ }^{90}$ Frascari. 4.

${ }^{91}$ Frascari. 6.

${ }^{92}$ Frascari. 6.

${ }^{93}$ Frascari. 6.

${ }^{94}$ Kunze, Donald. "Architecture as the Site of Reception, Part 2: Sea-Food and Vampires." Chora. 2 (1996): 13.

${ }^{95}$ Kunze. 13. 


\section{A Contemporary Cemetery Proposal: Vancouver B.C.,}

\section{Canada}

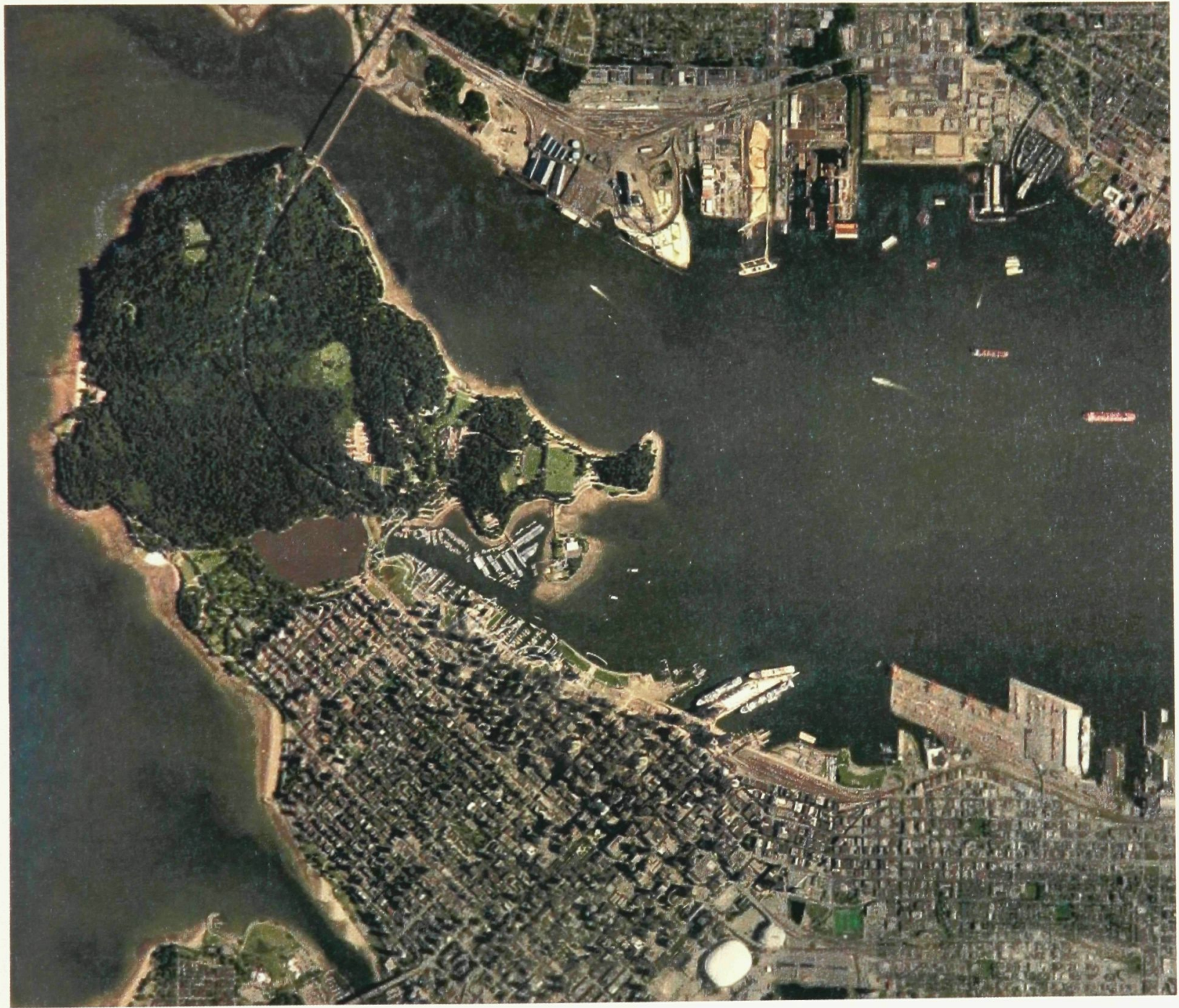

Fig. 5.1 Maps by Air 2004. 14 Dec 2004 <http://www.mapsbyair.com>. Satellite image of downtown Vancouver and Stanley Park. 


\section{Historical Analysis of Proposed Site}

\section{FIVE.ONE}

Recently, it has been necessary for the city of Vancouver to re-examine the role of cemeteries in the urban setting (Figure 5.1). Skyrocketing land prices have meant that it is increasingly difficult for cemeteries to be viable within the urban community. As a result, cemeteries are being pushed further beyond the city's periphery to the point that there is no longer a connection between the growing population of the city's core and its peripheral functions, including cemeteries. Dead Man's Island, in Vancouver, is a potential site for the reintroduction of the cemetery into the city's landscape that could act as a catalyst to reform western attitudes of death within the context of a city. A brief history of the city of Vancouver and of Dead Man's Island will illustrate the logic behind the selection of this site (Figure 5.2). 


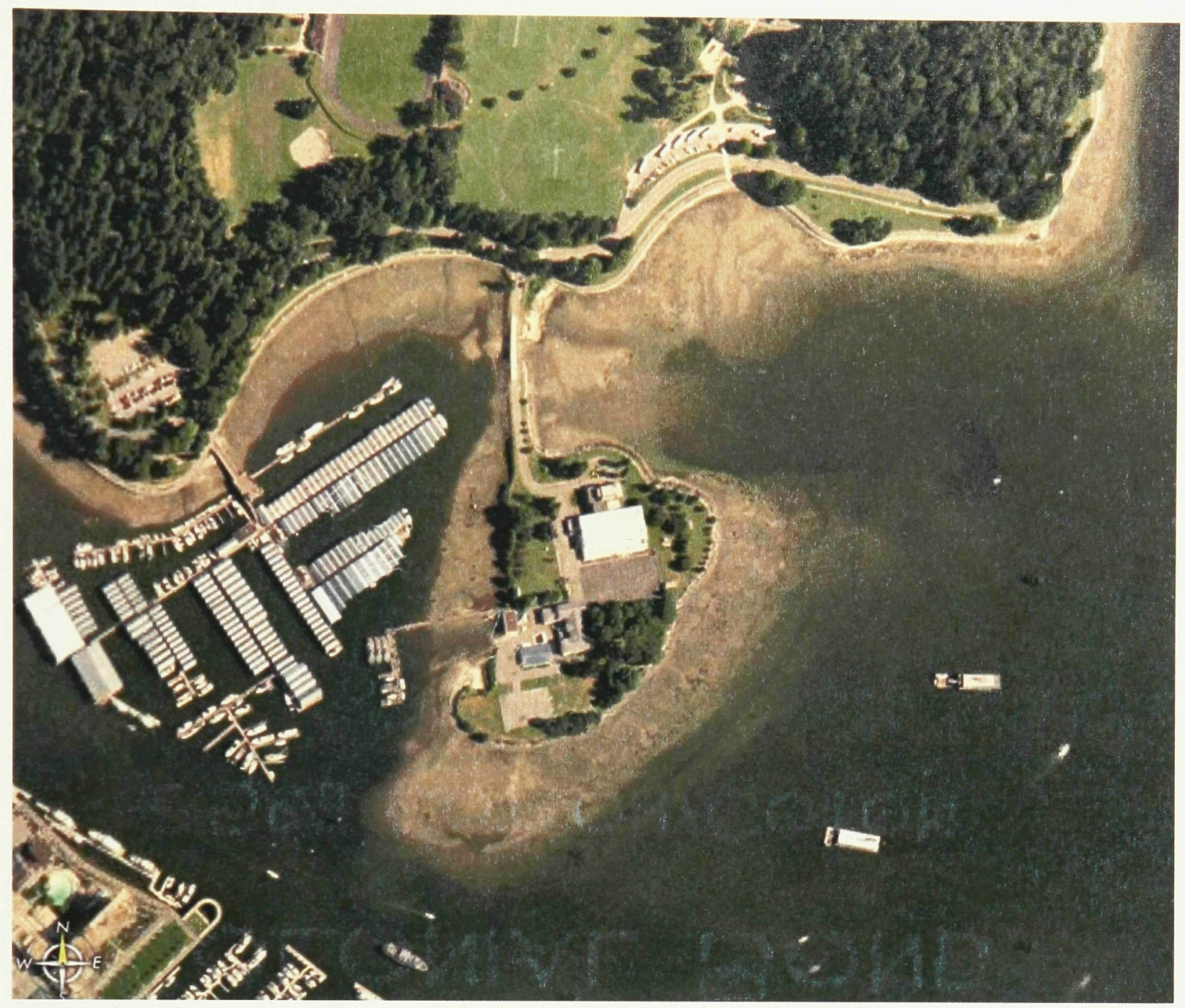

Fig. 5.2 Maps by Air 2004. 14 Dec 2004 <http://www. mapsbyair.com>. Satellite image of Dead Man's Island.

'The serenity of the climate, the innumerable pleasing landscapes and the abundant fertility the unassisted nature puts forth,' wrote navigator George Vancouver in 1792, describing an area that would later bear his name. ${ }^{96}$ Towards the end of the eighteenth century, the Lower Mainland (Vancouver and surrounding area) saw its first Europeans. However, massive settlement did not occur until the year of the gold rush to the Fraser River, and the creation of the Crown Colony of British Columbia in 1858. Before these settlements, the area 
was clearly Native land. The first establishment of a permanent European settlement was a trading post in 1827 called Fort Langley near the mouth of the Fraser River. Later, in 1881 , the native population was uprooted and relocated to remote reserves by the British settlers. Within a few years the area went through a series a remarkable transformations: from a community of fishing and hunting to a modern corner of the world economy within the British Empire, and then a part of the emerging federal nation-state, the Dominion of Canada. ${ }^{97}$

Modern-day Vancouver has a population of more than 1.5 million people, who live in 2,750 square kilometres of lowland flanking the Fraser River between Abbotsford and the Gulf of Georgia. It is estimated that another million people will call Vancouver and its region home in the next twenty years. ${ }^{98}$ Given this forecasted growth, and the continuation of current land development trends, the lower mainland may "end up like every other unattractive place on earth", warned one local planner. ${ }^{99}$ As well, a recent commentator in the Globe and Mail concluded: (in the Globe and Mail, 29 June 1991), 'There is no real centre to Vancouver... it is a place of pockets, strips, [and] urban moments.' ${ }^{100}$ This article illustrates that the city of Vancouver is becoming a resort, a leisure centre for grand hotels, fine restaurants, sailboats, and ski slopes, and less of a great hub of cultural diversity.

In light of Vancouver's developments, which continue to expand even further into the Fraser lowlands, and our society, which is inclined to value land and place in purely economic terms, the roots of familiarity and our connection to 
landmarks and landscapes are severed. In The Experience of Place Tony Hiss writes:

\begin{abstract}
"whenever we make changes in our surroundings, we can all too easily shortchange ourselves by cutting ourselves off from the sights or sounds, the shapes or textures, or other [pieces of] information from a place that have helped mould our understanding and are now necessary for us to thrive. Overdevelopment and urban sprawl can damage our own lives as much as they damage our cities and countryside". ${ }^{101}$ He continues to illustrate that nothing can make up for the destruction of 'long-lasting and familiar buildings' that we use to 'organize and prompt our memories' and thus anchor ourselves within the fabric of the city.
\end{abstract}

Before the arrival of the first settlers, the island known as Dead Man's Island was a Coast Salish tree burial ground. The natives of this area placed ornate wooden coffins on the ground or in the branches of trees, sometimes 20 feet or higher. ${ }^{102}$ The poet E. Pauline recounts in her 1911 book Legends of Vancouver of a bloody native battle between the northern and southern tribes on the island. This tale recounts when 200 northern warriors surrendered on Dead Man's Island, only to be killed soon after, in order to free women, children and elders the southern tribes had taken hostage. ${ }^{103}$

Reports from European sailors in the eighteenth century describe a "silent, gloomy isle whose ancient trees held cedar boxes filled with the remains of First Nations chiefs and elders. Some of the funeral chests were so fragile they crumbled when touched, raining bones on those below." ${ }^{104}$ From the early 1870 s until the Mountain View Cemetery opened in 1887, Brockton Point and Dead Man's Island were used as burial sites for British merchant seamen, as well as 
for people from Moodyville (known today as North Vancouver), Hastings Sawmill and the Granville townsite. ${ }^{105}$ Workers who were killed during the Canadian Pacific Railway line extension from Port Moody to Coal Harbour were buried on the island, as were some of the 21 people killed during the Great Fire of 1886. Boats acted as ferries that carried coffins from the mainland over to the island. The coffins were then buried in open areas between the trees. An early settler by the name of Harold Ridley recalls his perceptions of the graveyard on the island:

"The little collection of graves was not a cemetery; just little graves beneath the trees, with a little fence of sharp, pointed split cedar pickets and a headboard; [over time] the names became obliterated by the weather, and the grass grew tall and went to seed."106

During the 1880 s the island was home to banished sick prostitutes. In 1888 , the city suffered a smallpox outbreak and used the island as a site for "pest houses", constructed to quarantine victims. Although the Mountain View Cemetery remained open, a number of smallpox victims were instead buried on the island. During a logging dispute, squatters were ousted and then returned to Deadman's Island after 1911, building homes along the island's shoreline.

Between 1911 and World War II, entrepreneurs brought forth various plans to transform the island into a museum, a war memorial site, an amusement park, and a dancehall; none however, were undertaken. In 1930, the island was offered to the city by the federal government, with the intention that it be absorbed into Stanley Park, a plan that has never materialized. 
In 1942, the federal government gave the island to the navy, who in 1944 constructed the HMCS Discovery, a naval base and training centre. During World War II, this division trained hundreds of personnel in basic seamanship, served as liaison between civilian and defence authorities, hosted dozens of allied war ships, and provided support to harbour officials whenever necessary. When the war ended the HMCS Discovery acted as an area of demobilization for the West Coast. Because it is unclear exactly where the island's historical graves are located, the navy subsequently adopted a "better safe than sorry" approach to the sites development. Only two of the buildings, both built during World War II, have rooms that go a few feet below grade, in an attempt not to disturb the burial grounds of the past. ${ }^{107}$ The HMCS Discovery continues to be a training centre today, as the ship's members participate in exercises with the Coast Guard, navy divers and other reserve units. In addition, the HMCS Discovery continues to serve as host and ambassador to dozens of foreign vessels visiting the Port of Vancouver.

Dead Man's Island has been integral in shaping the fabric of Vancouver and its surroundings. It contains a timeline of the city's subculture and of its peripheral development. The site is rich with the history of the dead of Vancouver. However, this history can only be read in books, poems, and articles. Currently there are no markers or physical indications of who has lived and died on the site. The history of Dead Man's Island has been physically erased from Vancouver's modern culture. By using Dead Man's Island's history as a premise 
for a new cemetery for Vancouver, one can look at the immediate surroundings and uncover a potential dialogue between the living and the dead. 


\section{Process}

\section{FIVE.TWO}

Le Corbusier once claimed that he could spot an architect by the way they rearranged their place setting during dinner. It is a compulsive tendency of architects to reorder not just environments, but everything that sits before them, even extending to the area of the plate itself. ${ }^{108}$

Food is in architecture. The experience of space within food and its related activities are inextricably bound by architecture. We buy, cook and consume food in a variety of different ways and design places to accommodate, even enhance, these activities of daily life. By inverting this notion, architecture is in food. Chefs carve spaces from food, much like a sculptor, and use structure in order to tantalize our senses even further by making dishes stand up and figuratively say "please eat me".

Jean Anthelme Brillat-Savarin's in his discussion of The Physiology of Taste states "On devient cuisinier mais on naît rôtisseur" (One can learn to be a 
cook, but one must be born knowing how to roast). ${ }^{109}$ A century later August Perret rephrased this sentence in his Contribution a une theorie de l'architecture, stating "On devient ingenieur mais on naît architecte" (One can learn to become an engineer, but one must be born an architect). ${ }^{110}$ The engineer and the cook can read instructions from a recipe book, whereas the architect and the "rôtisseur" rely on a complicated, dialectical process of adaptation, interpretation and imagination in order to make each creation. ${ }^{111}$ The processes of design that they both use cannot be systematically explained or broken down into a list of methods.

Food and architecture are both constructed from raw materials and the imaginative process of the mind of an architect or chef. Both use the manipulation of colour, texture, and shape to create spaces that extend beyond our senses. Food and its processes have an incredible ability to shape and create space from our immediate environment.

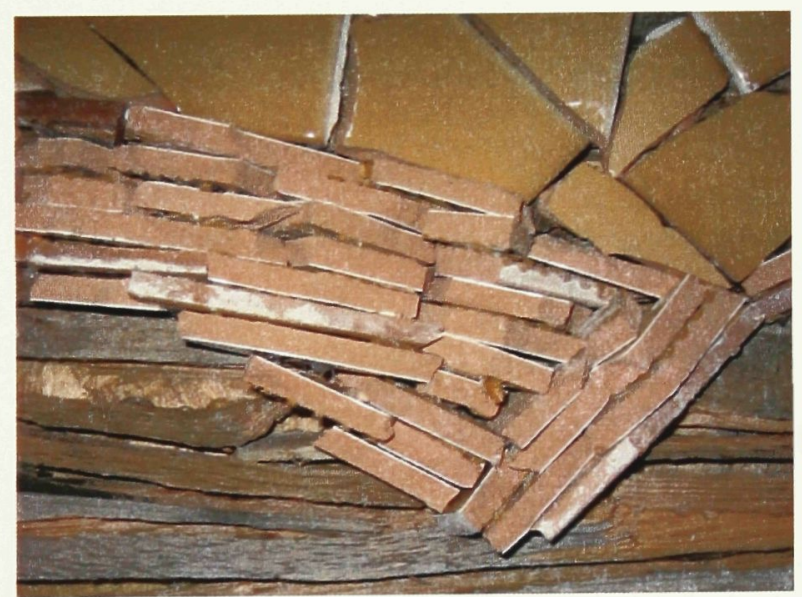

Fig. 5.3 Detail Photograph of Gestural Model: Historical Layering

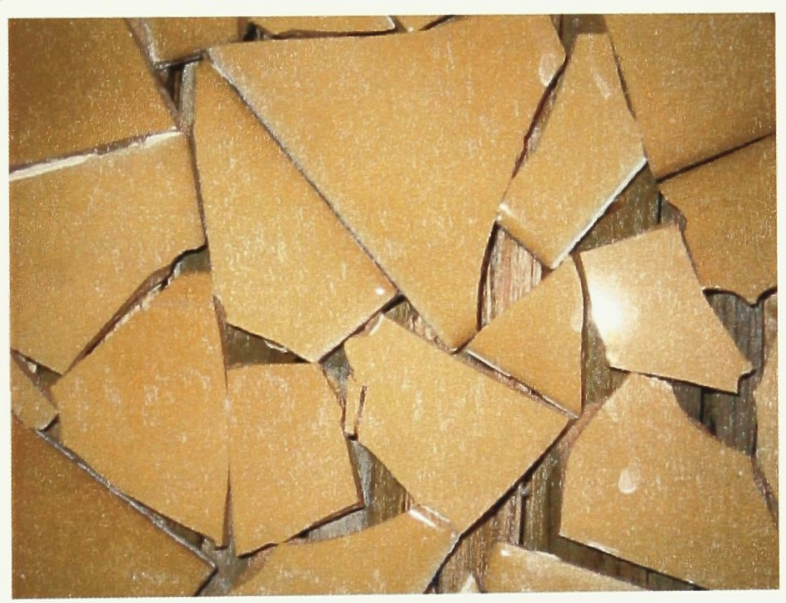

Fig. 5.4 Detail Photograph of Gestural Model: Historical Fragmentation 


\section{First Insights}

\section{FIVE.THREE}

Dead Man's Island is located in Coal Harbour, which borders the north edge of the downtown core of Vancouver. Connected only by a small bridge, the site is surrounded to the north and west by Stanley Park, which is used for recreational activities such as running and cycling. As is the case with San Michele in Venice, Dead Man's Island also has a visual connection with its downtown core that includes a physical separation by water. With its close proximity to downtown and to Stanley Park, the island's thresholds have the potential to mediate between the activities of the living and the commemoration of the dead.

With regard to Stanley Park, a direct connection could be made to Dead Man's Island. Potential uses for the park could be extended into the cemetery. In doing so, the park and the cemetery would be seamlessly joined for leisure activities. This would allow people great views of the downtown core and of the 
mountainous background on the horizon. Furthermore, a bridge would be created, which would begin to link the daily activities of urban dwellers with a place of civic memory and family rituals of commemoration. In this way, the worlds of the living and the dead would begin to intertwine.

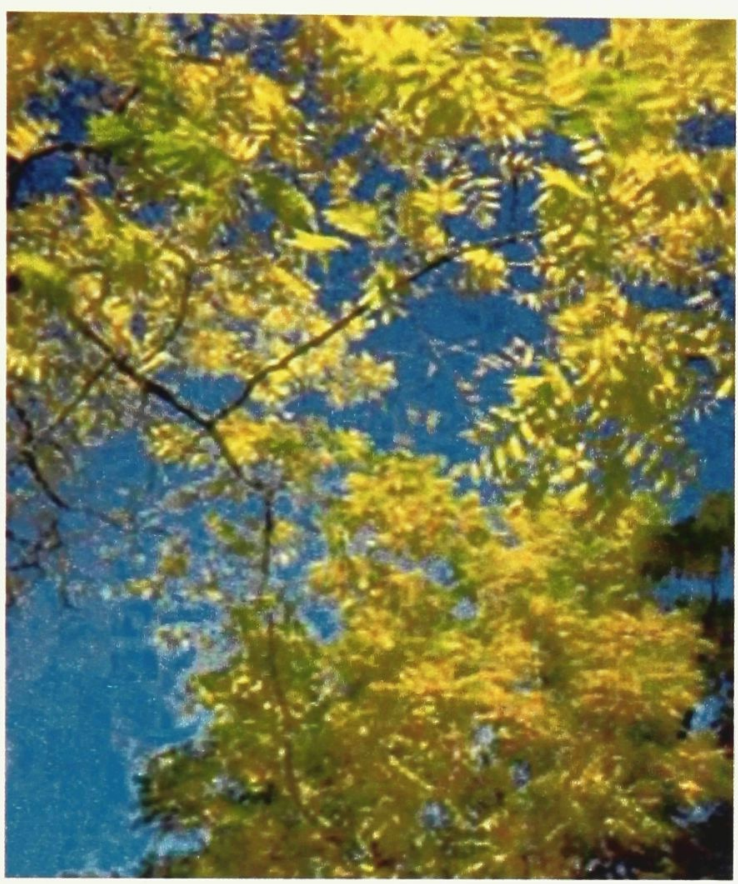

Fig. 5.5 Conceptual Image: Layering Study

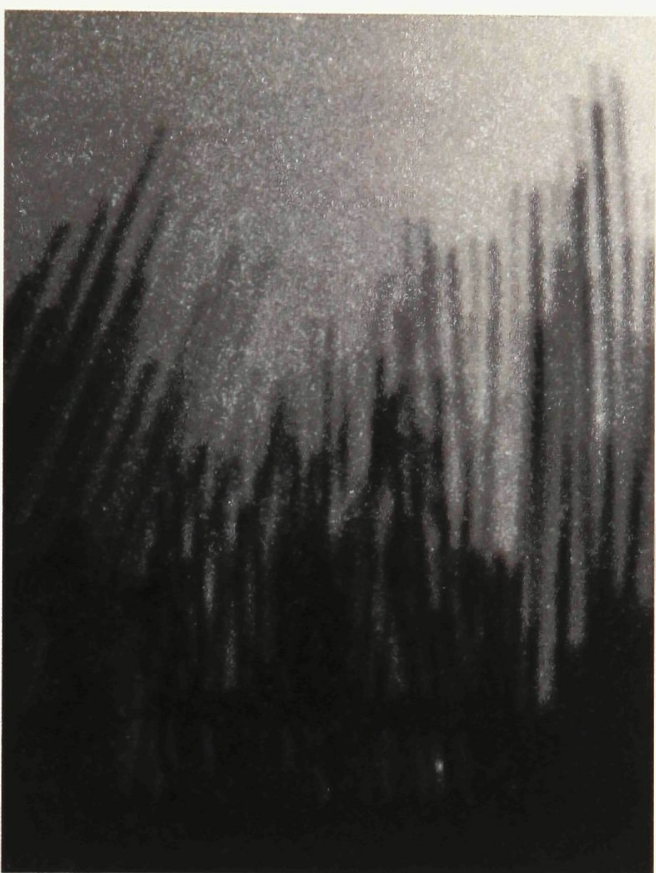

Fig. 5.6 Conceptual Image: Light Study

Visual connections from the downtown core of Vancouver to the island can also be provided by a man-made landscape. This would engage the urban dweller's cyclical relation to the natural environment, whether it is physical or spiritual, a concept that many Vancouverites hold dear to their hearts. Due to the limited and concentrated land area, the cemetery would be developed vertically reflecting the downtown core, suggesting a city of the dead equal and adjacent to the city of the living. Thus, the columbarium would be a monument for the 
absent, which would mirror the city as a whole. In keeping with the iconic theme along the harbour front, as illustrated by the massive convention centre known for its sail-like construction as well as the endless construction of high-rise condominiums, I chose to continue this datum and produce a series of responses in my architecture that reflected the harbour front and its activities.

Looking at the proposed site through a wider lens, I wanted to create a landscape that acted as a series of permeable layers. When one looks at the harbour front in section there are evenly spaced high-rise buildings, green spaces with pedestrian paths, the docks, and finally the water. The overall area is very porous. Because a large area was required for the placement of urns, I decided to construct a series of equidistant structures that maintained the same general architectural theme, to complement the porous nature of the immediate area. If one were to create a massive singular narrative on the site, it would act as a dam controlling any visual connection with Stanley Park in the background. The introduction of a series of man-made structures in the foreground needed to be sensitive to this natural landscape. Therefore, in creating a language for the columbaria, I extrapolated from many sources. The conception of the hearth; the acknowledgment of the symbolic use of the "tree" in both Christian and Native beliefs relating to death; the use of the landscape of the harbour front, were all used as reference points to create an architectural language. From the downtown edge of the harbour, I wanted my architecture to act as a medium that would merge the horizontal datum of the living with the vertical alignment of the monuments to the dead. Therefore, I designed porous structures that visually 
blend the horizontal datum with the vertical and act in a similar fashion to the medium of fire that has been used throughout history, and which continues to be used today to connect our plane of existence with that of the celestial.

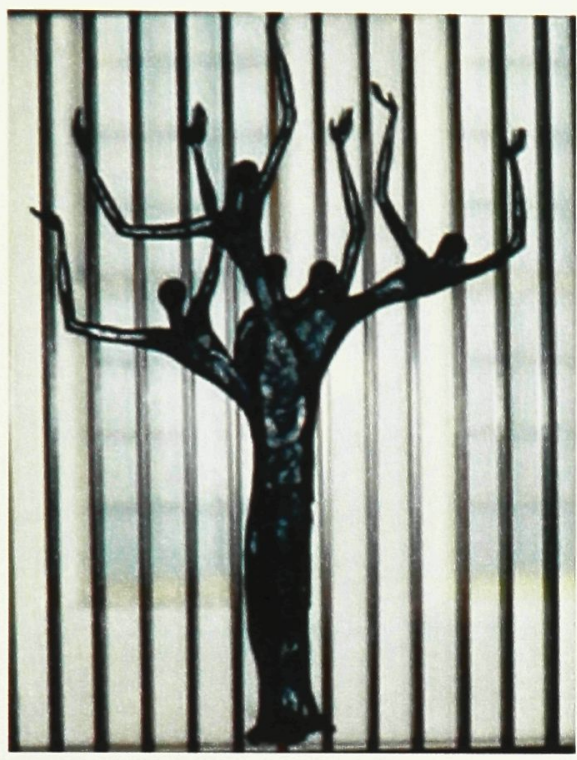

Fig. 5.7

$<$ http://collections.ic.gc.ca/art context/death.htm>. Art work

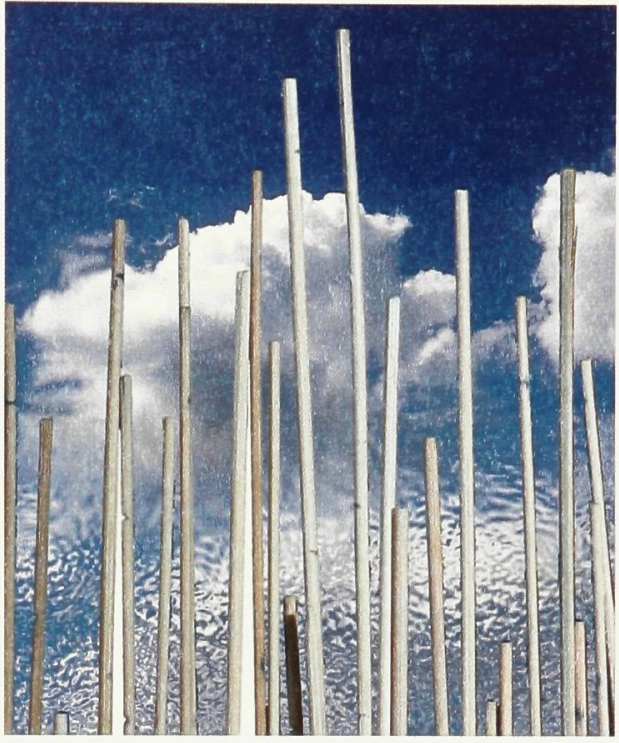

Fig. 5.8 Conceptual Image: Merge of land and sky study

In developing a layout for the island, I referenced its history and traced the boundaries of existing buildings and structures. One of my first steps was the elevation of the existing ground plane of the island, in order to allow for hollow areas around the boundaries of existing buildings. These spaces provide areas of reflection, which refer to a past that once existed on the island, but that was covered up and is now forgotten. In a sense, the modern framework of the island creates the framework that exposes its past. In addition, raising the ground plane preserves the consecrated ground on the island from any further disruptions. 
Making reference to Native history (the 200 warriors that surrendered and were later slain), I created a grid layout of 200 poles. The poles, each proportional to the height of a coffin, are inserted into the landscape of the island and create an abstract forest condition. This refers to the forest that once existed on the island. Natives used the forest to create totem poles for ceremonial rituals such as for potlatch and death customs. Each pole in the grid, much like a traditional totem pole, is a marker and threshold of the history of the island's dead, and forms an integral part of the architectural language of my structures.

Similar to Scarpa's masterpiece at Brion cemetery in Italy, I use water not only as a cleansing spiritual agent, but also use its reflective capabilities to merge the world of the living with the underworld of the dead. Water becomes a surface that flattens space creating a threshold to the next life which, can only be imagined, not experienced.

In the following sections, I will be constructing a series of narratives that all begin at a specific point in the landscape, the bridge that acts as the entrance to the island.

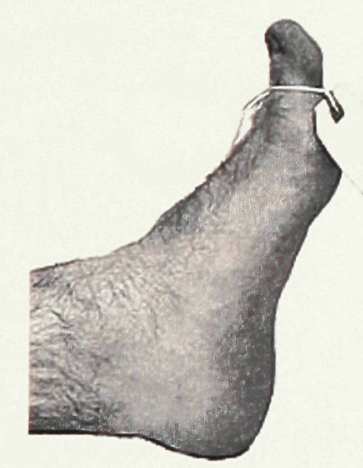

Fig. 5.9 Conceptual Image The Deceased

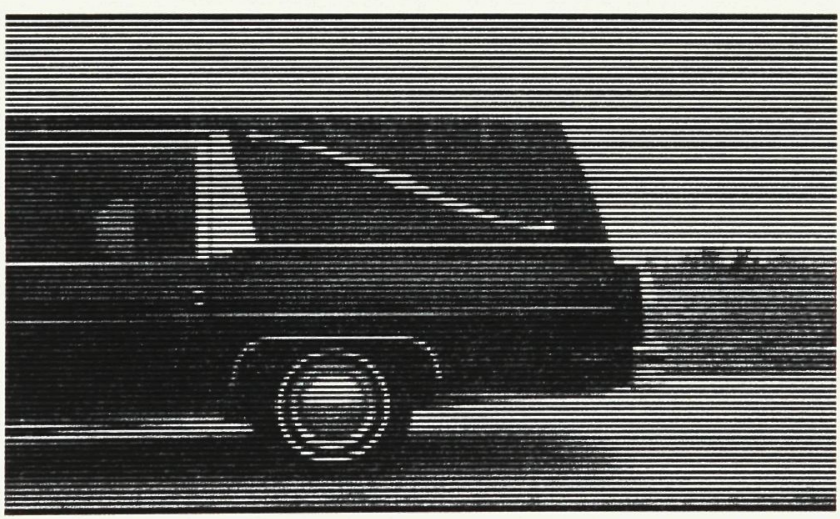

Fig. 5.10 Conceptual Image: Journey 1 


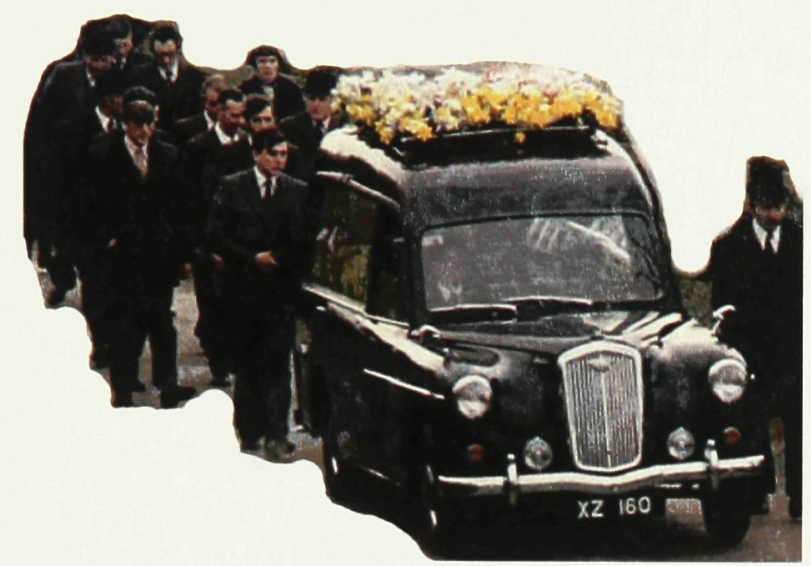

Fig. 5.11 Conceptual Image: Journey 2

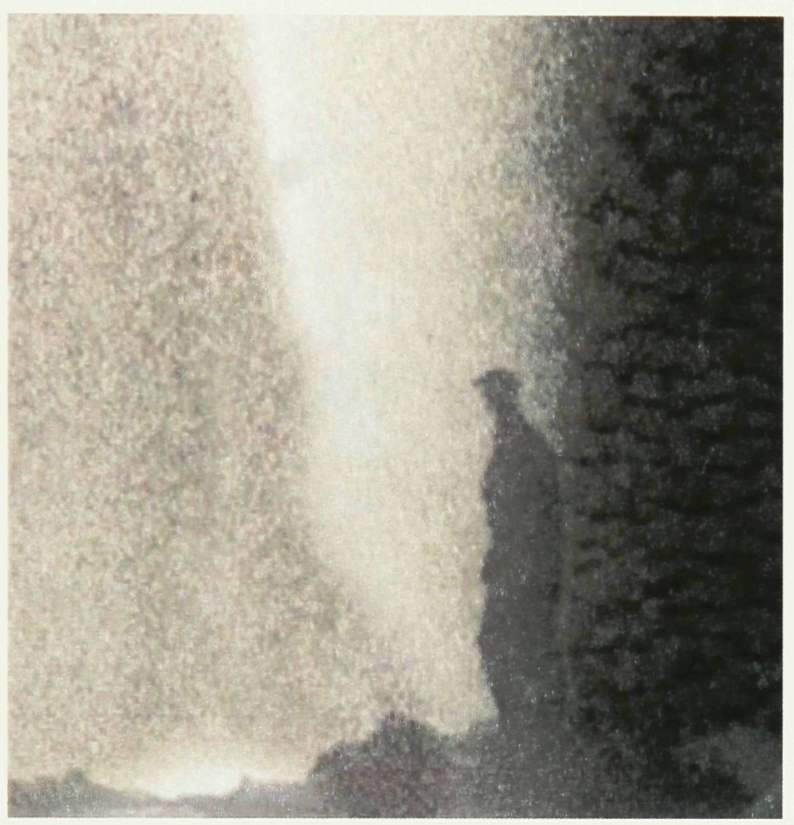

Fig. 5.12 Conceptual image of courtyard

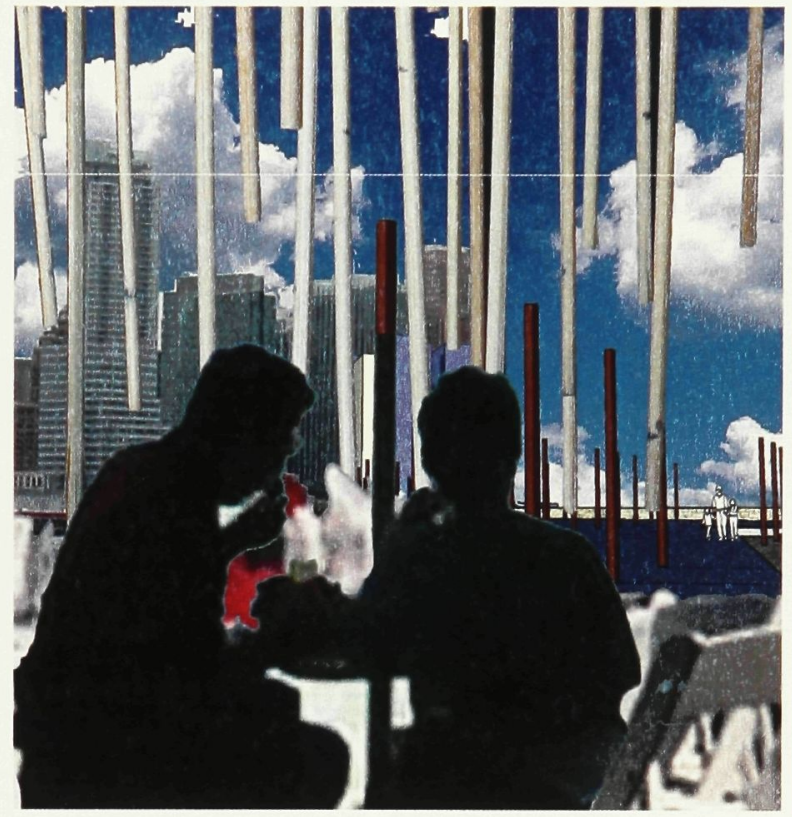

Fig. 5.13 Conceptual image of Interior Looking out.
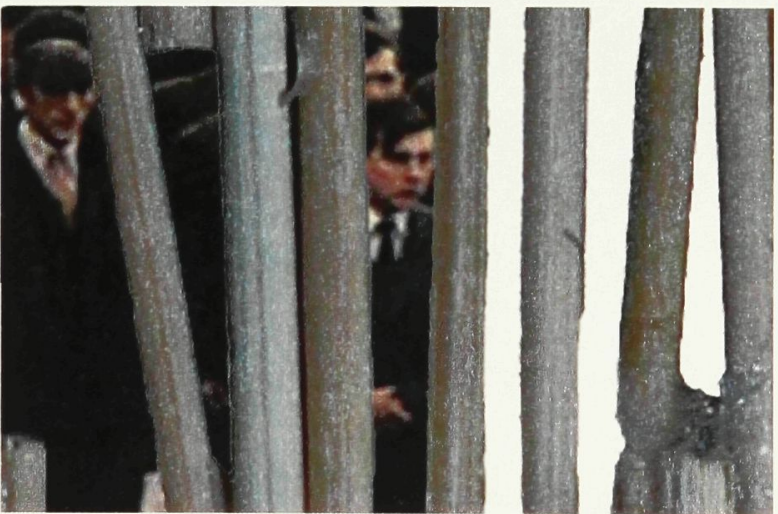

Fig. 5.15 Conceptual image looking inside Columbarium
Fig. 5.14 Conceptual image looking out of Columbarium. 


\section{The Narrative of the Deceased}

\section{FIVE.FOUR}

The narrative of the deceased begins with the hearse driving over the bridge that connects Dead Man's Island to Stanley Park (Figure 5.16 \& 5.17).

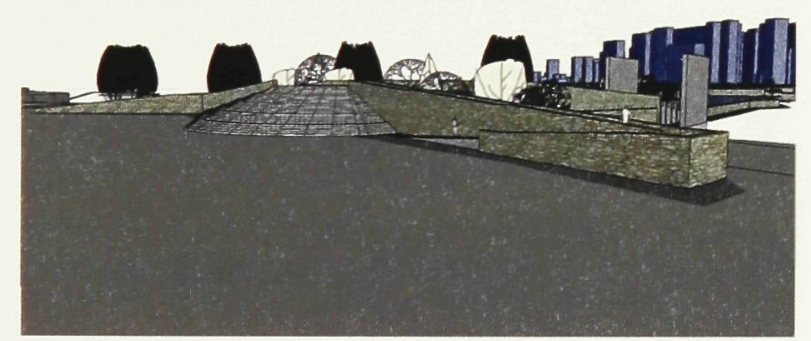

Fig. 5.16 View of ramp access to island 1.

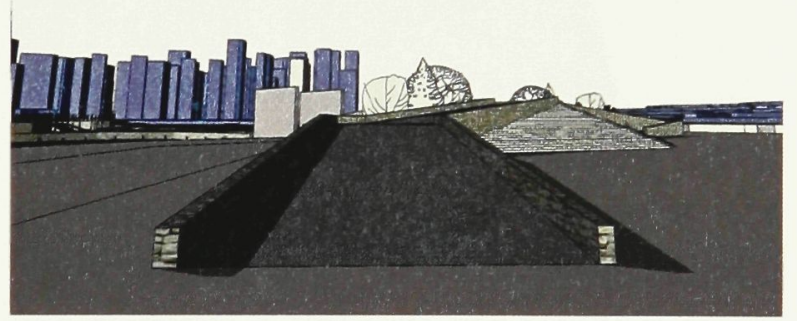

Fig. 5.17 View of ramp access to island 2.

Once over the bridge the hearse stops in a courtyard and is able to turn around

(Figure 5.18). On the east end of the courtyard there are two rectilinear waterfalls separated by a ramp; on the south-end of the courtyard there is another ramp with a set of stairs. The coffin is retrieved from the hearse by the pallbearers and A Contemporary Cemetery Proposal: Vancouver B.C., Canada 68 
carried up the ramp between the two waterfalls (Figure $5.19 \& 5.20$ ). From this point, the deceased can be taken either to an outdoor facility or an indoor facility for the funeral ceremony.

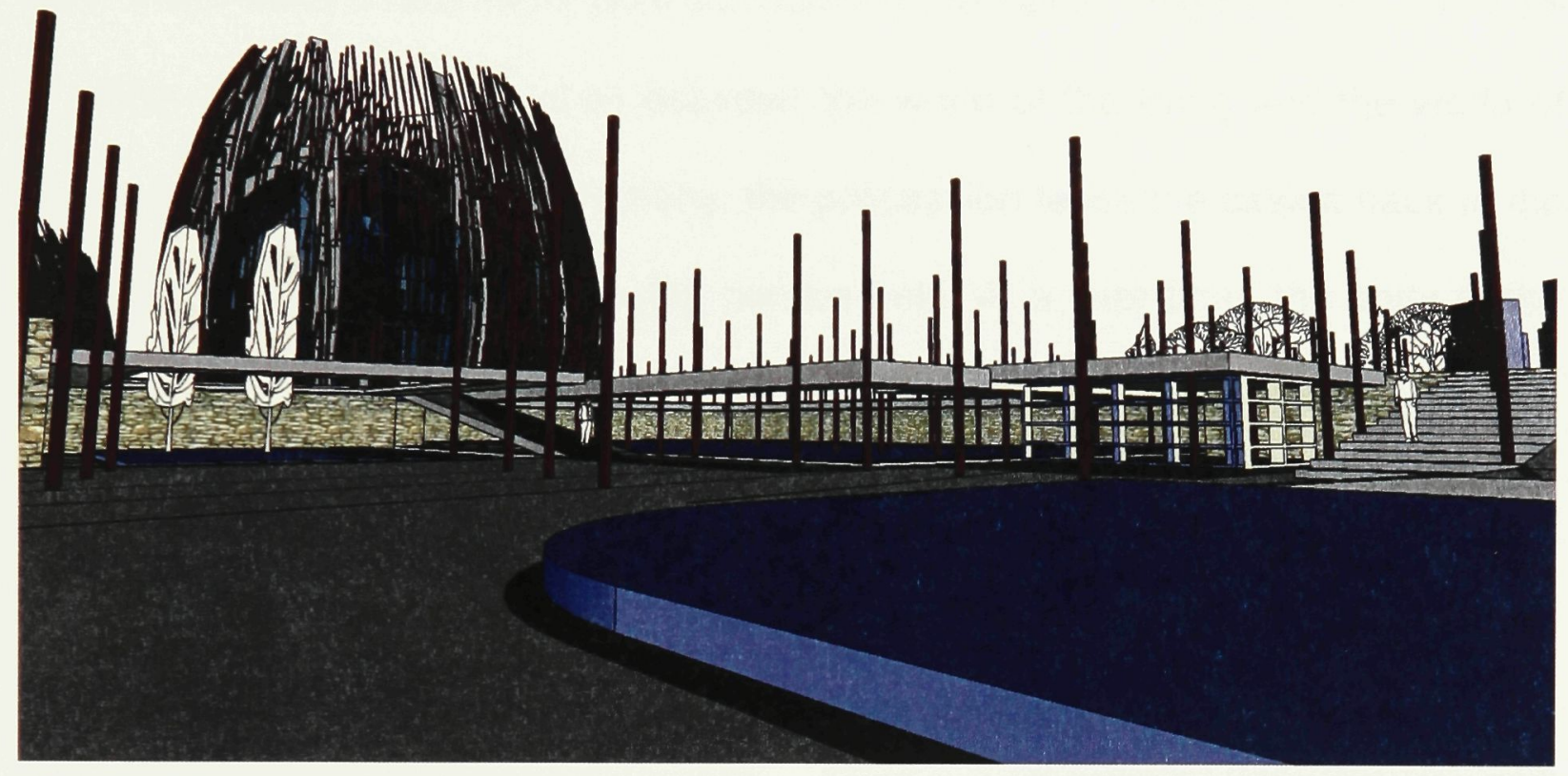

Fig. 5.18 View of courtyard looking South East.

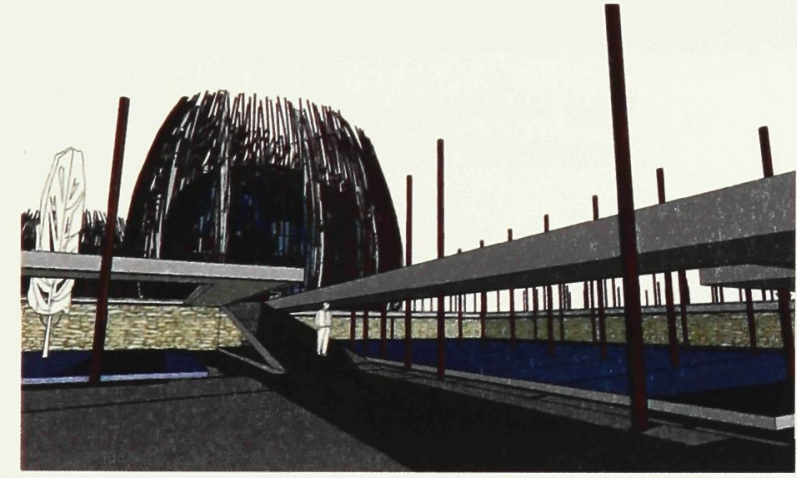

Fig. 5.19 View of ramp to main structure.

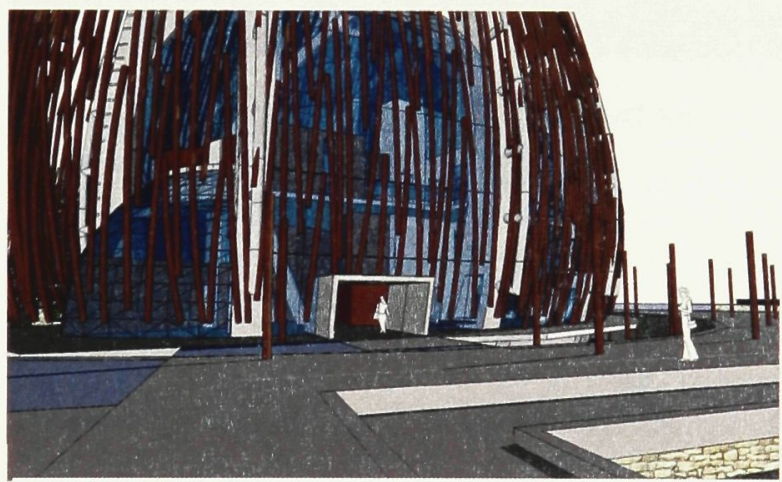

Fig. 5.20 View of main structure exiting ramp.

Following the route towards the outdoor facility, the procession walks among the series of 200 poles erected in the landscape of the island (Figure 5.21). At the end of the route, the procession comes to a downward sloping ramp A Contemporary Cemetery Proposal: Vancouver B.C., Canada 69 
that blends into the entrance for the outdoor ceremonial area (Figure 5.22). This ceremonial area is rectilinear with a series of landings extending from the ramp. These landings step down much like those that one would see in an auditorium (Figure 5.23). The casket is then carried down the ramp. At the end of the ramp the casket is raised onto a platform, which has, as a backdrop, a trickling black slate waterfall that falls into a pool surrounding the casket (Figure 5.24). The pool of water acts as a demarcation between the world of the living and the world of the dead. After the funeral ceremony, the procession takes the casket back to the main structure where a last viewing can be held. At a later time, the body of the deceased is taken to be cremated.

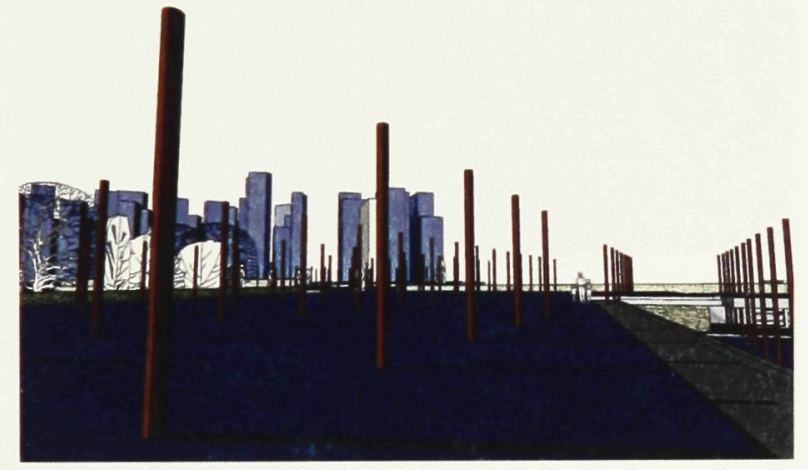

Fig. 5.21 View of processional path towards outdoor ceremonial area.

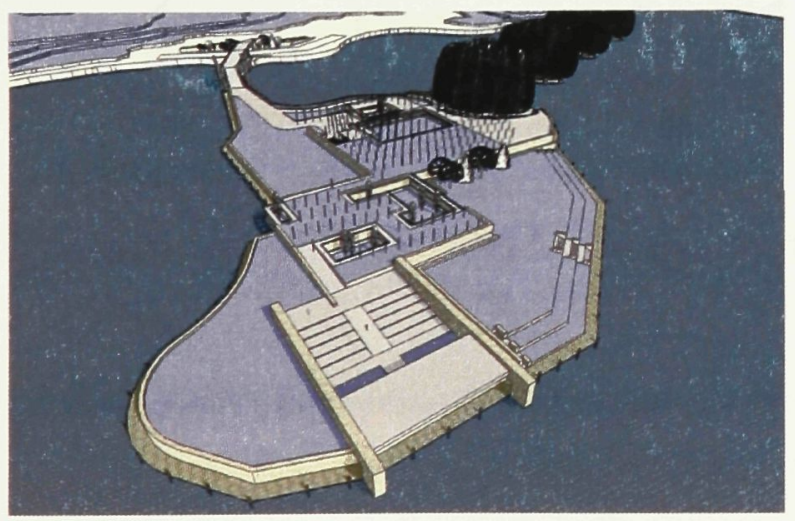

Fig. 5.23 Ariel view of outdoor ceremonial area.

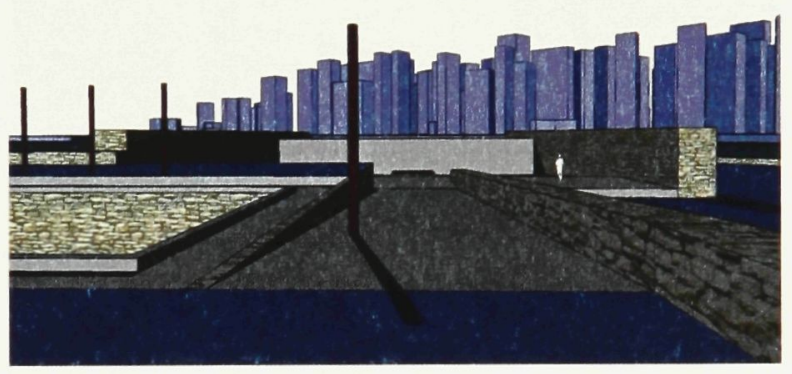

Fig. 5.22 View of ramp down to outdoor ceremonial area.

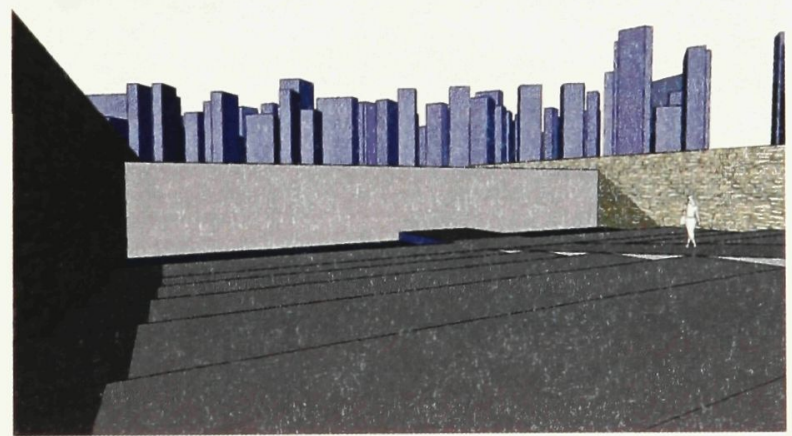

Fig. 5.24 View of outdoor ceremonial area looking south. 
Starting again from the ramp, the procession continues along the path into the main structure. For an indoor ceremony, the procession goes through the principal entrance into the main atrium (Figure 5.25). From here, the procession moves between two chutes that are the crematorium chimneystacks, located in the lower level (Figure 5.26). The procession then continues down a corridor into the ceremonial area (Figure 5.27).

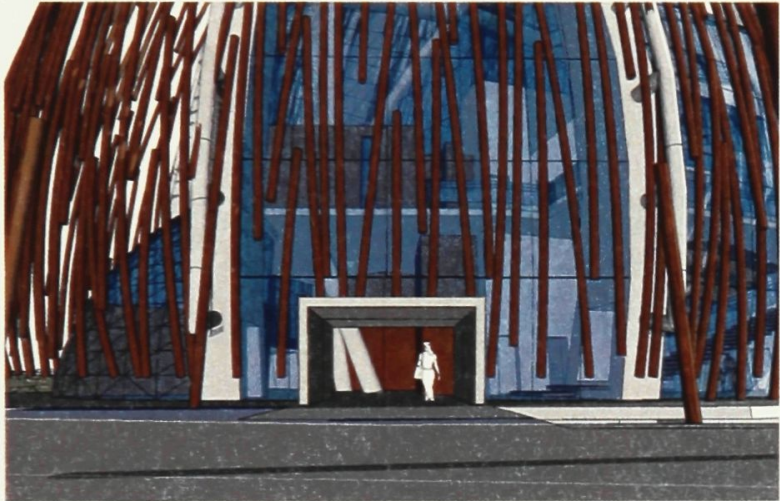

Fig. 5.25 View of main entrance.

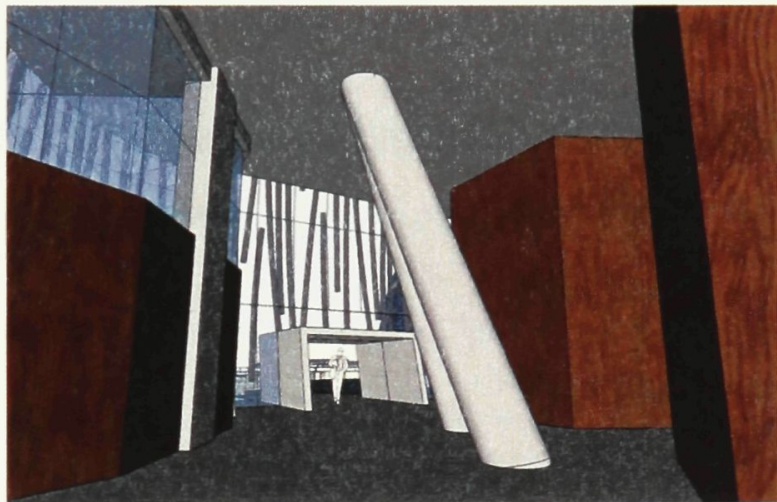

Fig. 5.26 View after entering main entrance.

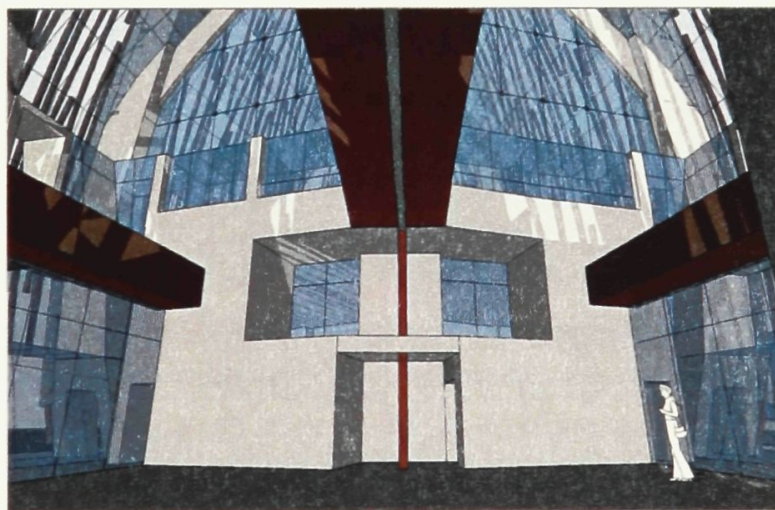

Fig. 5.28 View of main ceremonial area.

Fig. 5.27 View of stacks leading into indoor ceremonial area.

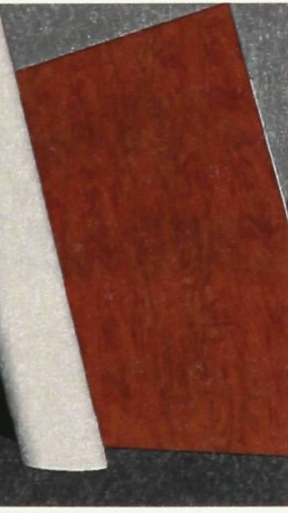


In the ceremonial area the casket is placed in the centre of the room as the funeral ceremony begins (Figure 5.28). This ceremonial area can be divided in half if necessary to accommodate two simultaneous funerals, or if less space is required. On the second floor there is a bridge that connects the kitchen of the complex with the main dinning hall, dividing the ceremonial room from above. An outer skin of glass encompasses the area, and its façade acts as a backdrop that allows for external viewing while creating the illusion of a larger space. After the funeral ceremony the casket is taken down by elevator to the crematorium. The deceased's ashes are received by the immediate family after the ceremonial meal that takes place in their honour. After the meal this narrative merges into that of the deceased's beloved as follows. 


\section{The Narrative of the Deceased's Beloved}

\section{FIVE.FIVE}

The narrative of the deceased's beloved exemplifies what I want to illustrate in my design of the island. My design is devoted to the experience of a participant in the funeral, and this guides me in creating architecture for this landscape. In this narrative the thresholds and layers of the living world start to merge with the dead, thereby achieving my principal design objective.

After exiting their cars on the mainland, individuals walk towards the bridge (Figure $5.29 \& 5.30$ ). As they cross, they notice that the bridge is tall and slender, allowing access for one vehicle at a time, specifically the hearse. It is here that they experience the first of many thresholds. In addition to providing access to the island and a view of the grand vistas of the Vancouver skyline, the bridge demarcates the city of the living and the consecrated ground of the dead. The bridge therefore, becomes a gateway. Traditionally cemeteries were 
surrounded by an enclosure with a gate or a series of gateways that provided access (Figure 5.31). On Dead Man's Island, the water acts as an enclosure with the bridge as the only access point to the island. This singular path symbolizes the fact that death is a journey that each individual must make, and that this journey must be made alone.

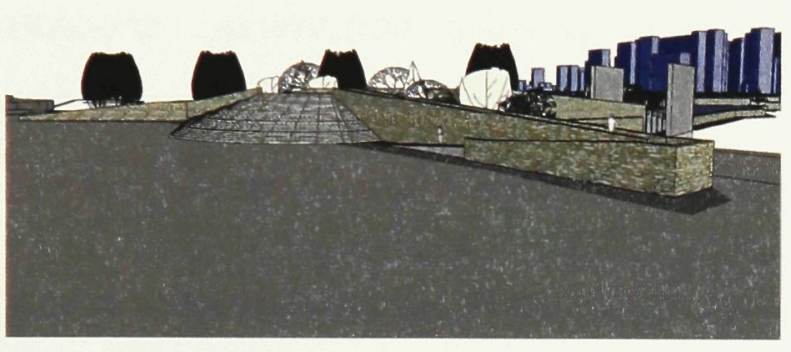

Fig. 5.29 View of ramp to main structure.

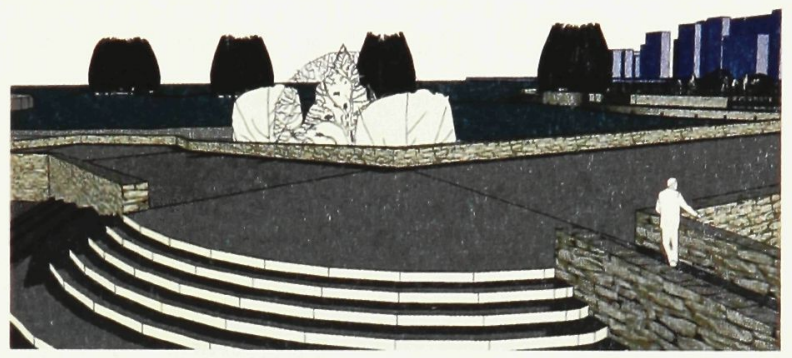

Fig. 5.30 View of stairs leading toward bridge.

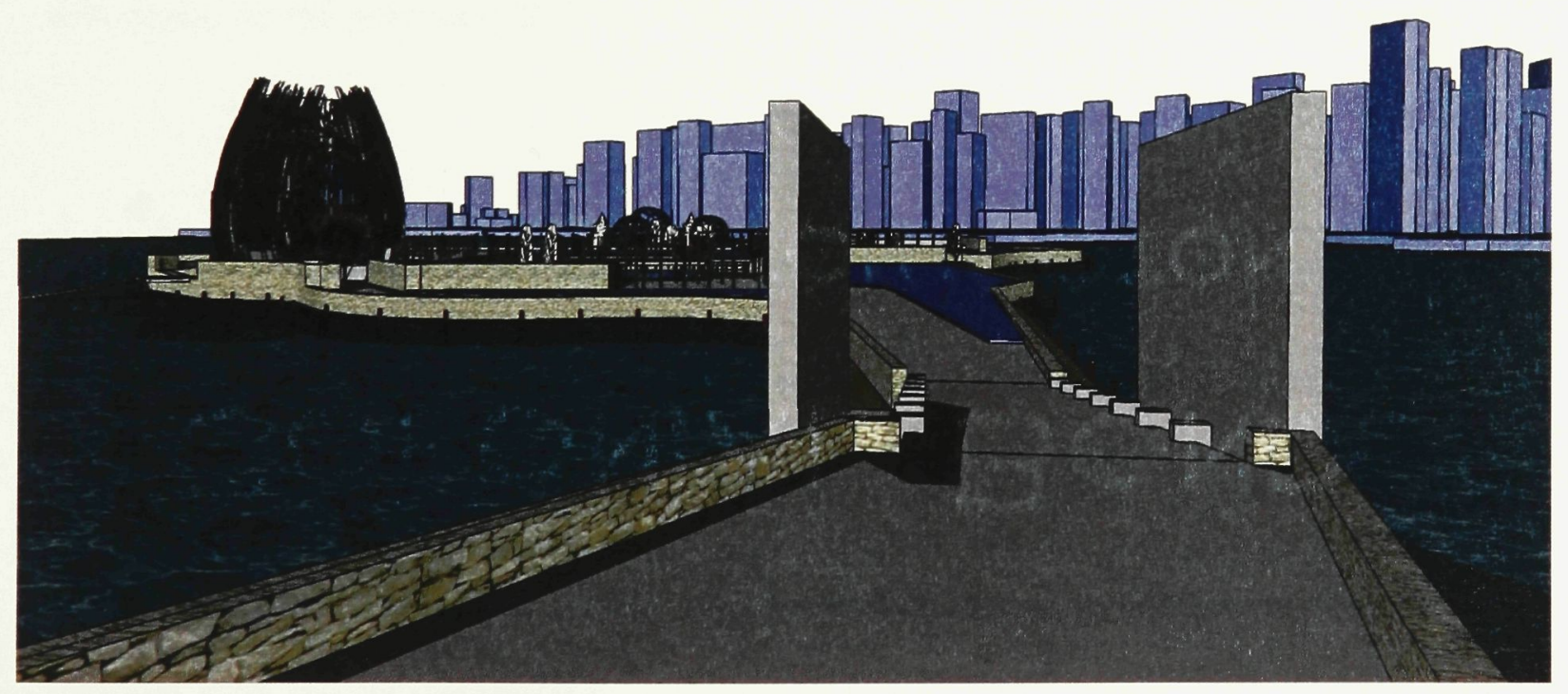

Fig. 5.31 View of bridge connecting the island to Stanley Park. 
After coming across the bridge individuals reach a square (illustrated in Section 5.4.), where they follow the same path as the deceased, going up the ramp in between two waterfalls. Adjacent to one of the waterfalls is a chapel that pierces through the water (Figure 5.33). It is dedicated to the individuals who perished on the island, but whose remains have never been found or exhumed, and acts as a memorial to individuals who have no physical body to cremate or bury (Figure 5.32). At the top of the ramp the participants can either take the path to the outdoor ceremonial area or the path to the main structure for an indoor ceremony.

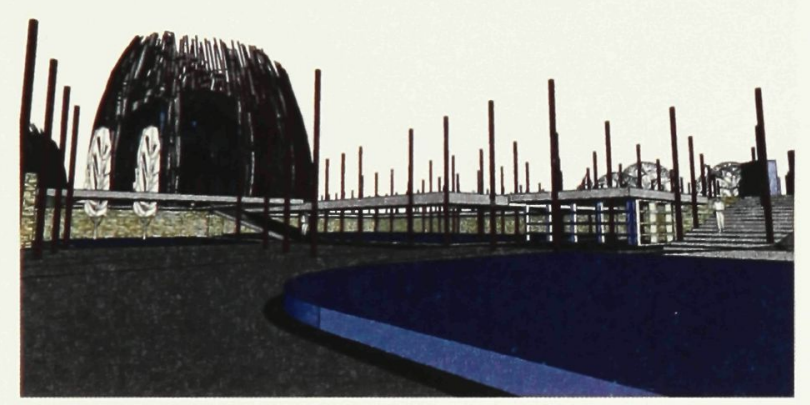

Fig. 5.32 View of ramp to main structure with chapel on the right hand side.

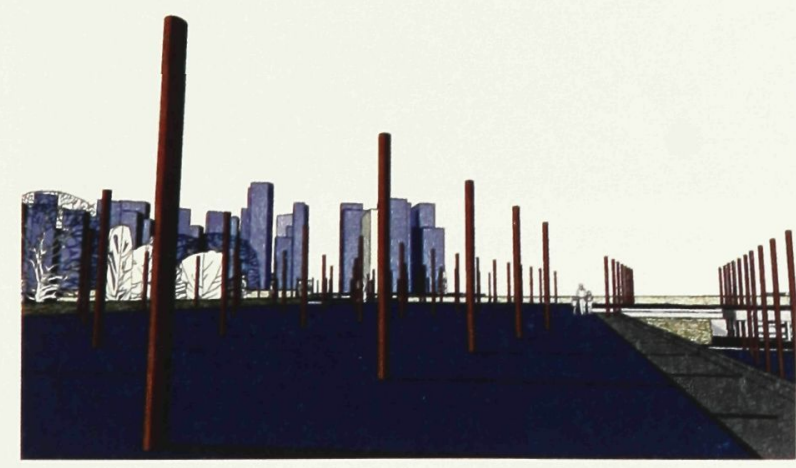

Fig. 5.34 View of processional path towards outdoor ceremonial area.

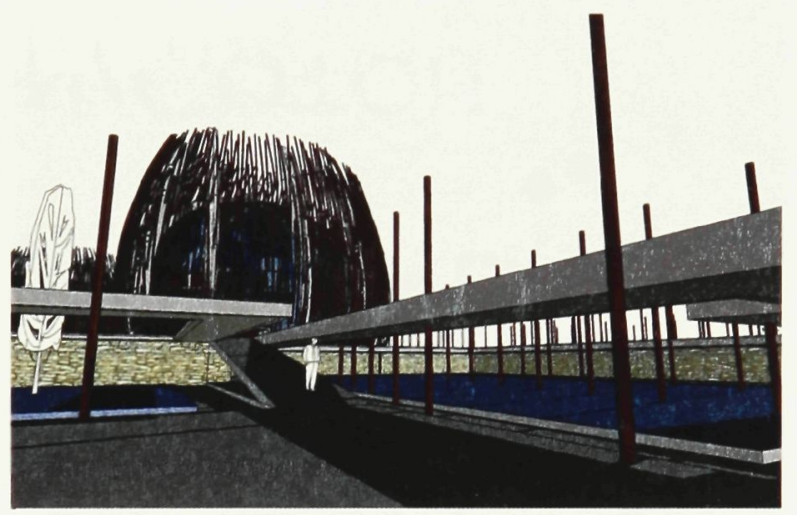

Fig. 5.33 View of ramp to main structure.

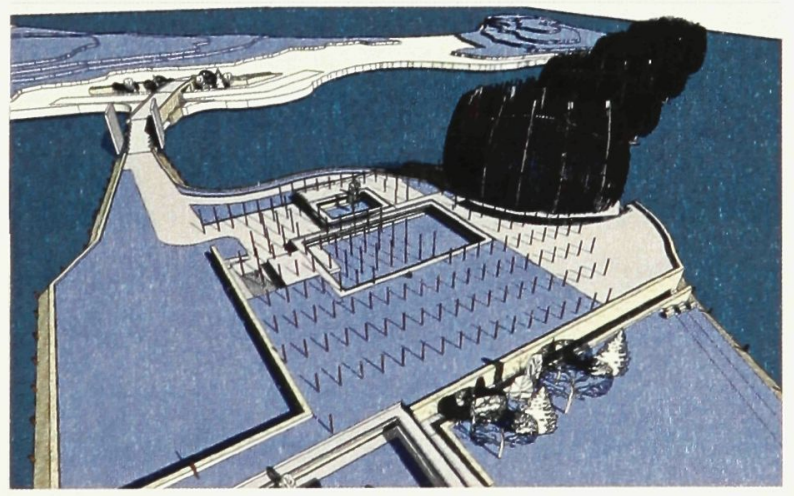

Fig. 5.35 Aerial view of island looking north. 
Going towards the outdoor ceremonial area the visitors continue to follow the path of the deceased through the grid of poles and down the same ramp as described in Section 5.4 (Figure $5.34 \& 5.35$ ). As the visitors continue down the ramp they can see the city's skyline in the distance slowly sinking into a pool of water that turns into the waterfall, which provides the backdrop for the casket (Figure $5.36 \& 5.37)$

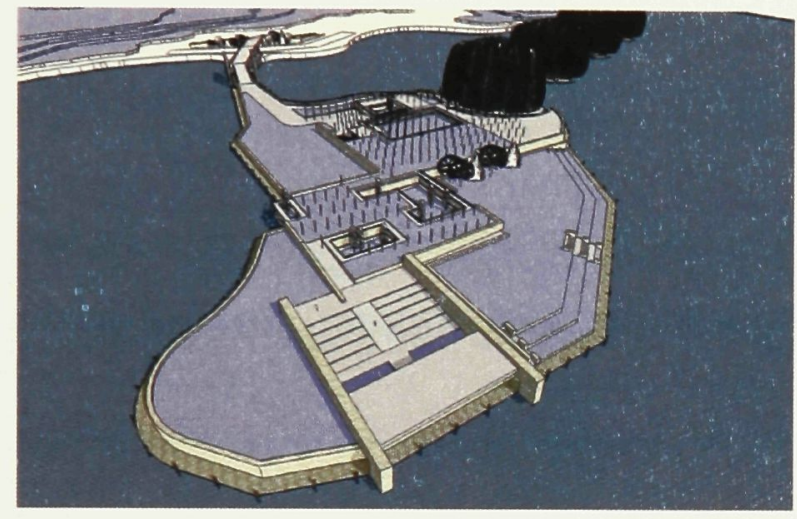

Fig. 5.36 Aerial view of the outdoor ceremonial area looking north.

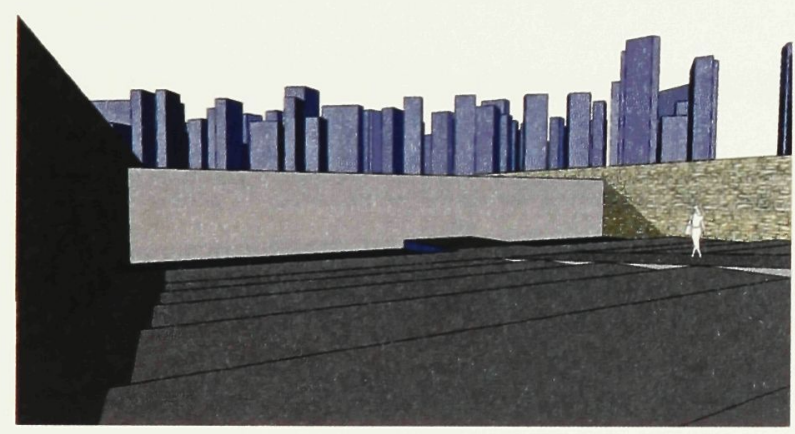

Fig. 5.38 View of ramp to main structure.

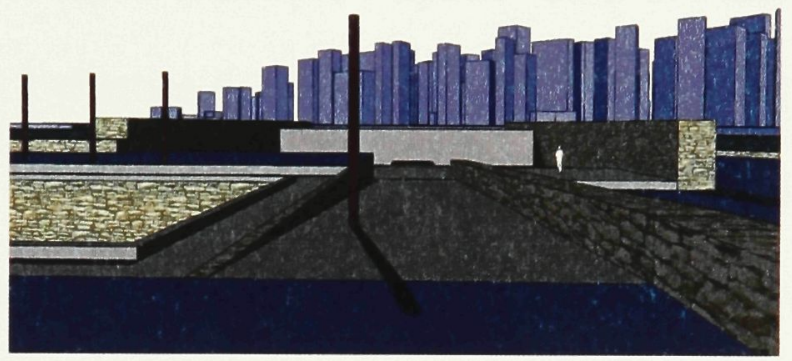

Fig. 5.37 View of ramp down to outdoor ceremonial area.

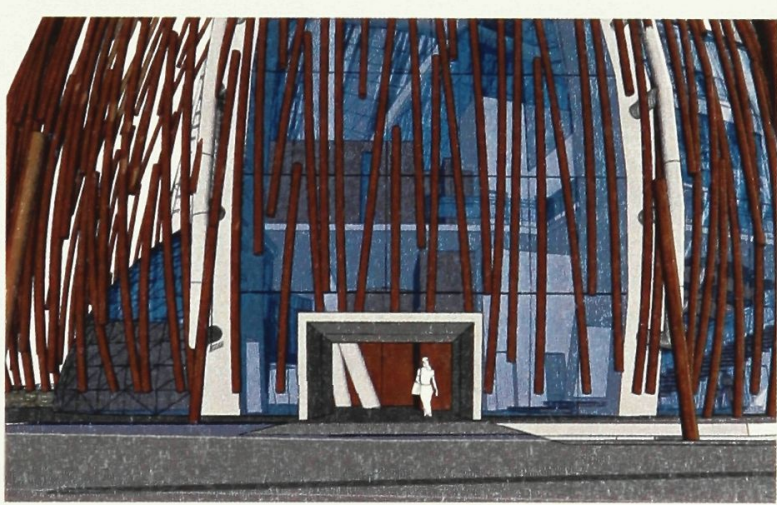

Fig. 5.39 View of ramp to main structure.

It is here that participants begin to notice that as they continue down the ramp they cross the vertical threshold of the living into the realm where the history of 
the island's dead lies. As one sits down they have the experience of being enclosed by high, thick stone walls that reach up towards the sky, and their gaze is drawn towards the front of the space where the casket lies. The casket appears to float underground in a black abyss of water. To create the platform on which the casket is placed, a cantilevered slab of concrete is pinned to the side of the wall of the waterfall allowing for a gap for the water to fall through (Figure 5.38). After the ceremony is finished the participants take the same path back to the main structure for a last viewing and the ceremonial meal.

For the indoor ceremony, guests slip inside the façade of the main structure through a gateway that pierces it (Figure 5.39). Once inside, the main procession proceeds between the two chutes/stacks into the centre of the building where the main ceremonial area is located (Figure $5.40 \& 5.41$ ). For funeral ceremonies with no procession the immediate family waits in adjacent family rooms for the ceremony to begin. These rooms are located down the corridor from the ceremonial area. Other guests are directed from the entrance and continue along the outer perimeter of the building until they reach the centre, the entrance to the main hall (Figure $5.42 \& 5.43$ ).

Seating in the main hall is available on two floors. The main floor is structured to be flush with the existing ground plane with seating on the second floor set up in a mezzanine configuration. As one sits on a chair on the main floor, their perception of the horizon line changes to lie at the same level at which the casket is presented. Through this subtle change of perspective guests feel as though they are participants in the ceremony, and become immersed in the 
occasion. All barriers are released, and thresholds of each individual become translucent and receptive to all senses.

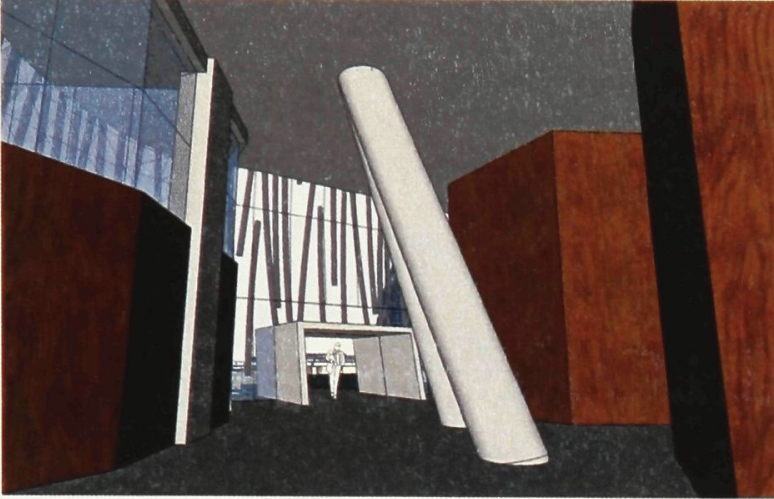

Fig. 5.40 View after entering main entrance

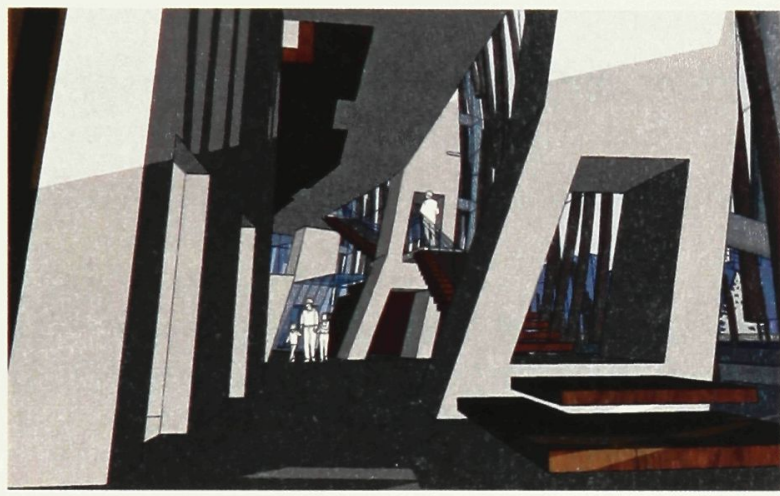

Fig. 5.42 View from entrance looking south along main structure.

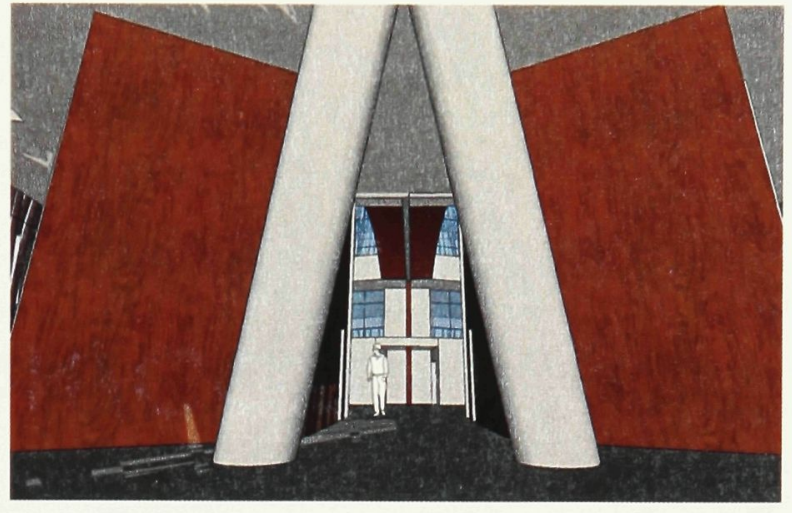

Fig. 5.41 View of stacks leading into indoor ceremonial area.

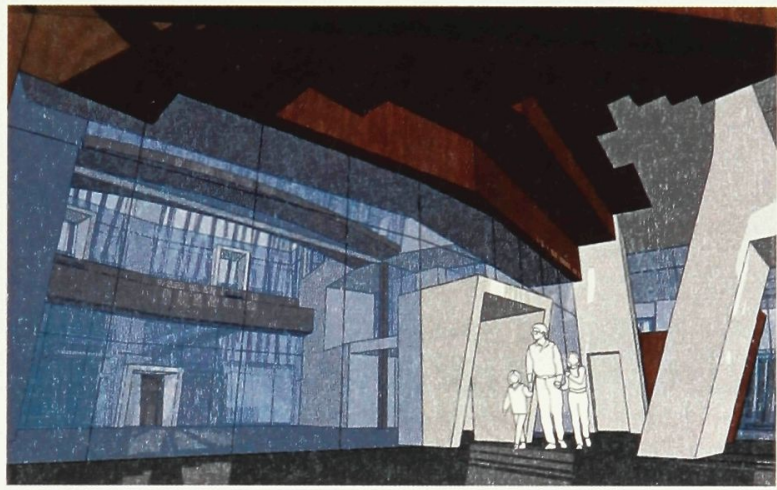

Fig. 5.43 View from corridor looking into ceremonial area.

Encompassing the main hall a film of glass separates the outside from the inside with the façade framing the outer surroundings. The copper façade acts as an interstitial layer that fragments, then merges the horizontal plane with the vertical plane and creates fixed views from the inside and out. From every fixed view boundaries are merged into a singular perspective. At this time, the ground plane of the living merges with the plane of the sky, with the architecture of the structure acting as the mediator between both conditions. At the centre of the 
architecture, the main hall is a place of ascendance for the deceased, from living world to the hereafter (Figure $5.44 \& 5.45$ ).

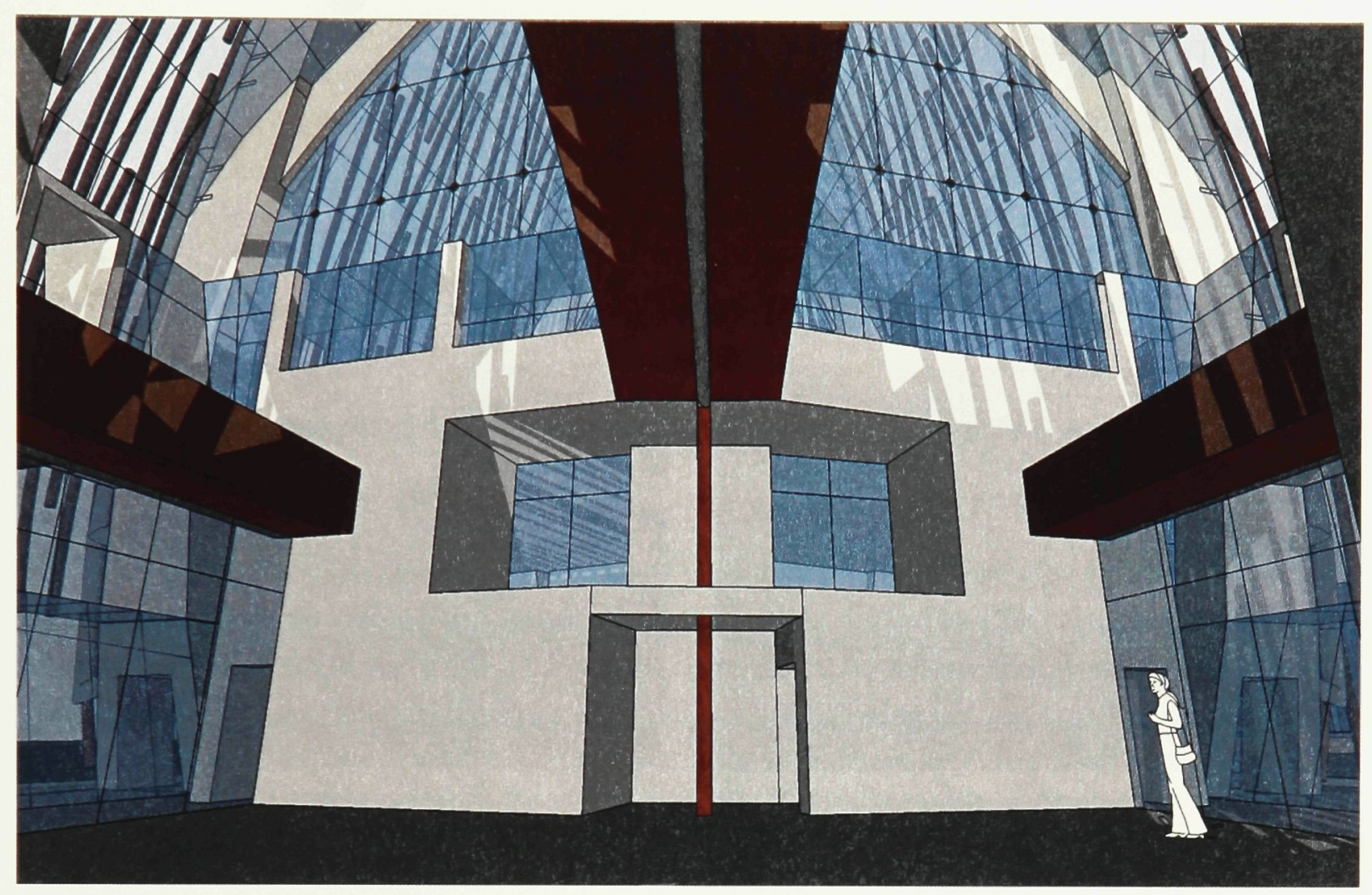

Fig. 5.44 View of main ceremonial area looking south east.

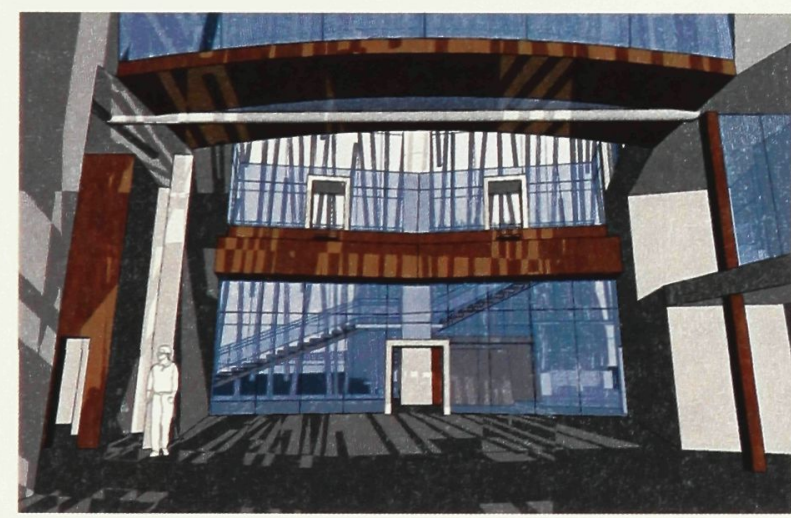

Fig. 5.45 View main ceremonial area looking north east.

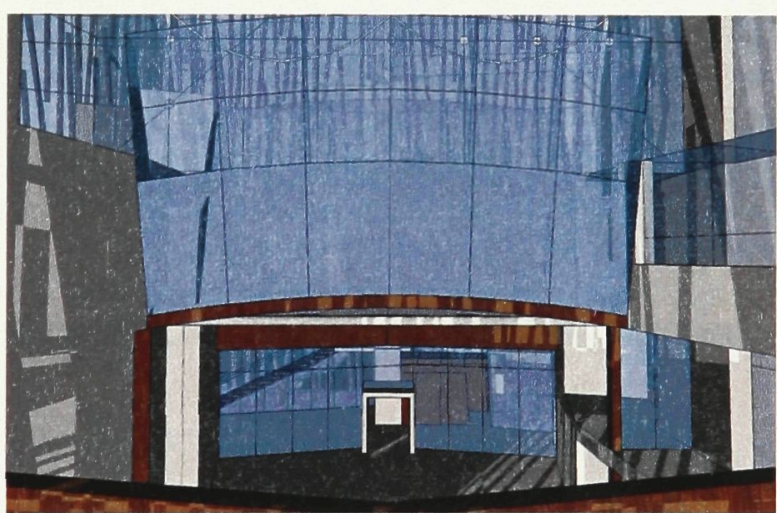

Fig. 5.46 View of main ceremonial area from mezzanine.

A bridge with opaque glass walls connects the kitchen and the dining hall on the second floor, effectively dividing the main hall in two (Figure 5.46). The A Contemporary Cemetery Proposal: Vancouver B.C., Canada 79 
bridge is used by the staff catering a ceremonial meal. As the staff prepare for the meal, guests at the funeral see the ghostly outline of bodies through the glass as they move back and forth between the dining hall and kitchen. The bridge symbolizes the thin line or threshold where food and death rituals interact, as is also illustrated in the Eucharistic ritual described in Section 4. The deceased is "sacrificed" to the hereafter. Later, this sacrifice becomes embodied, through commemoration, within the food one consumes during the ceremonial meal.

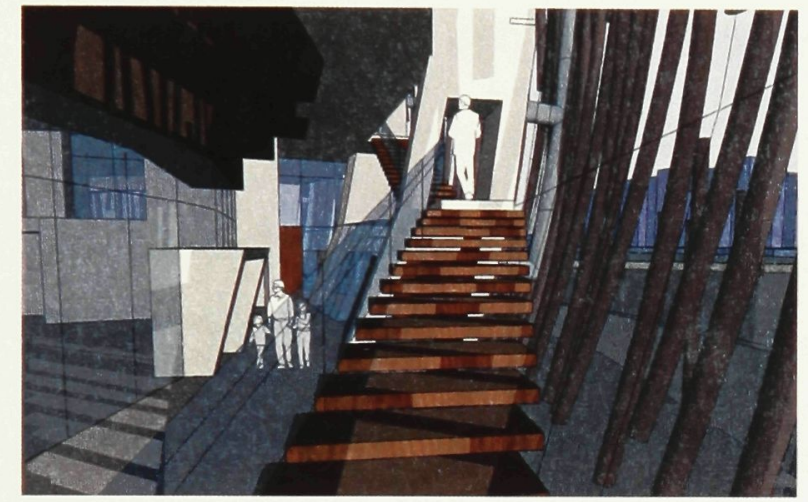

Fig. 5.47 View of stairs to second floor.

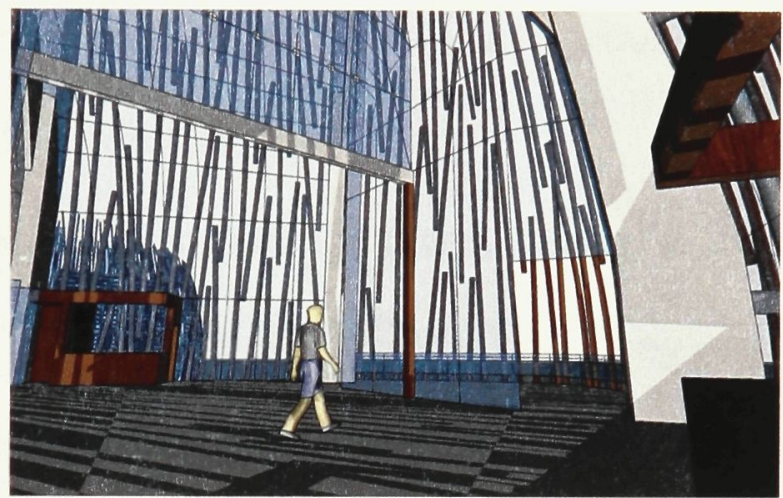

Fig. 5.48 View of main dinning hall.

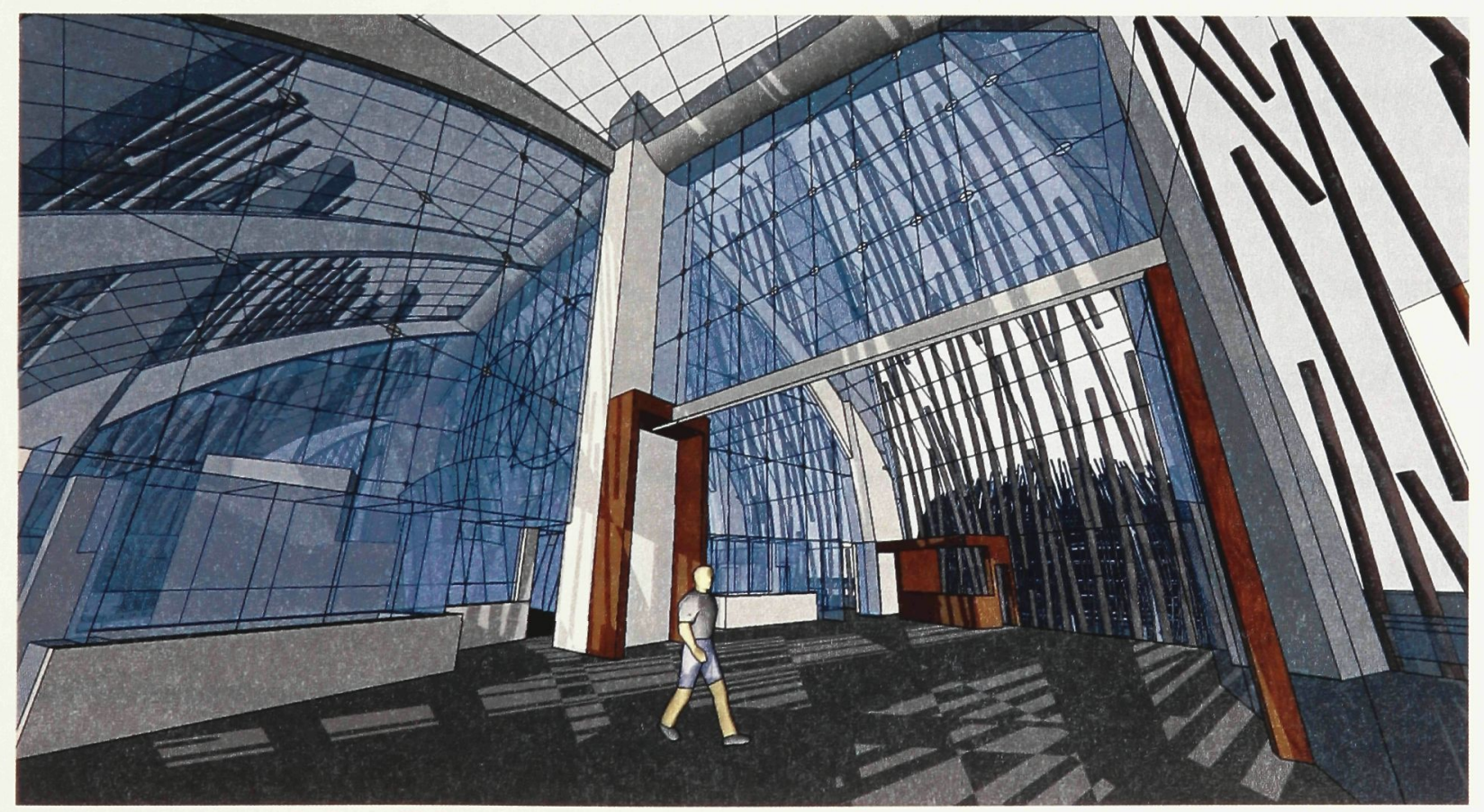

Fig. 5.49 View of main dinning hall looking north towards main ceremonial area. 
After the main ceremony finishes, guests return to the entrance where a set of stairs leads them up into a dining hall on the second floor for the ceremonial meal (Figure 5.47). Overlooking the main hall, the dining hall, which is designed in a similar fashion, provides grand vistas of the harbour with the city's skyline as the backdrop (Figure 5.48). As with the main hall, the dining hall is able to divide into two separate halls if the need arises (Figure 5.49). Once the ceremonial meal finishes guests and members of the immediate family proceed to receive the urn with the deceased's cremated remains. The group then continues to the columbaria for the urn's final placement.

Heading towards the columbaria the procession walks along a thin wooden pier that rises and falls with the tide (Figure $5.50 \& 5.51$ ). As they walk the columbaria seem to rise out from under the abyss of the water. Once inside the columbarium the urn will be placed in a niche or, alternatively, the deceased's ashes are scattered.

During the scattering of the ashes, the ceremony focuses on the centre of the structure. A concrete basin lies at the centre and creates a pond where the deceased's ashes are scattered (Figure 5.52). As is the case in the main structure, the centre becomes the focal place of the ascendance of the deceased. Surrounding the pond is a series of walking platforms that rise and fall with the tides, from which guests can view the ceremony. Functioning as lookout points during non-funeral activities these same series of platforms provide wide vistas of the harbour for moments of pause and reflection. Each columbarium 
contains eight floors constructed in the same fashion as the main structure, but with the addition of niches in between each column (Figure 5.53).

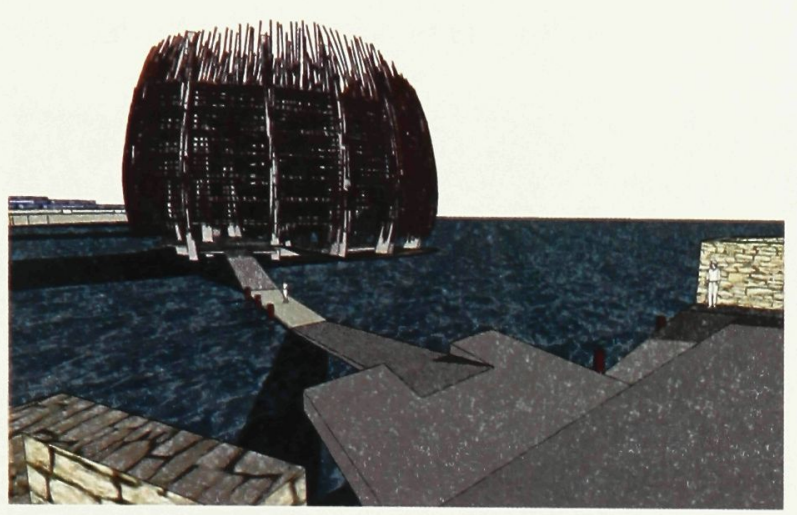

Fig. 5.50 View of columbarium east of main structure.

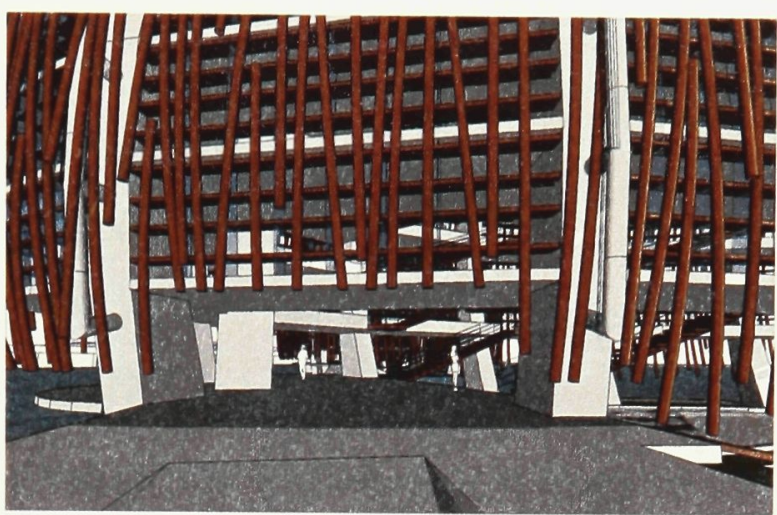

Fig. 5.51 View of entrance for columbarium.

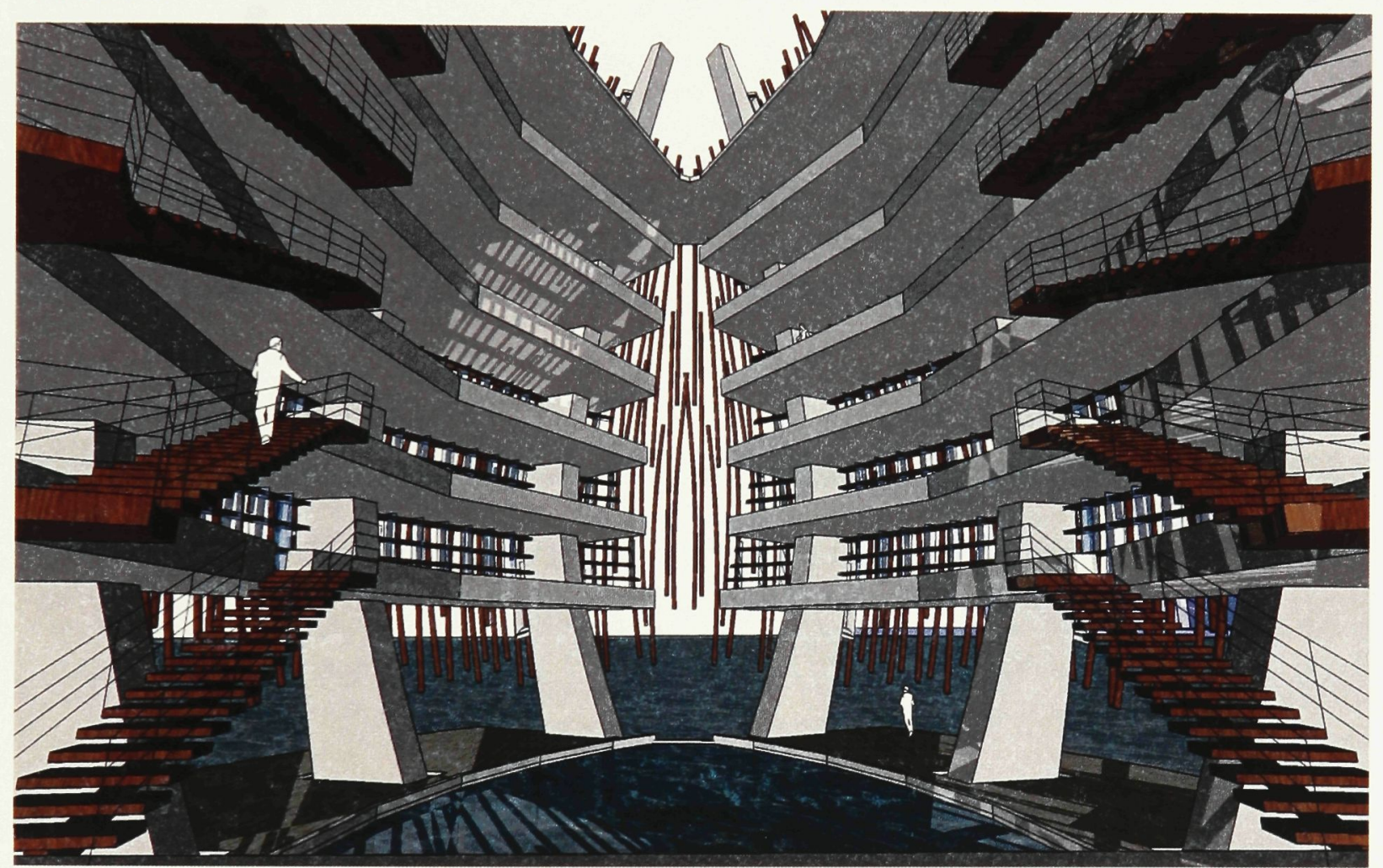

Fig. 5.52 View from inside columbarium.

For the placement of the urn, the final ceremony takes place on the main floor. Afterwards the immediate family takes the urn to its final resting place in one of the niches (Figure 5.54). The niches are designed so that the urn is centred creating ample room on either side for any personal effects, and provide A Contemporary Cemetery Proposal: Vancouver B.C., Canada 82 
a place to insert a photograph of the deceased. The glass behind the urn can be etched with a family's personal message. After the placement of the urn, the narrative of the deceased and the deceased's beloved ones comes to an end

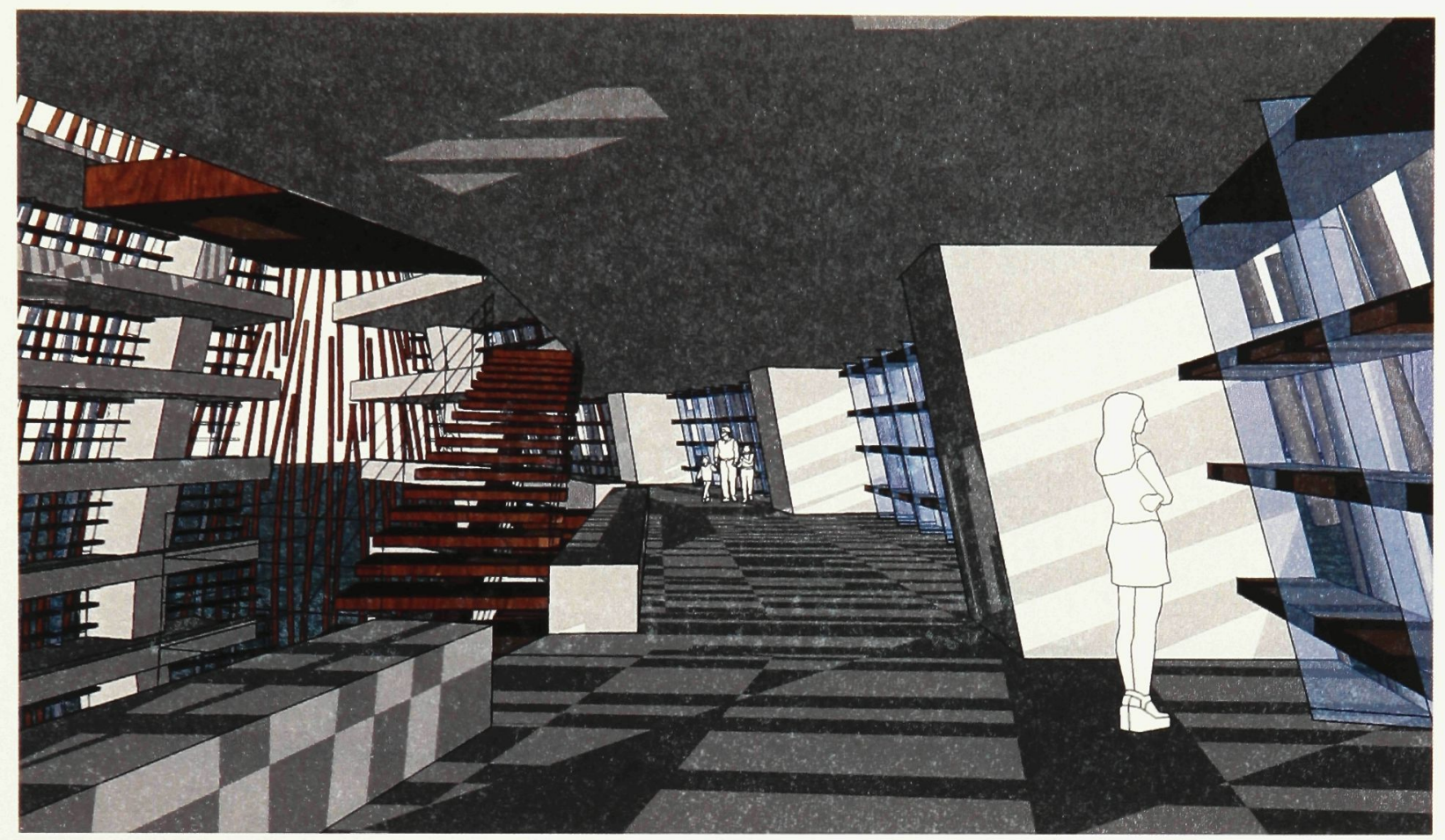

Fig. 5.53 View from floor five inside columbarium

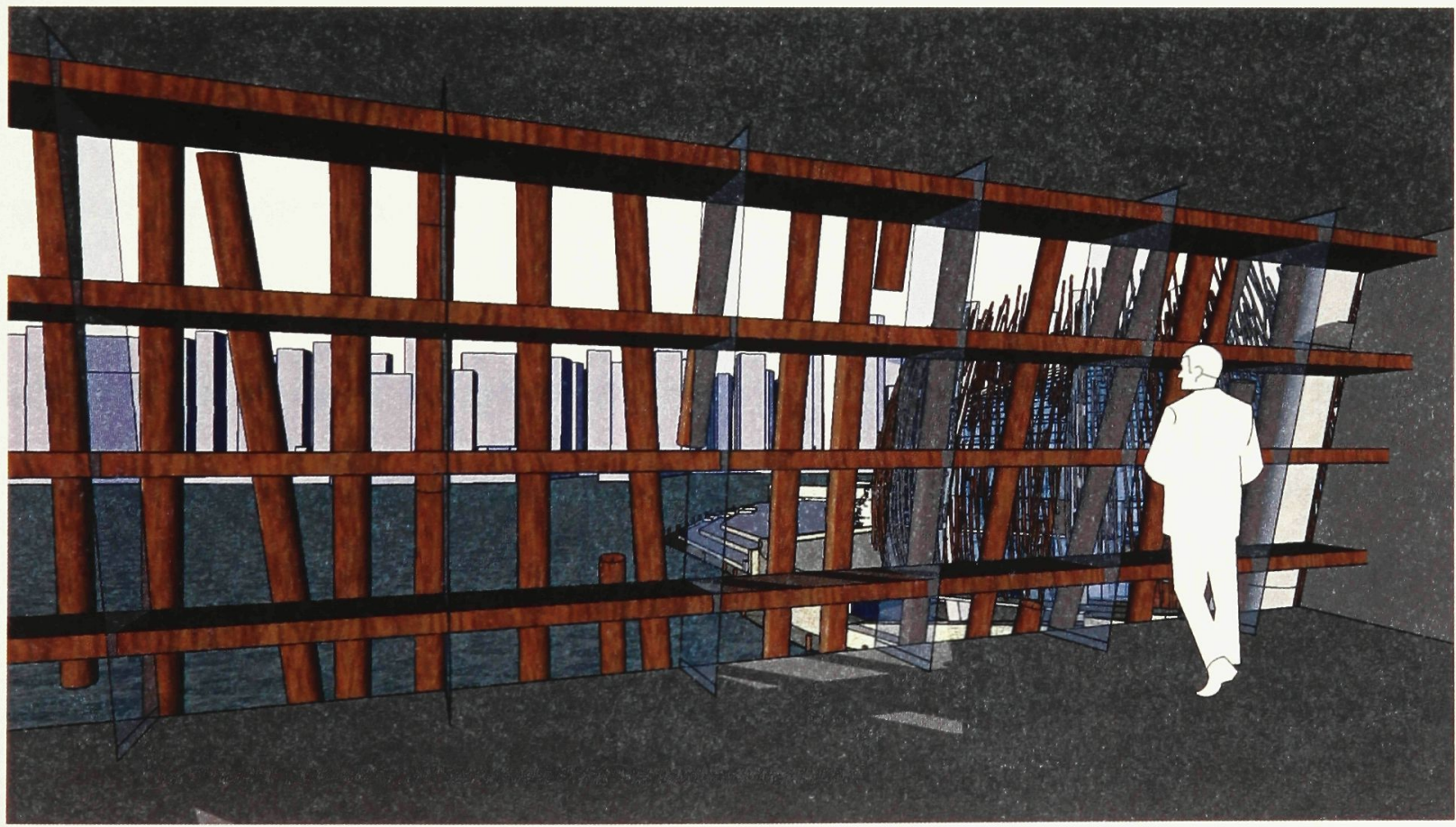

Fig. 5.54 View of niche looking south from columbarium. 


\section{The Narrative of the Pedestrian}

\section{FIVE.SIX}

Starting at the bridge, the pedestrian is able see grand vistas of the island and its structures with Vancouver's skyline as a backdrop (Figure 5.55). It is at this junction that the pedestrian is separated from the main route, and is taken along the bridge to a separate path. This path leads them below and to the side of the bridge (Figure 5.56). The path to the side of the bridge, which continues around the island, is constructed much like the piers that one would see at a docking facility for boats in any harbour (Figure 5.57). It is constructed from a series of wood slats on a wooden frame that is connected to floatation devices. Looking at the side closest to the bridge, the path is connected to the bridges columns with a $U$ shape brackets. The bracket is fitted with a roller that allows the path to rise and fall with the tides. At the end of the bridge the paths converge and are attached to concrete piers. It is at these series of concrete piers where the island has its first interaction with the rest of the harbour. 


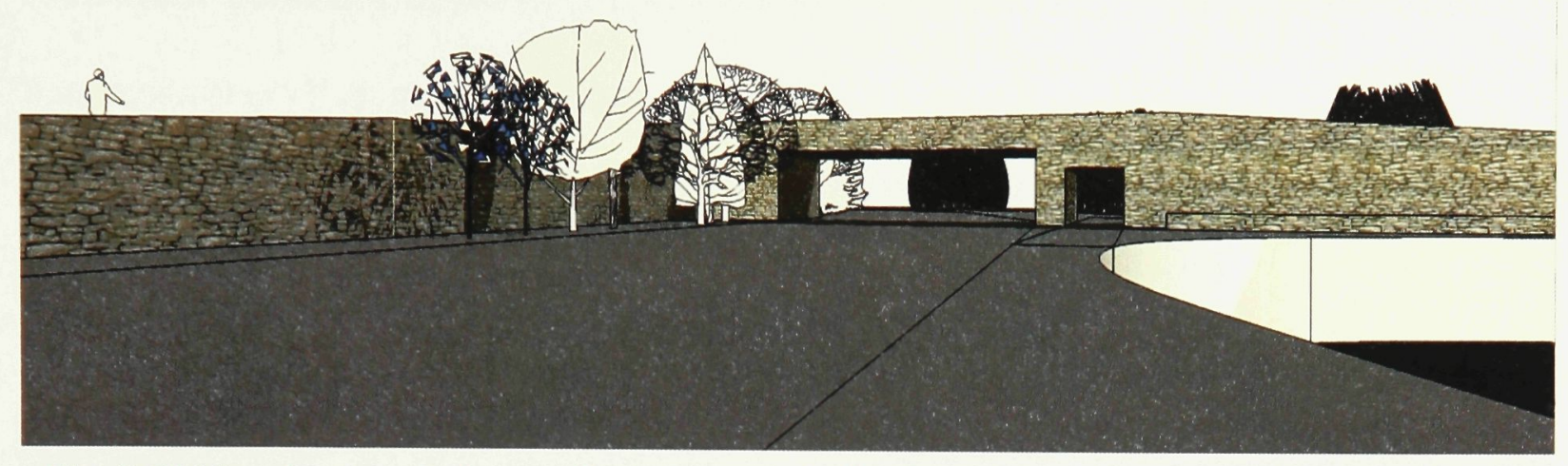

Fig. 5.55 View from pedestrian path looking east at bridge.

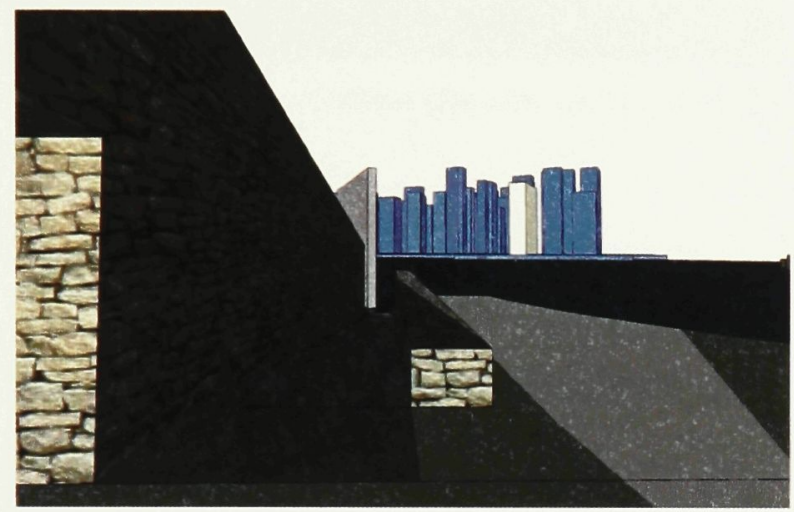

Fig. 5.56 View of pedestrian path leading to bridge.

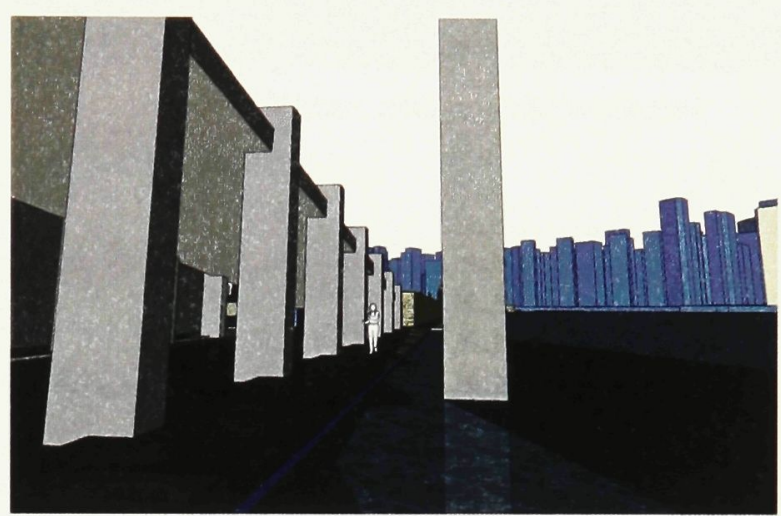

Fig. 5.57 View of path looking south under bridge.

Further along, pedestrians come across a rectilinear water garden that is fed by a waterfall (Figure 5.58). This garden is a part of the consecrated land, discussed in Section 5.3. A series of interventions are introduced here. At this junction, the path steps down to a point where it is submerged under water during high tide; however, during low tide pedestrians are able to continue along the path. I chose to do this to reflect the cyclical relationship of humans with nature, a relationship that involves death. During low tide pedestrians are able to continue along the path and experience the water garden at their eye line, in keeping with the horizontal plane of the past. The waterfall descends into a 
rectilinear concrete basin in a continuous sheet, creating a translucent screen to the vegetation that grows inside.

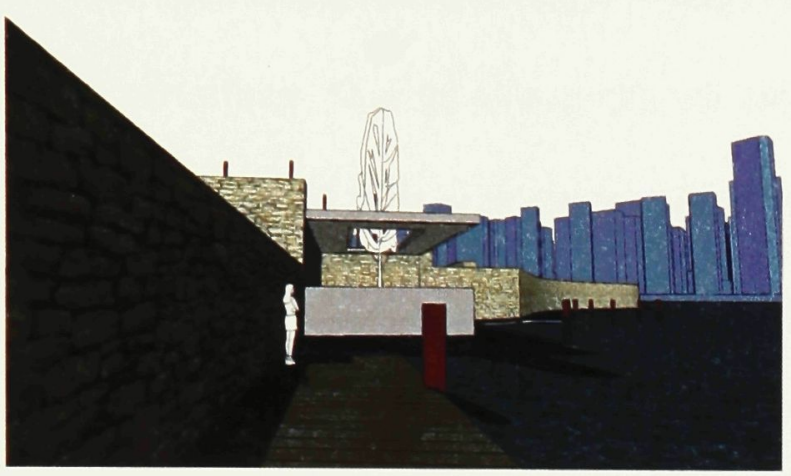

Fig. 5.58 View of water garden looking south.

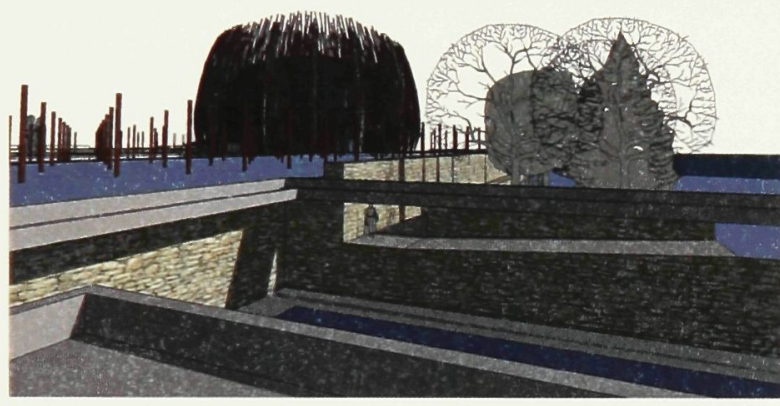

Fig. 5.60 View of path that provides access to park.

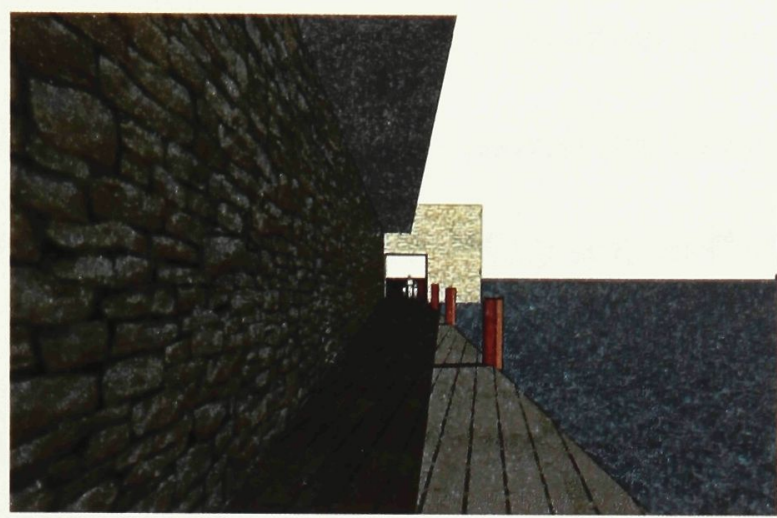

Fig. 5.59 View from path under waterfall.

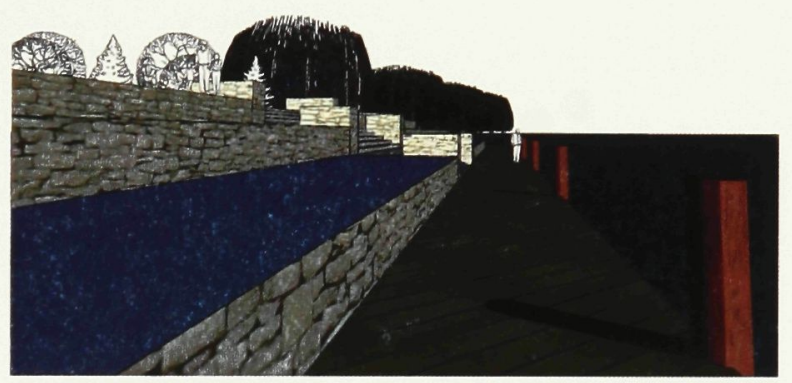

Fig. 5.61 View from path looking at park.

Along the path, around a bend, pedestrians walk underneath the waterfall that is located just above them (Figure 5.59). This waterfall connects to an outdoor funeral ground. When walking under the waterfall the participants experience a tunnel-like enclosure with water rumbling to their side. This water, much like that in the water garden area, comes down in sheets obscures the city's harbour front. Coming out from underneath the waterfall pedestrians are then able to walk out into an open park were they can enjoy all the harbour has 
to offer (Figure $5.60 \& 5.61$ ). Continuing along the path, past the park, pedestrians eventually come to an intersection where their path is crossed by that of the deceased and their loved ones or to a restaurant that is located in the main structure. It is at this juncture where the path once again descends below the level of high tide. This is to prevent pedestrians from interrupting any part of the funeral procession. During low tide, when no funerals are taking place, the pedestrian is free to continue along the path that leads them to the columbaria, and they can experience the same spaces that I illustrated in Sections 5.5 and 5.6. If one were to continue along the same path then it would lead back to the bridge and to the mainland creating a full circle.

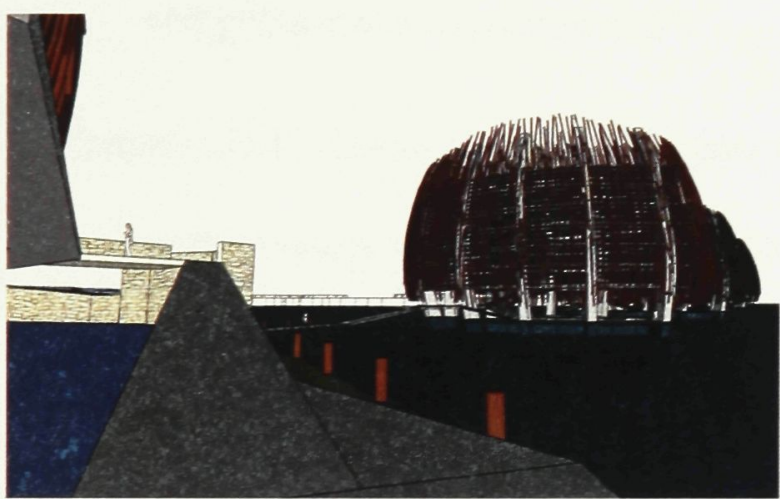

Fig. 5.62 View of ramp to restaurant located in main structure.

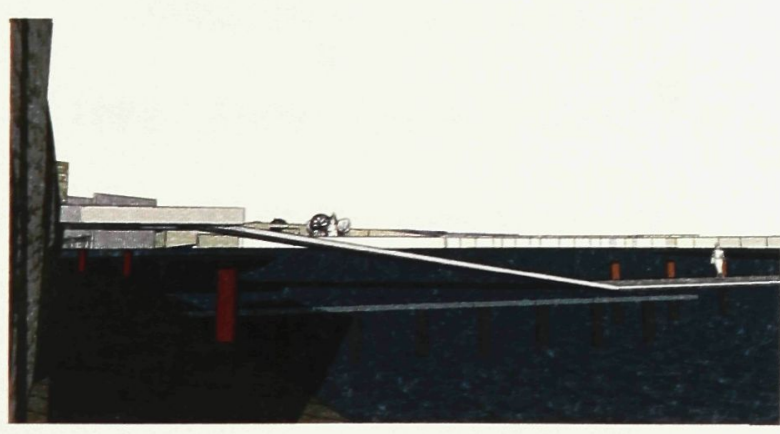

Fig. 5.64 View from path looking at path that connects to columbarium.

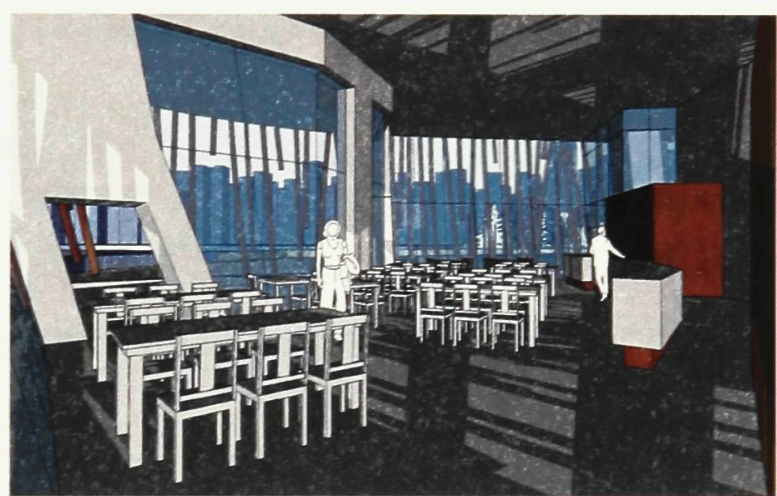

Fig. 5.63 View from inside restaurant.

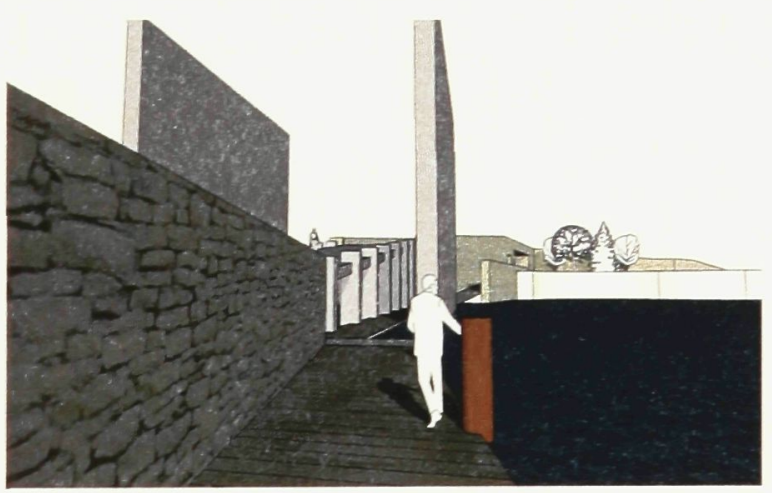

Fig. 5.65 View from path below bridge looking north towards Stanley Park. 


\section{Section V Endnotes}

${ }^{96}$ Wynn, Graeme. Vancouver and Its Region. Vancouver: UBC, 1992. xi.

${ }^{97}$ Wynn. 38.

${ }^{98}$ Wynn. xii.

${ }^{99}$ Wynn. xiii.

100 Wynn. xiii.

${ }^{101}$ Hiss, Tony. The Experience of Place. New York: Random House. 1990

102 Miller, Chris. "Spirits of Deadman's." The Vancouver Courier 15 $<$ http://www.vancourier.com>.

${ }^{103}$ Miller, Chris. "Spirits of Deadman's." The Vancouver Courier <http://www.vancourier.com>.

104 Oaten, Jim. "Dead on Arrival." Vancouver Magazine <http://www.vanmag.com/9708/secrets_dead.html>.

105 Miller, Chris. "Spirits of Deadman's." The Vancouver Courier <http://www.vancourier.com>.

${ }^{106}$ Miller, Chris. "Spirits of Deadman's." The Vancouver Courier 15 <http://www.vancourier.com>.

107 Miller, Chris. "Spirits of Deadman's." The Vancouver Courier 15 $<$ http://www.vancourier.com>.

${ }^{108}$ Morris, Mark. "Architecture Yum!" Architectural Design. 56. 
${ }^{109}$ Frascari, Marco. "Semiotica ab Edendo, Taste in Architecture." Journal of Architectural Education. 6.

${ }^{110}$ Frascari. 6.

${ }^{111}$ Frascari. 6. 


\section{Conclusion}

The cemeteries within the modern city are slowly fading away from its landscape. Cemeteries play a vital role in the collective memory of a city, from the inscriptions on tombstones to their location in the urban fabric. They provide a record of past generations, and are a reflection of the people of a community.

As I have illustrated, food rituals play a role in funeral ceremonies, and also have the ability to transform, structure, and delineate architectural space. Food and eating play an important role in the modern city as evidenced by the proliferation of restaurants and specialty food stores in urban centres such as Vancouver. In fact, cooking and eating food has become about more than just survival, it is now a sort of status symbol that is on par with the likes of fashion and art. And this trend is not limited to a narrow demographic; over the last decade the internet and mass media have made global cuisine accessible to the masses. The new role and importance of food and eating, especially in urban multi-ethnic settings like Vancouver, makes food rituals an ideal catalyst to alter contemporary perceptions about cemeteries. 
By introducing references such as food, cemeteries can mirror aspects of culture and its changing complexities, and take on a more central role in the urban setting. Although it is important for the cemetery to reflect contemporary culture and ideas, its history, and that of the city where it is located also play an important role in its reinvention. This idea is best illustrated by the proposed cemetery extension for San Michele in Venice. Chipperfield evokes the strong sense of belonging that people already have for the San Michele cemetery through built forms that reflect Venice's indigenous qualities. Similarly, my proposal for Dead Man's Island also uses the island's history as well as Vancouver's contemporary realities to shape the built environment and uncover a potential dialogue between the living and the dead.

As I noted, one experiences these same thresholds and spaces during a meal and a funeral. My architecture merges these two experiences together, highlighting their similarities and differences. By creating spaces where these rituals can occur simultaneously, I hope to bridge the threshold between the worlds of the living and the dead, and create a unique setting for commemoration, remembrance and reflection. The columbaria take on the role of the grave marker through their physical construction and through the rituals for which they are a backdrop. By sharing a meal there and remembering a loved one, an association is created with the architecture, whereby the columbarium is the physical reminder of the experience of commemoration. In this way, the individual memories of the deceased are preserved within the collective memory of the city. 


\section{The Manifestation of an Idea}
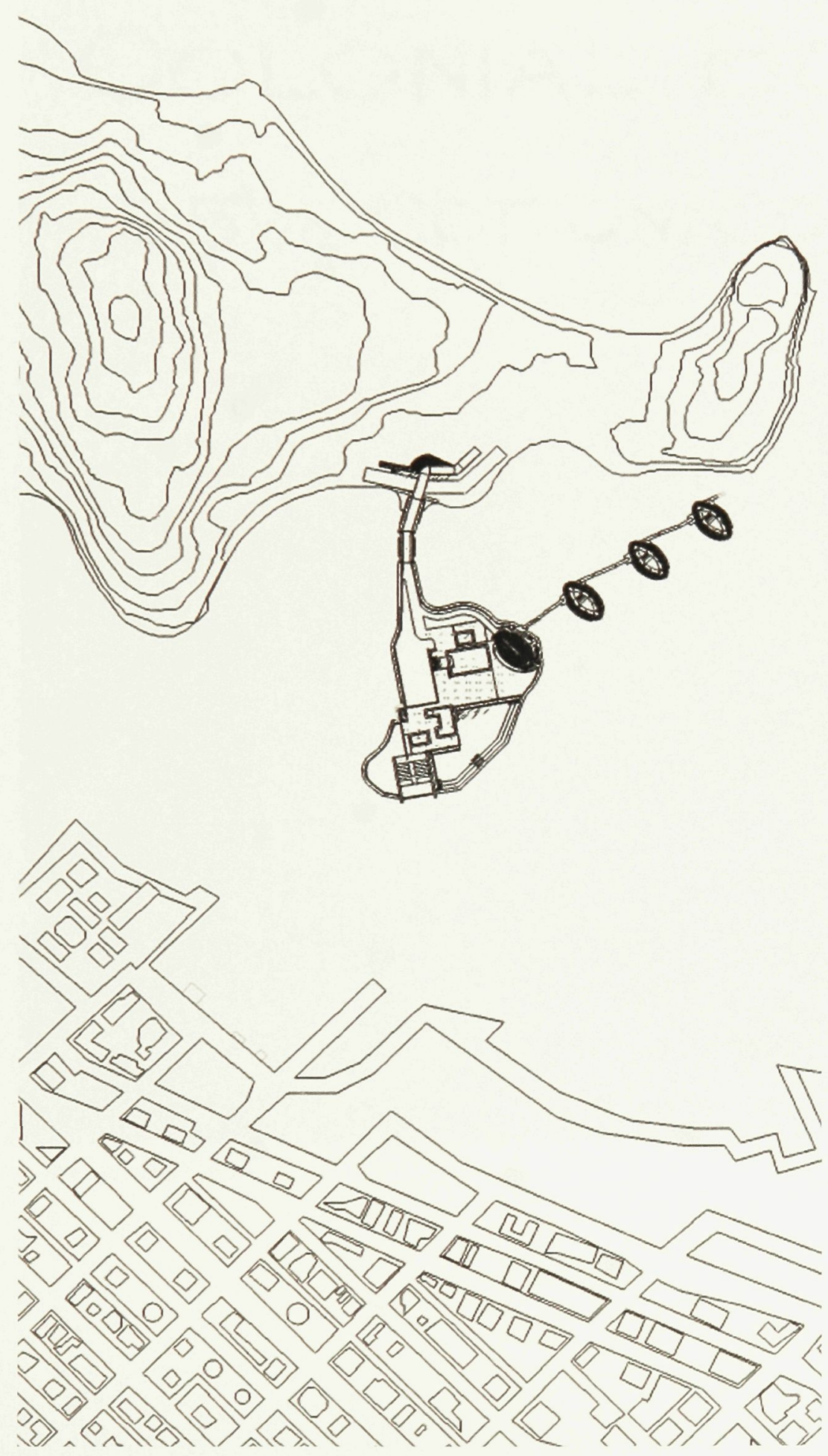

Fig. 6.1 Site Plan of downtown Vancouver with Dead Man's Island. 


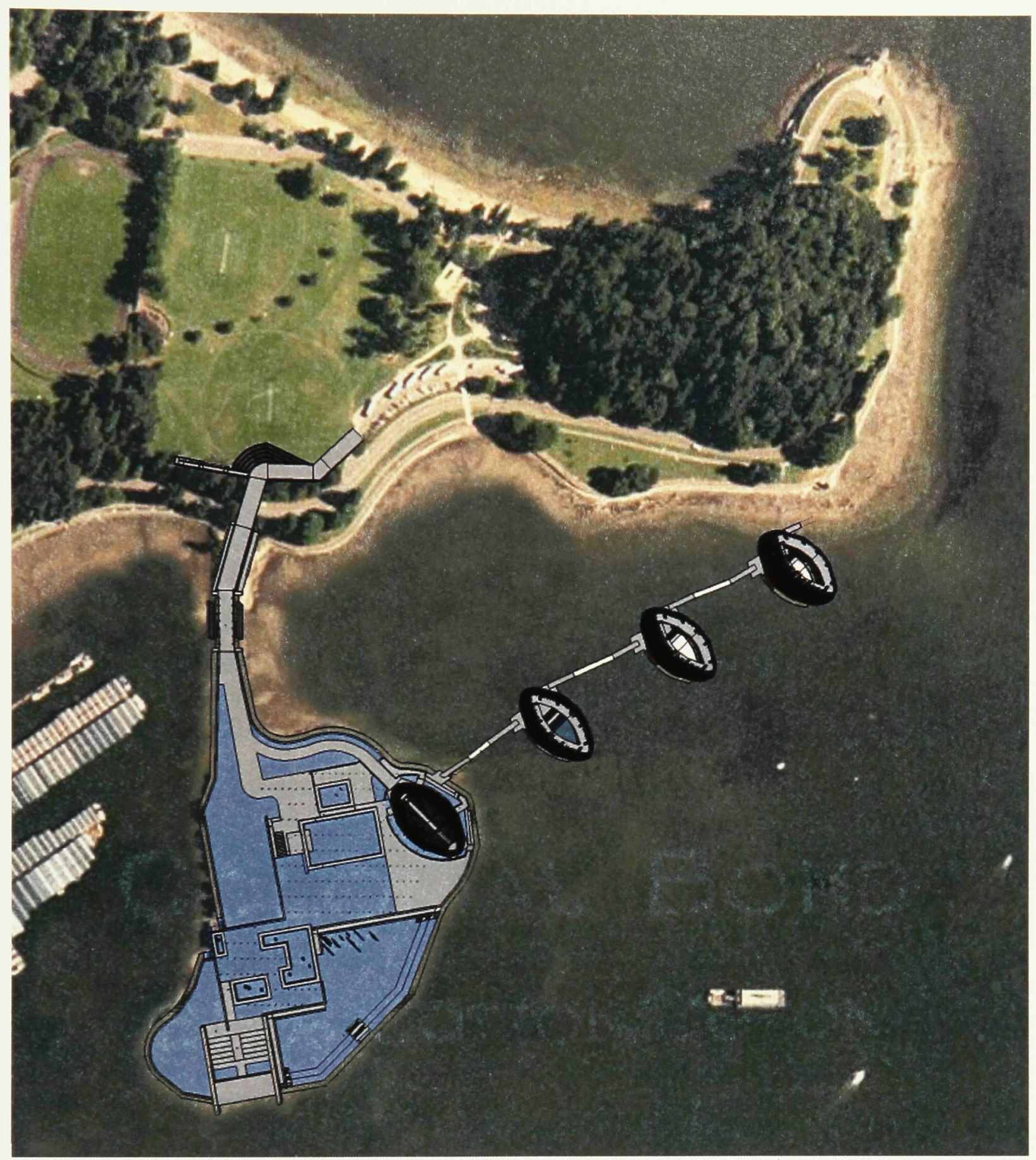

Fig. 6.2 Site Plan 


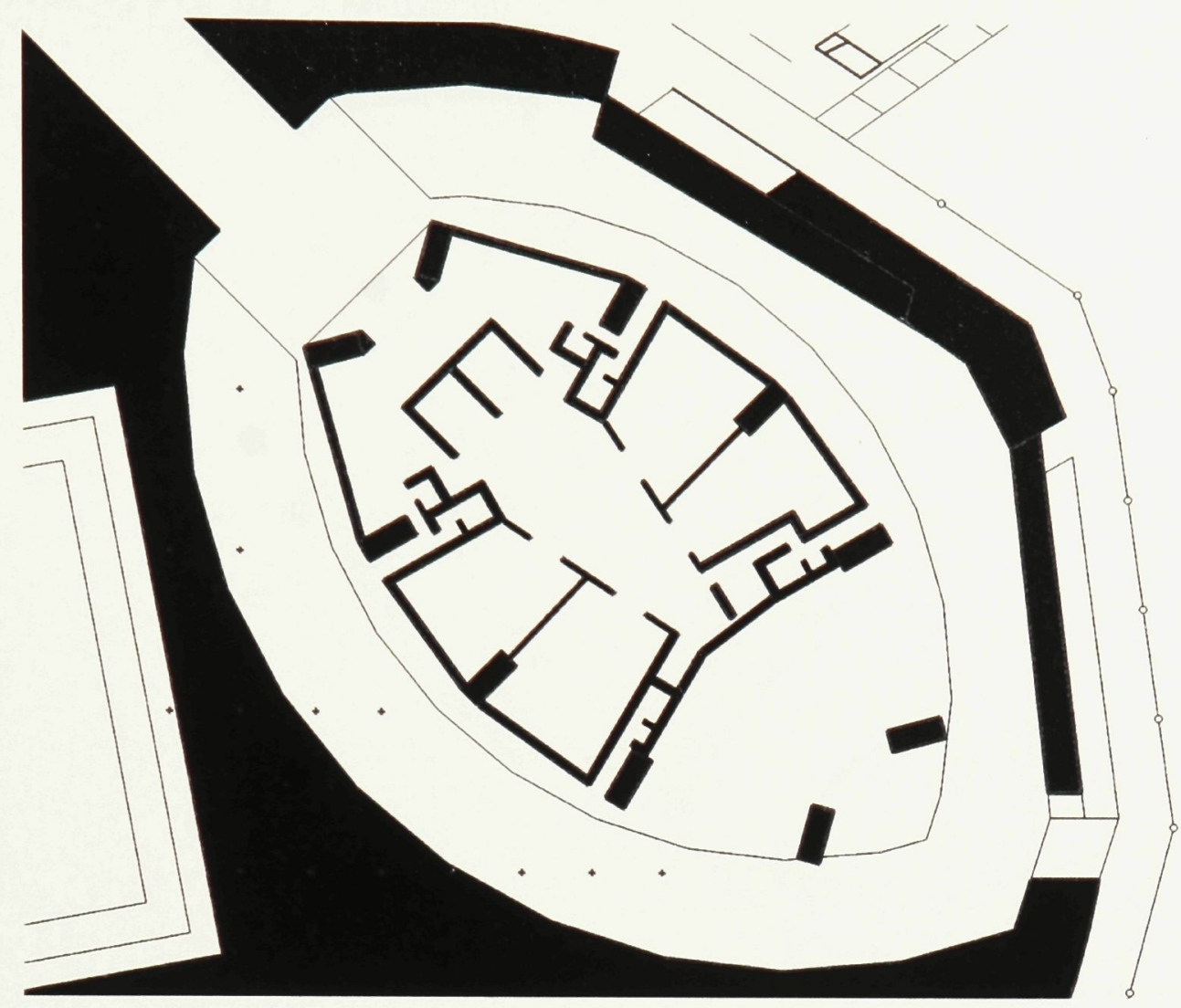

Fig. 6.3 Main Structure: Sub Floor Plan

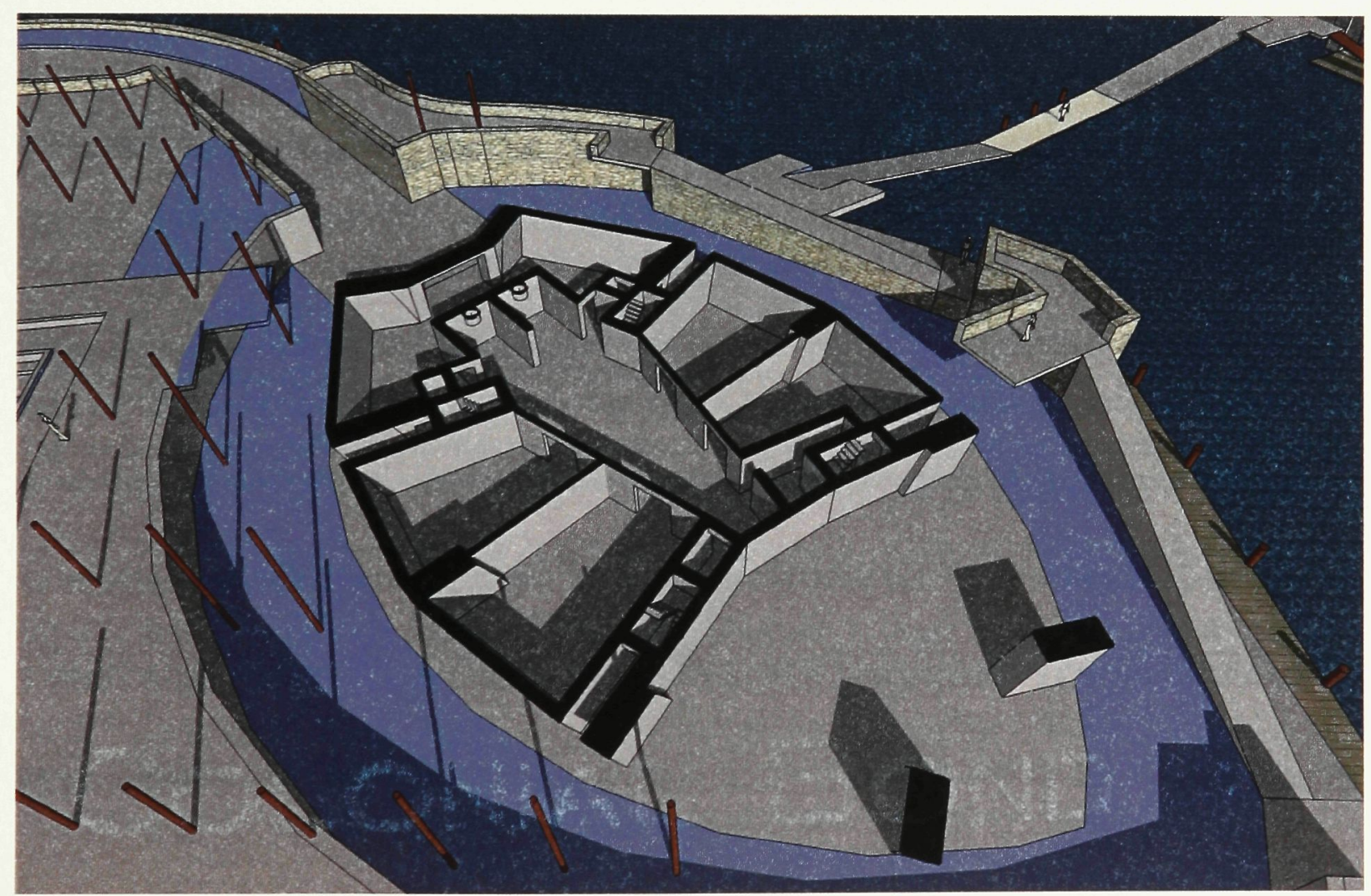

Fig. 6.4 Main Structure: Perspective Sub Floor Plan 


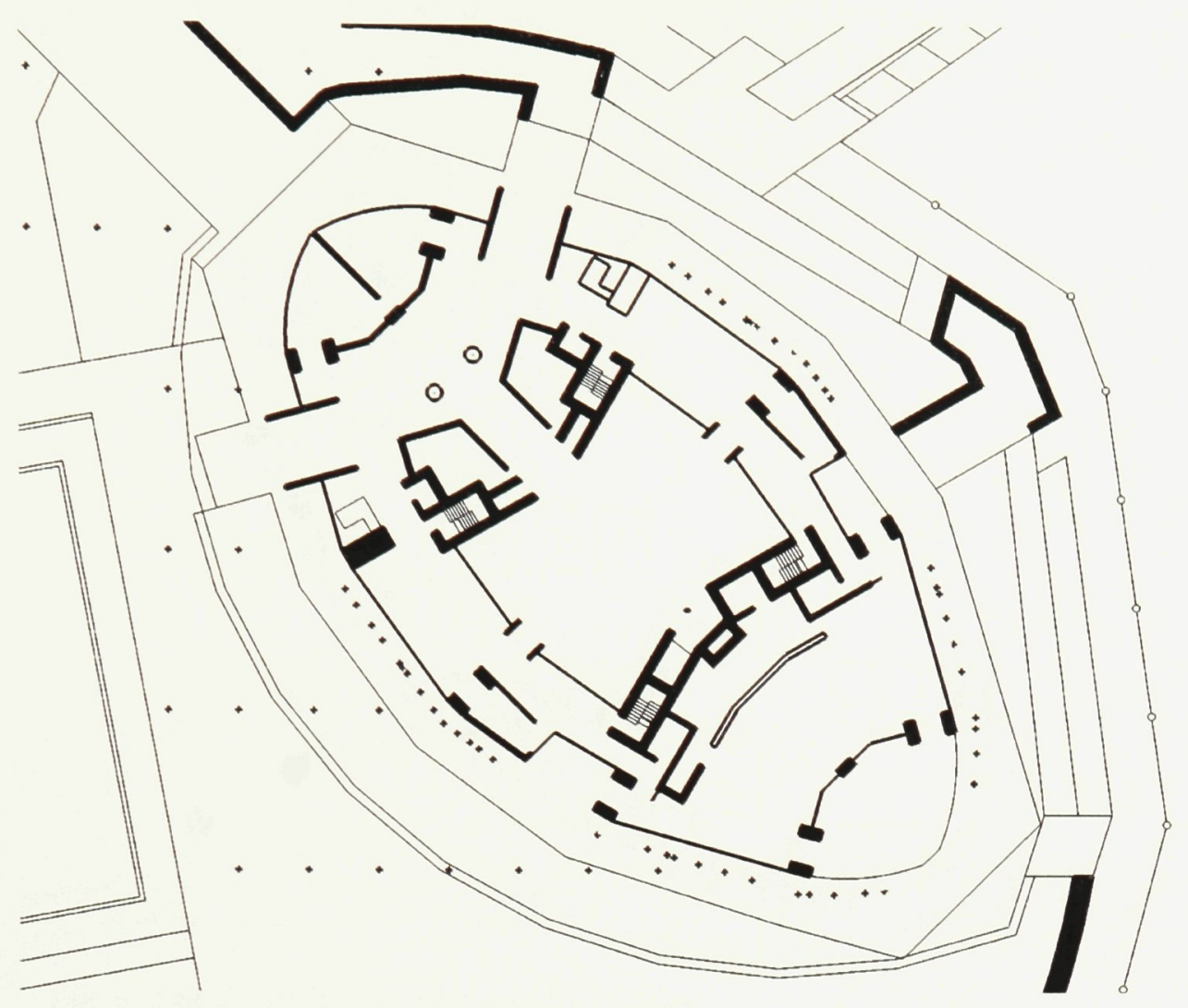

Fig. 6.5 Main Structure: First Floor Plan

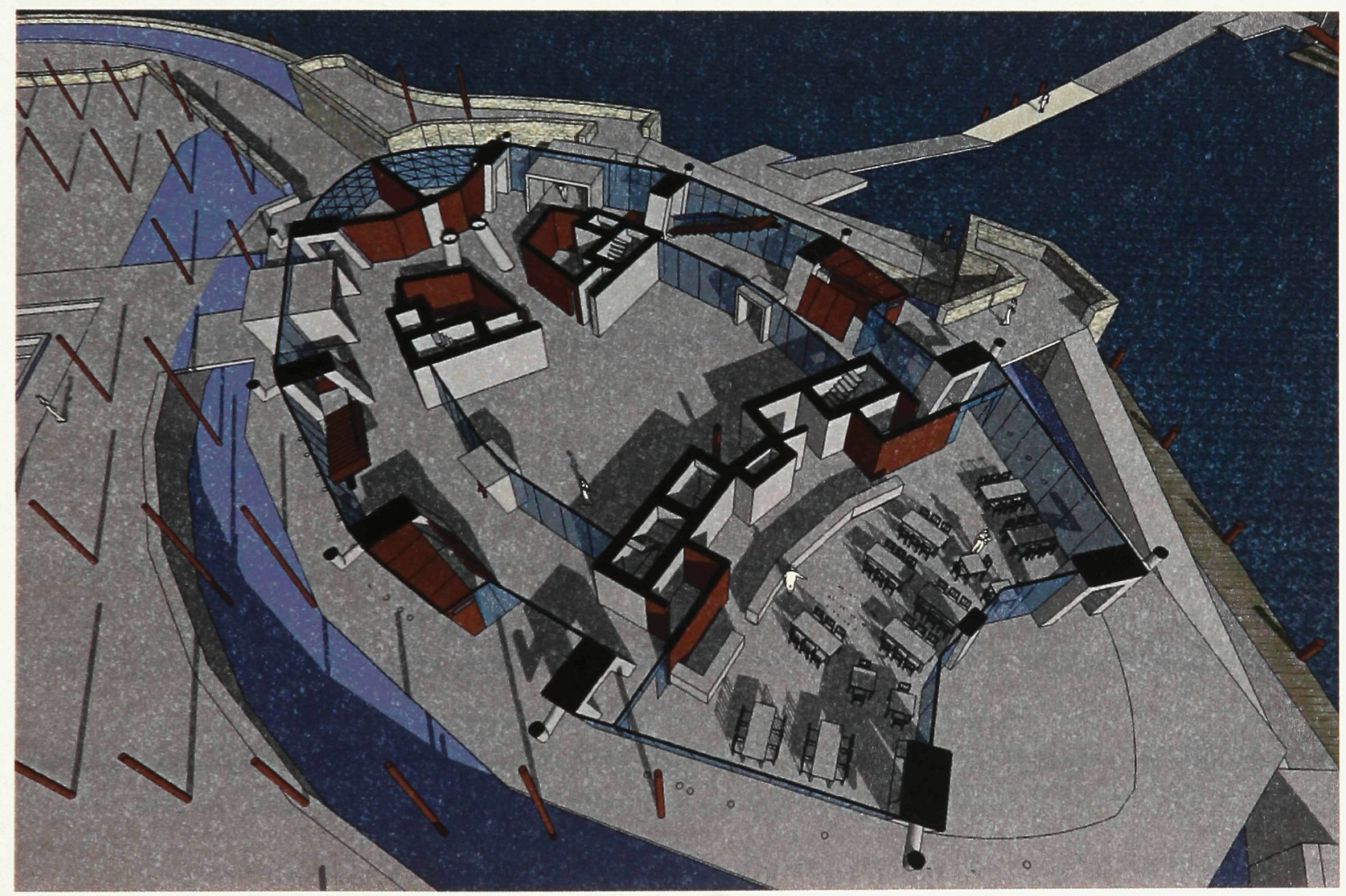

Fig. 6.6 Main Structure: Perspective First Floor Plan 


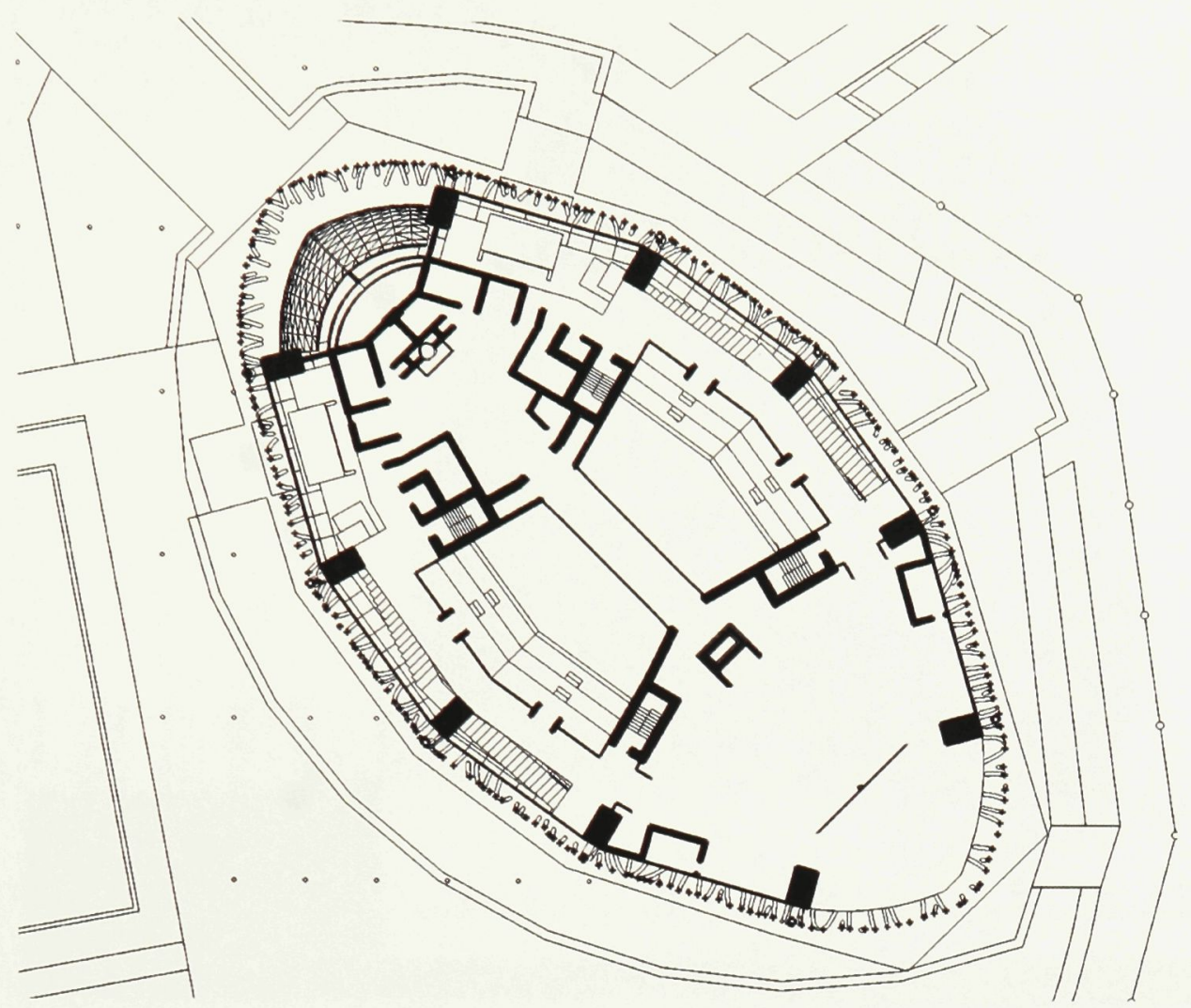

Fig. 6.7 Main Structure: Second Floor Plan

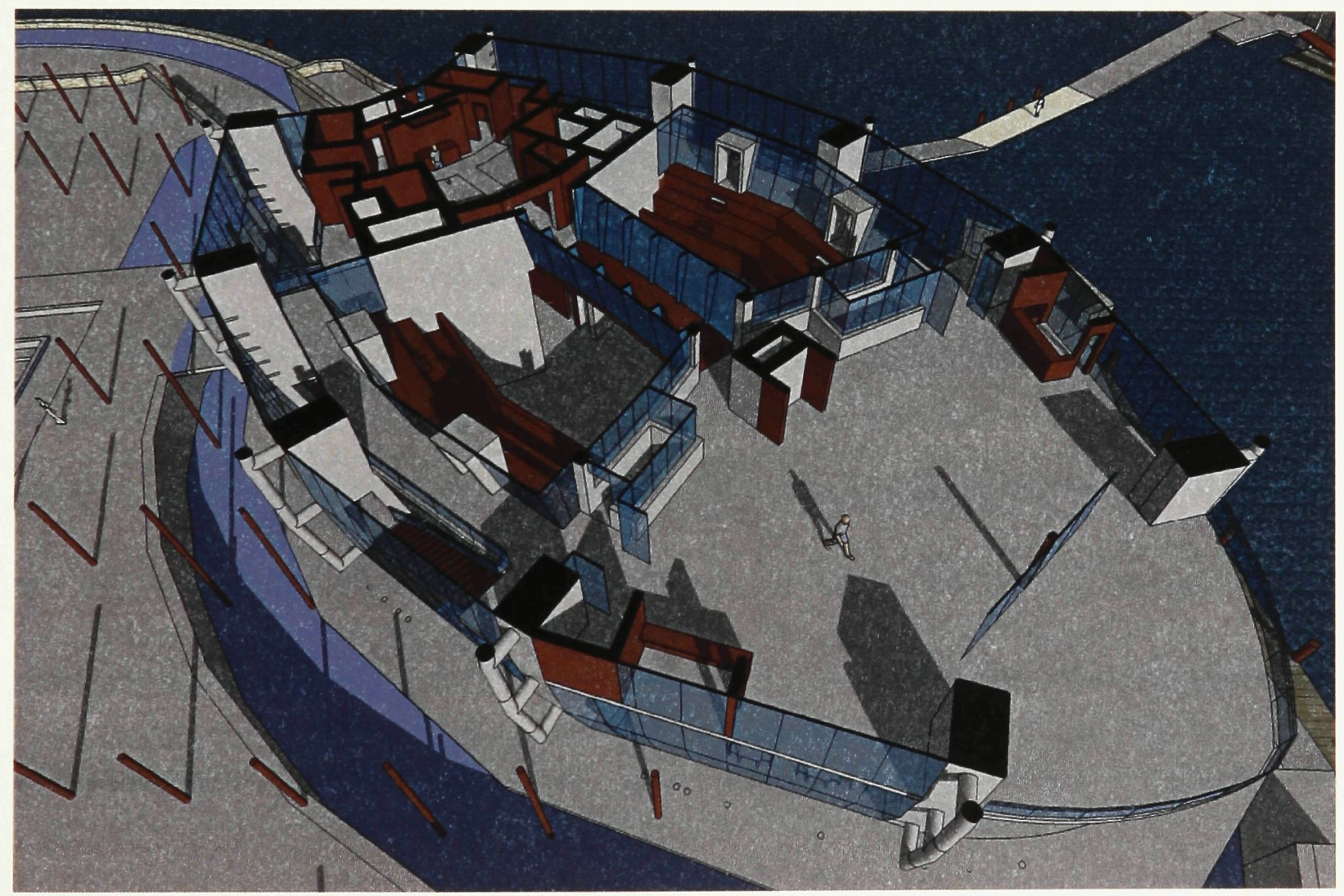

Fig. 6.8 Main Structure: Perspective Second Floor Plan 


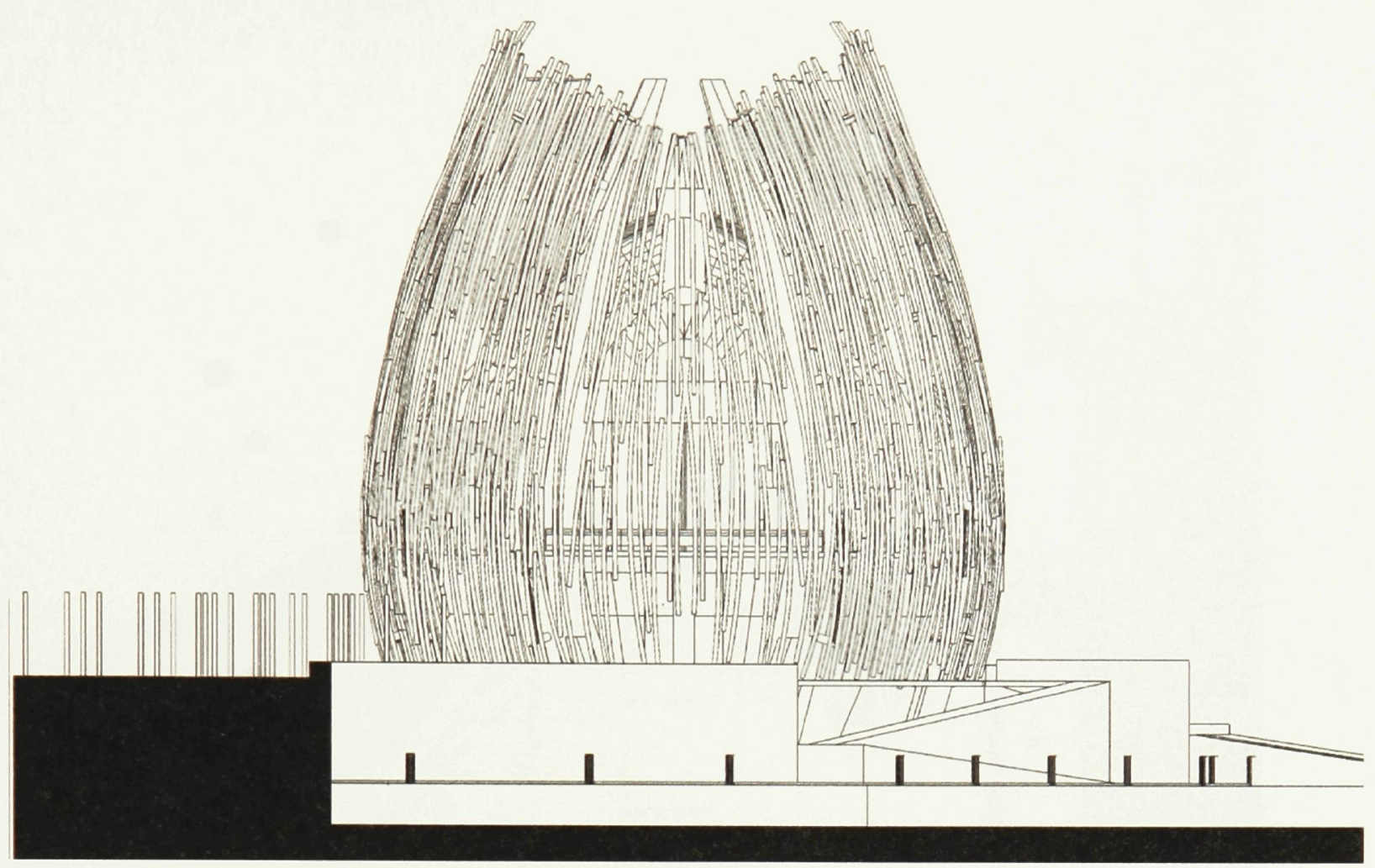

Fig. 6.9 Main Structure: North East Elevation

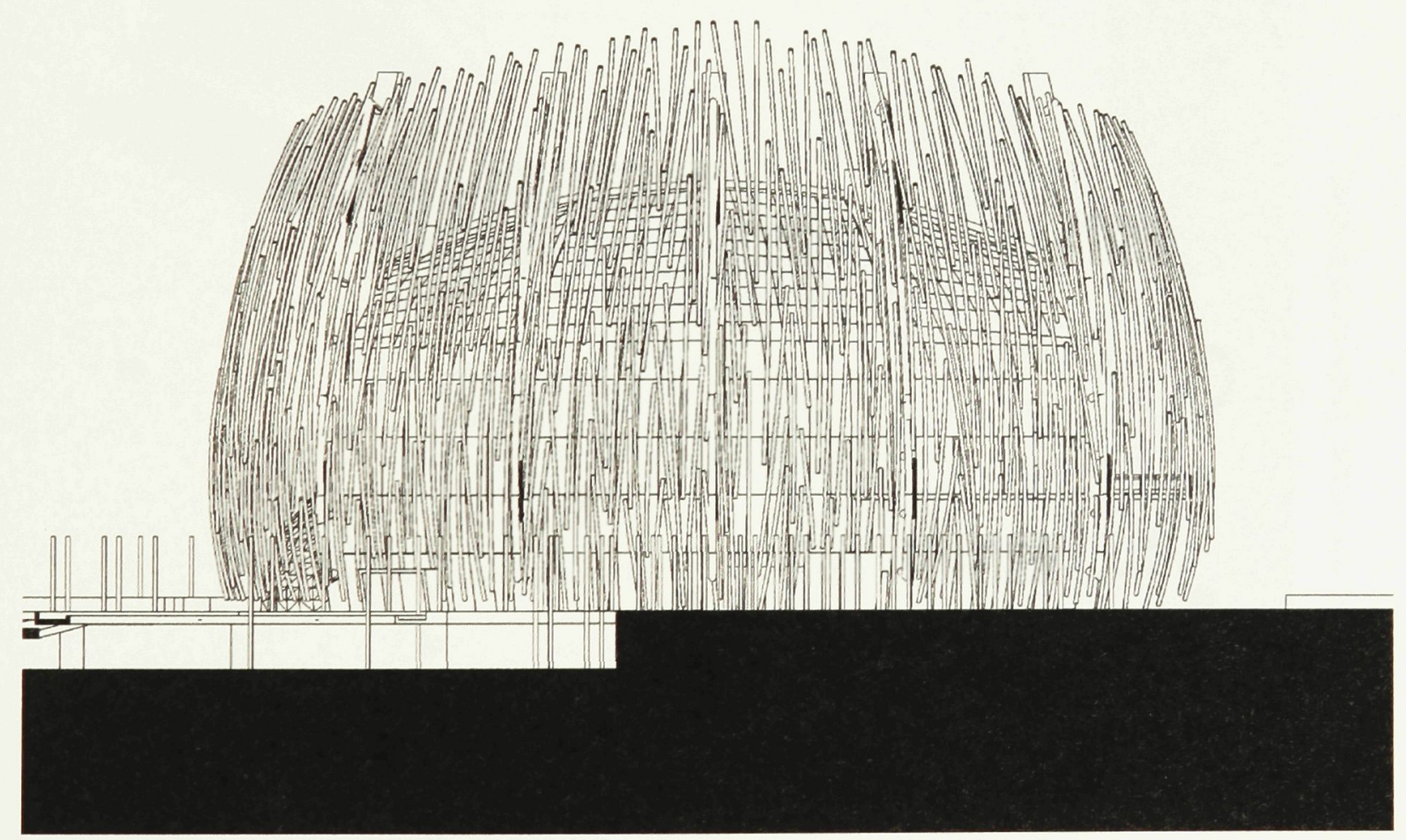

Fig. 6.10 Main Structure: North West Elevation

The Manifestation of an Idea 97 


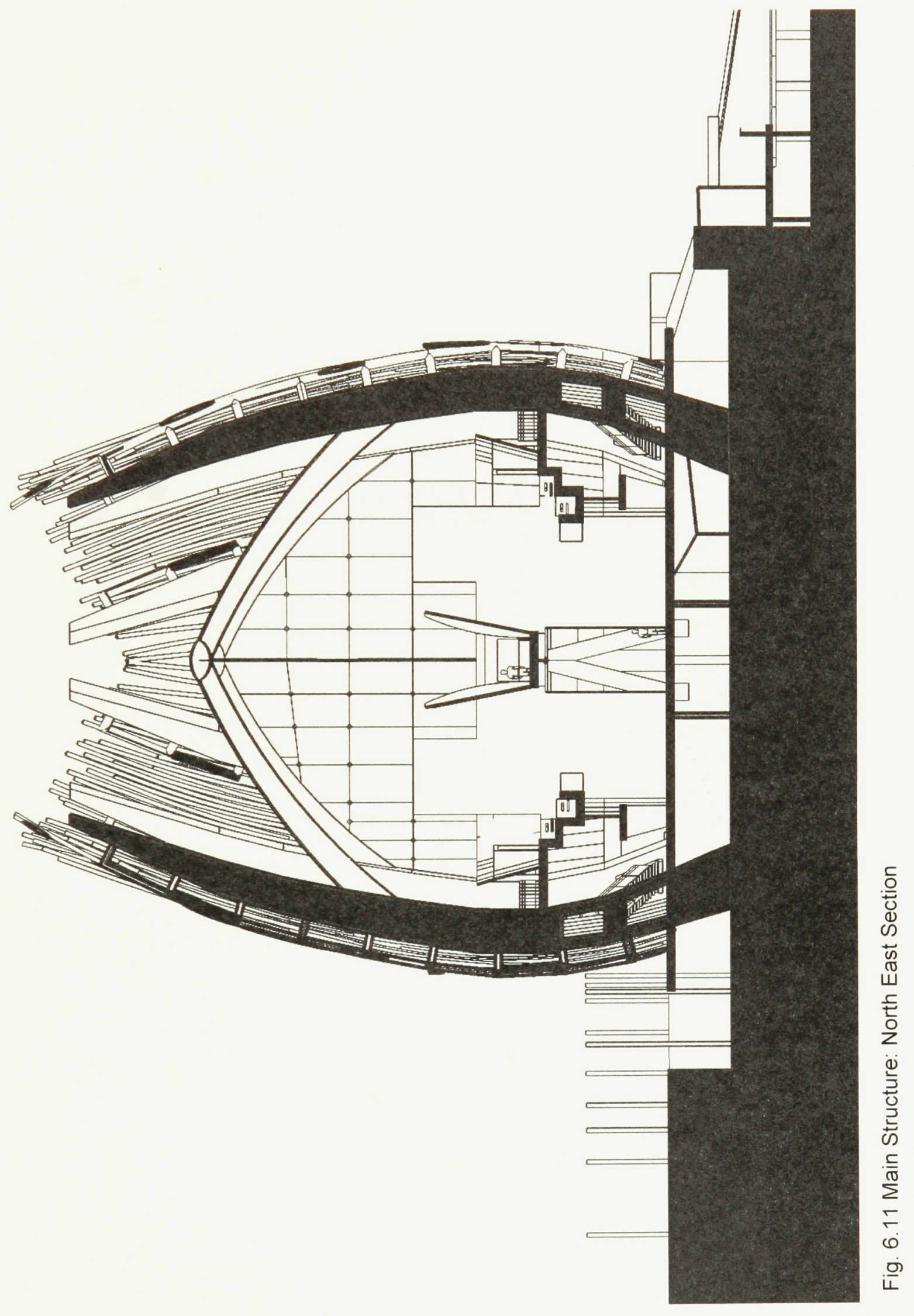

The Manifestation of an Idea 98 


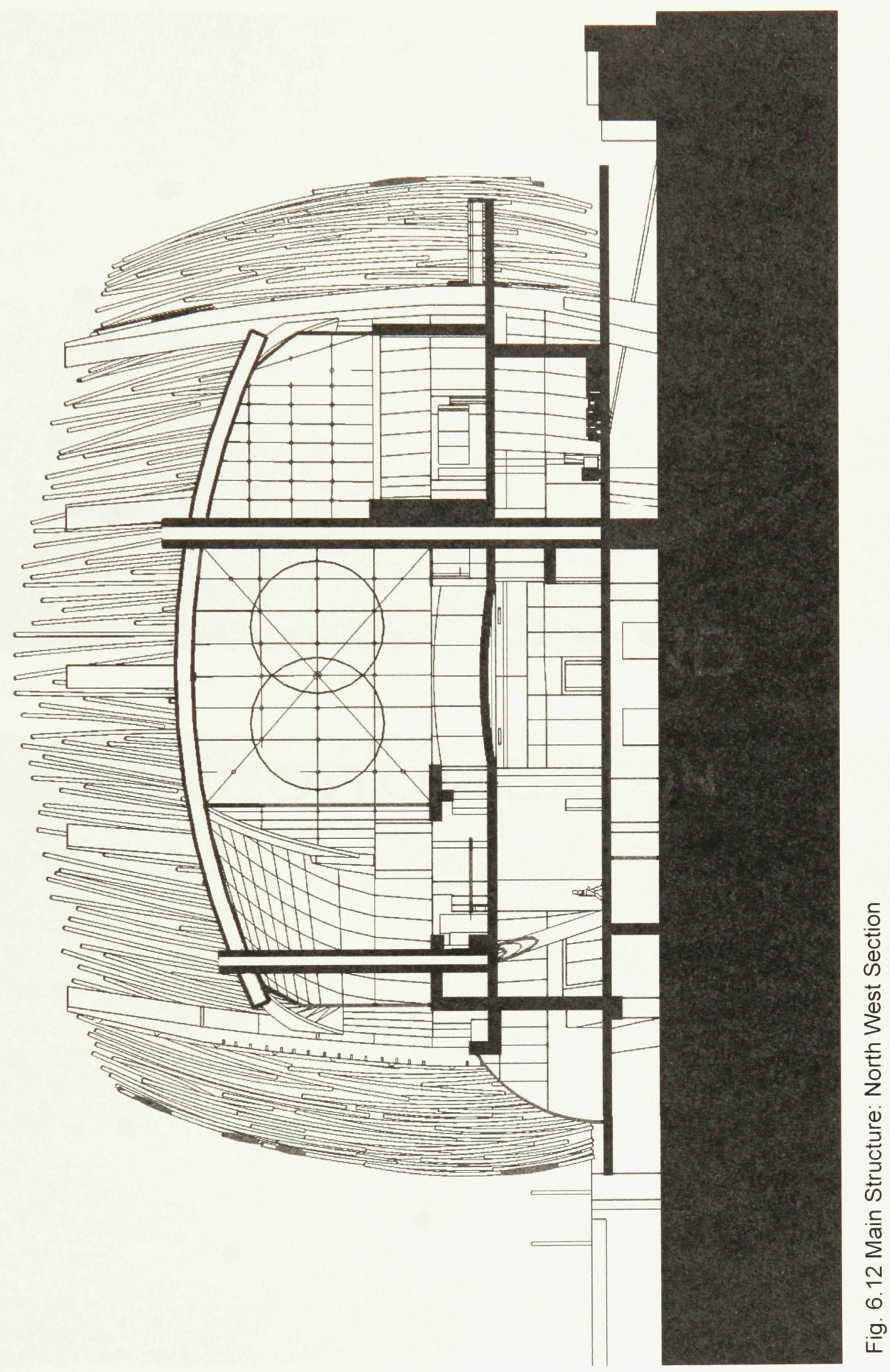

The Manifestation of an Idea 99 


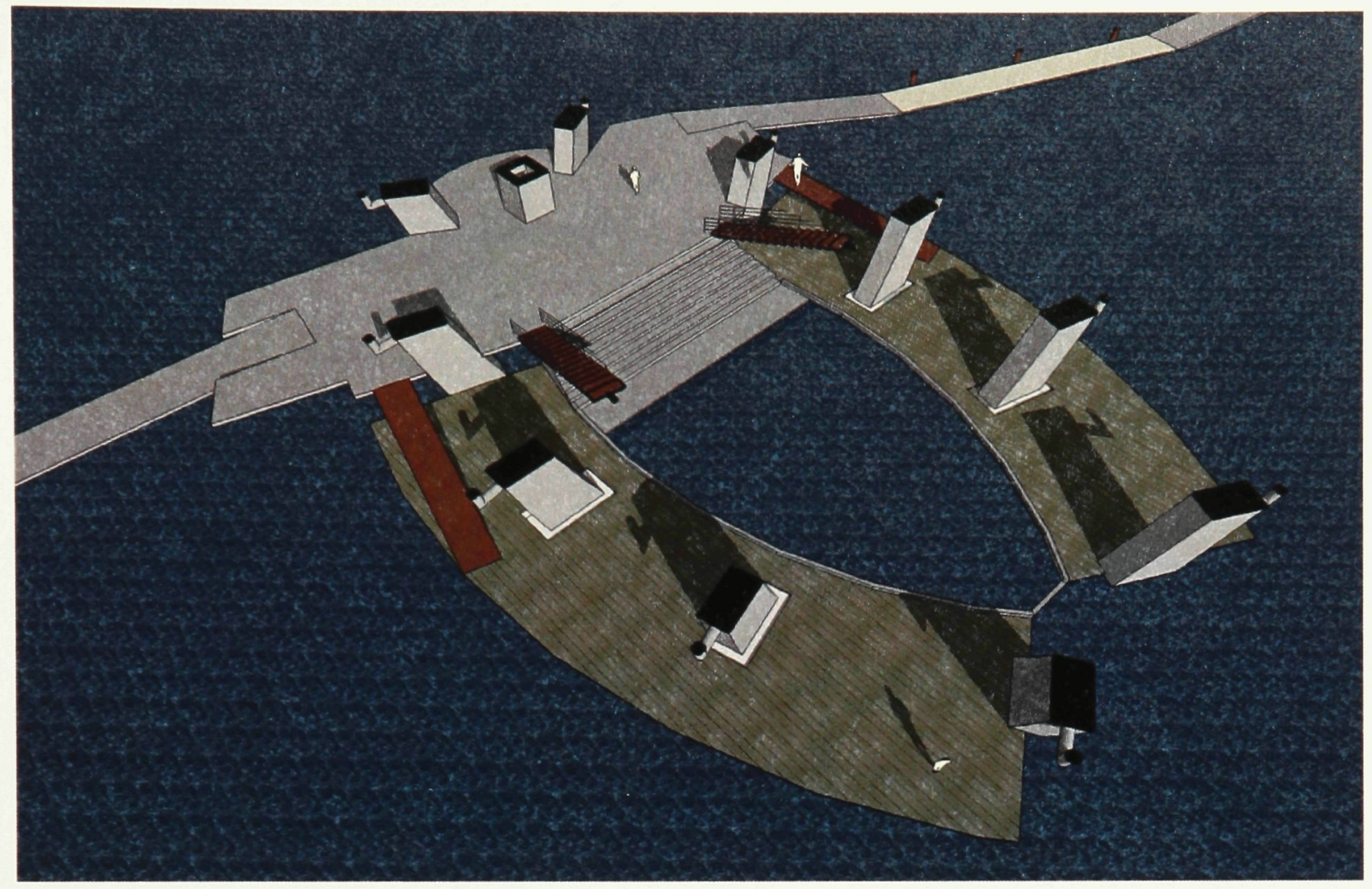

Fig. 6.13 Columbarium: Sub Floor \& First Floor Plan

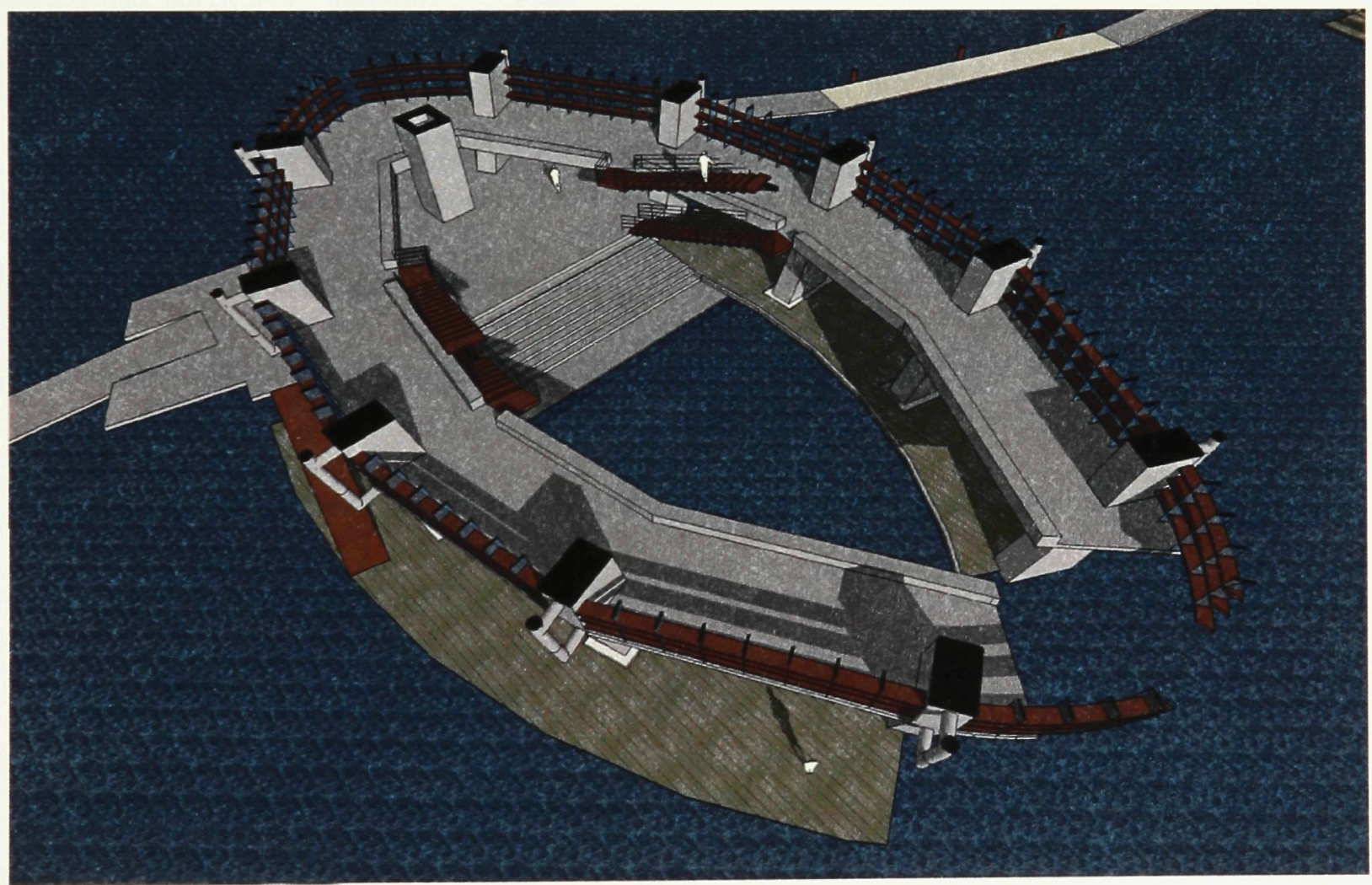

Fig. 6.14 Columbarium: Second Floor Plan 


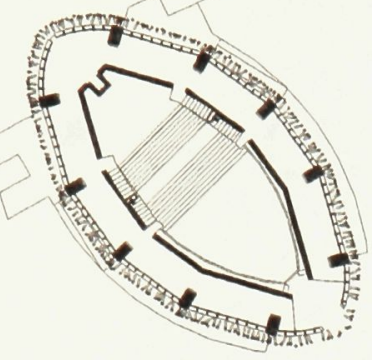

Fig. 6.15 Columbarium: Floor Plan 2

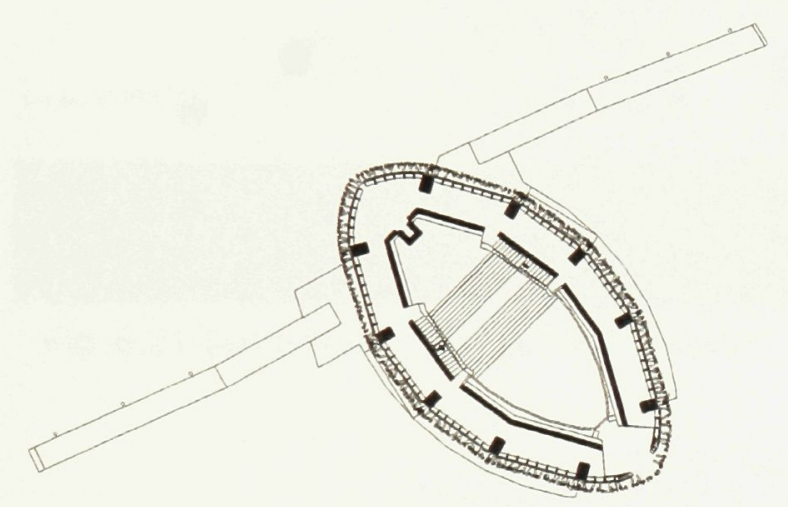

Fig. 6.17 Columbarium: Floor Plan 4

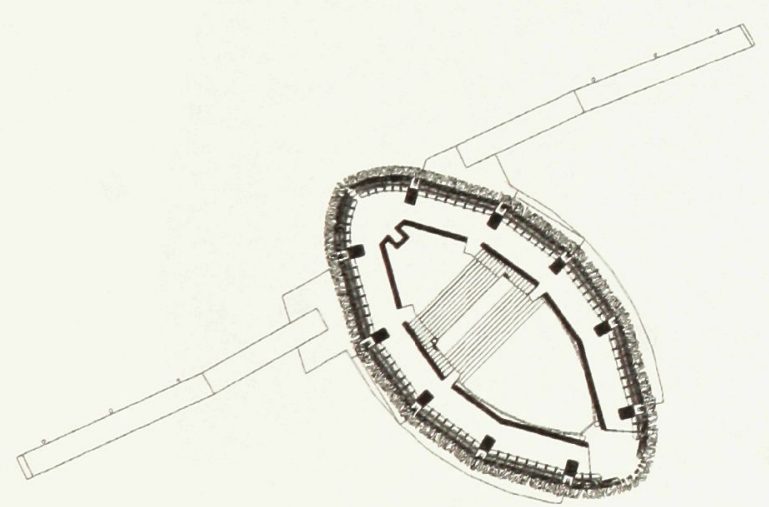

Fig. 6.19 Columbarium: Floor Plan 6

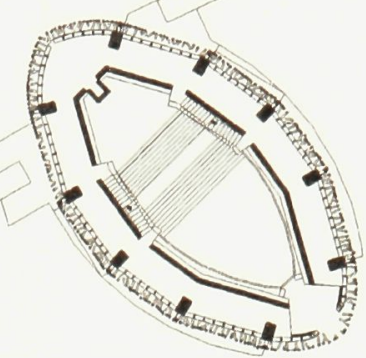

Fig. 6.16 Columbarium: Floor Plan 3

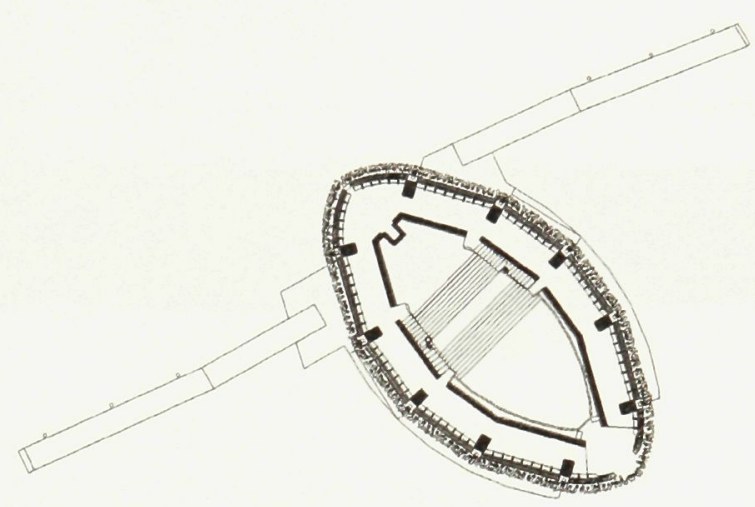

Fig. 6.18 Columbarium: Floor Plan 5

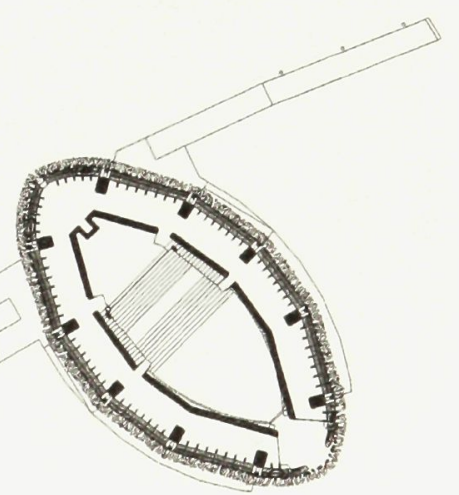

Fig. 6.20 Columbarium: Floor Plan 7 


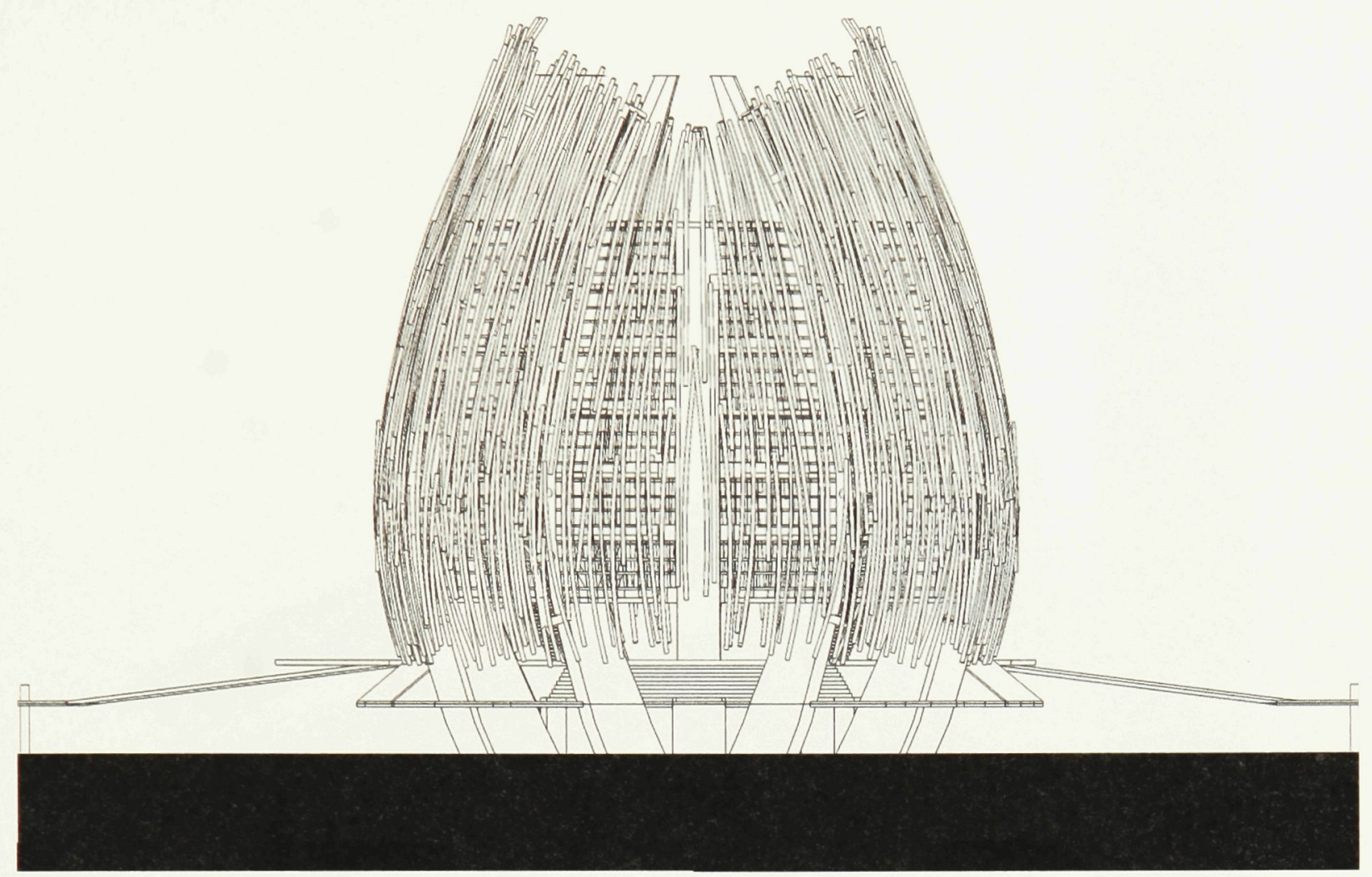

Fig. 6.21 Columbarium: North East Elevation

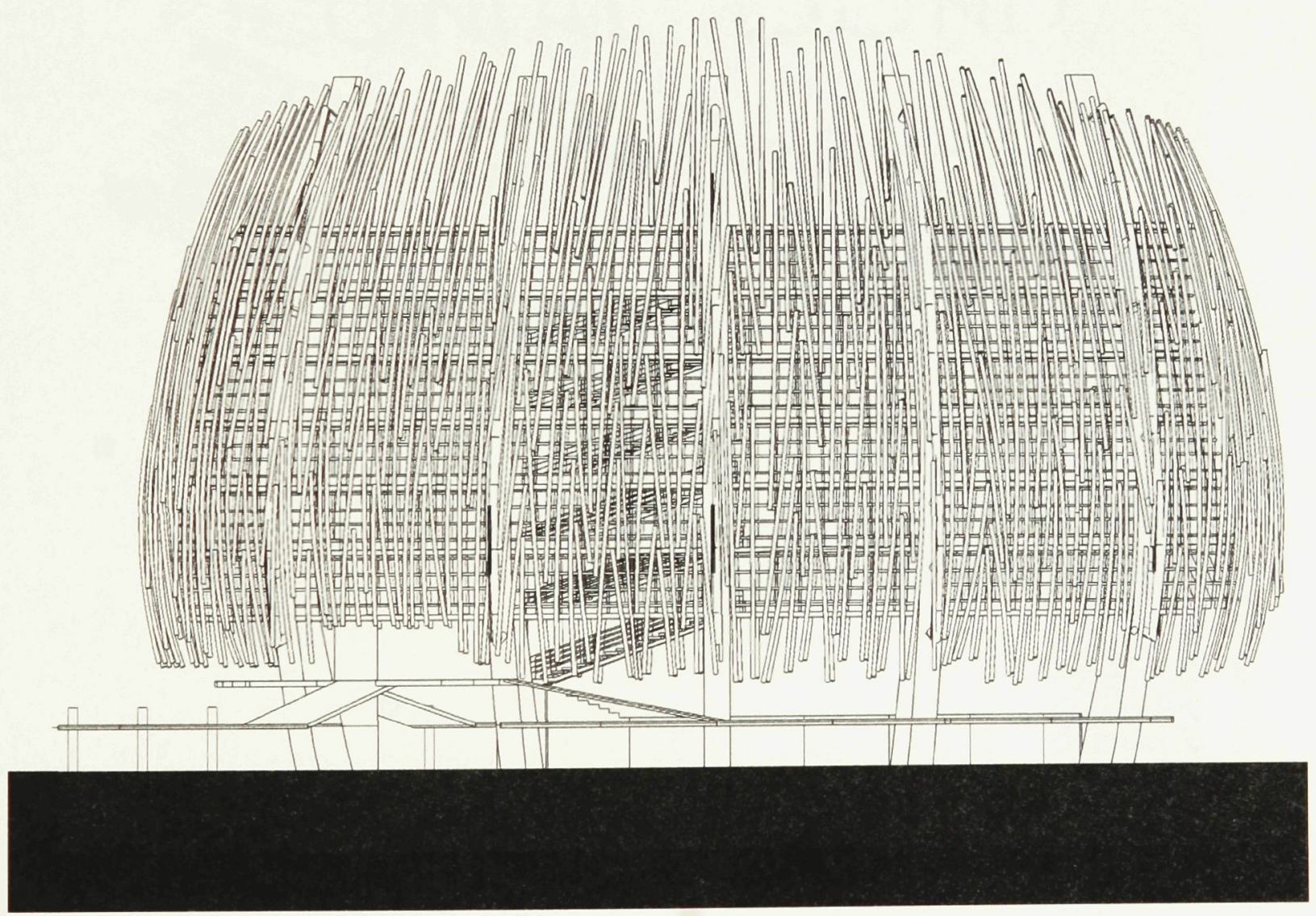

Fig. 6.22 Columbarium: North West Elevation 


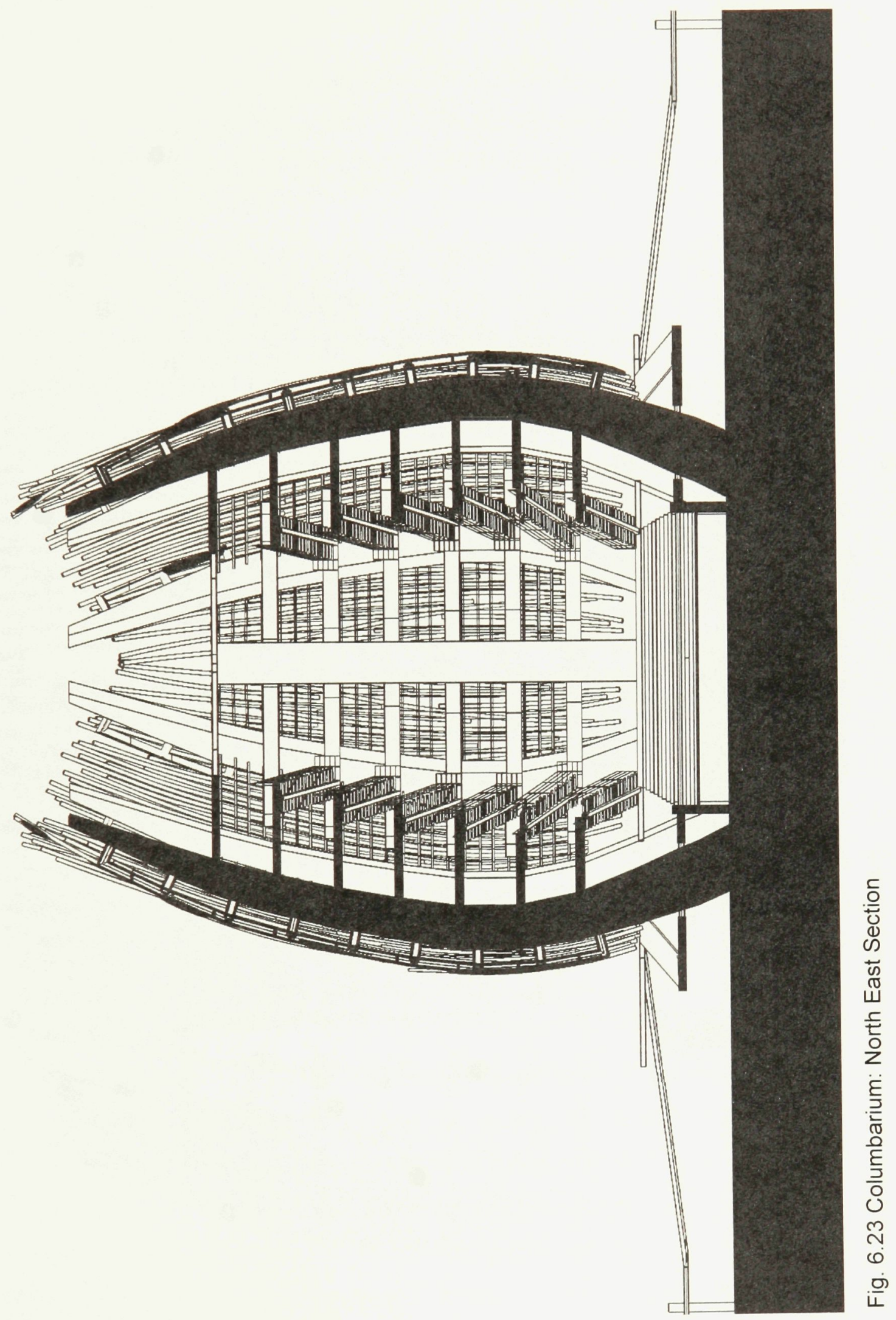

The Manifestation of an Idea 103 


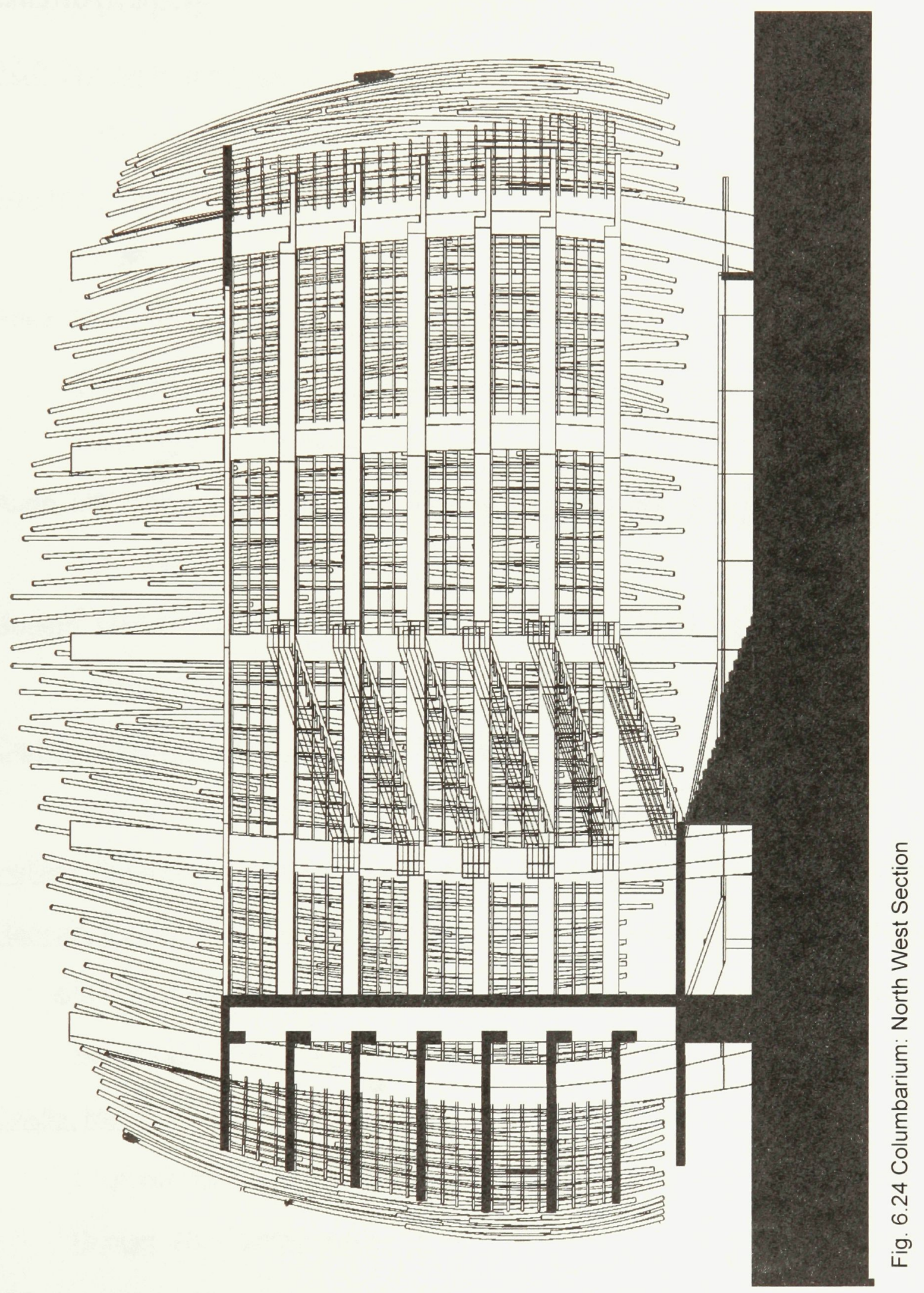

The Manifestation of an Idea 104 


\section{Bibliography}

ACC-Seattle Home Page Aug 29, 2005

$<$ http://www.acc-seattle.com/.../St_James_Acres.htm>.

Altreligion Home Page. Oct 15, 2004

<http://altreligion.about.com/library/weekly/aa101502a.htm>.

Ariès, Philippe, Western Attitudes Toward Death: From the Middle Ages to the

Present. Translated by Patricia M. Ranum (Johns Hopkins University

Press: London. 1974) 75.

Augé, Marc. Non-Places. Introduction to an Anthropology Of Supermodernity.

N.Y.: Verso, 1992

Bottero, Maria. "Carlo Scarpa: the Brion Family Cemetery, a Poetic Oasis."

Abitare. 272 (1963): 208-211

Cartoon Stock Home Page. August 29, 2005

$<h t t p: / / w w w . c a r t o o n s t o c k . c o m / d i r e c t o r y / f / f r e n c h \_f r i e s . a s p>$.

Hallam, Elizabeth. Death, Memory \& Material Culture (Berg: NewYork, 2001) 42.

Hannah, Dorita. "Butcher's White: Where the Art Market Meets The Meat Market

In New York City," Eating Architecture, Ed. Jamie Horowitz and Paulette

Singley (Mit: Cambridge, Massachusetts, 2004) 285.

Castle, Helen. "Death in Venice: The Spectre of the Tragedy in David

Chipperfield's New Extension to San Michele Cemetery." Architectural

Design. 70.5 (2000): 44-51

Frascari, Marco. "Semiotica ab Edendo, Taste in Architecture." Journal of Architectural Education. 4. 
Hiss, Tony. The Experience of Place. New York: Random House, 1990.

Jackson, J.B.. "The Vanishing Epitaph: From Monument to Place." Landscape. 17.2 (1967): $22-26$

Kephart, W. "Status After Death". American Sociological Review. 15.5 (1950): 642.

Knight, David B. Cemeteries as Living Landscapes. Ottawa: Ontario Genealogical Society, Ottawa Branch, 1973.

Kunze, Donald. "Architecture as the Site of Reception, Part 2: Sea-Food and Vampires." $\underline{\text { Chora. }} 2$ (1996): 13

"The Missing Guest: The Twisted Topology of Hospitality," Eating Architecture, Ed. Jamie Horowitz and Paulette Singley (MIT: Cambridge, Massachusetts, 2004) 171.

Maps by Air. 2004. 14 Dec 2004 <http://www.mapsbyair.com/>.

Miller, Chris. "Spirits of Deadman's." The Vancouver Courier 15 Dec 2004. 30 Oct 2003 http://www.vancourier.com.

Morris, Mark. "Architecture Yum!" Architectural Design. 56.

Oaten, Jim. "Dead on Arrival." Vancouver Magazine 15 Dec 2004 <http://www.vanmag.com/9708/secrets_dead.html>.

Price, Larry W. "Some Results and Implications of a Cemetery Study." Professional Geographer. 18.4 (1966): 201-207 Rifkin, Jeremy. Beyond Beef: The Rise and Fall of the Cattle Culture (New York: Penguin Books, 1992)

"San Michele Cemetery." Architecture and Urbanism. 402.3 (2004): 51 
Scholliers, Peter. Food, Drink and Identity: Cooking, Eating and Drinking in Europe (New York: Berg, 2001) 7.

Singley, Paulette. "Hard To Swallow: Mortified Geometry and Abject Form,"

Eating Architecture, Ed. Jamie Horowitz (MIT: Cambridge, Massachusetts, 2004) 342 .

Sopher, David. Geography of Religions, N.J.: Prentice-Hall, 1967.

Taylor, David. "News in Pictures: Chipperfield Takes on Death in Venice." The Architects Journal 208.6 (2004): 10-12

Visser, Margaret. Much Depends on Dinner: The Extraordinary History and Mythology, Allure and Obsessions, Perils and Taboos, of and Ordinary Meal. Toronto: McMlelland and Stewart. 1987

The Geometry of Love: Spaces, Time, Mystery, and Meaning in an Ordinary Church (HarperCollins: Toronto. 1991) 108.

The Way We Are (Toronto: HarperCollins. 1994) 213.

Price, Larry. "Some Results and Implications of a Cemetery Study". Professional Geographer. 205

Wikipedia Home Page. Oct 17, 2004 http://en.wikipedia.org/wiki/Cardo.com $<$ http://en.wikipedia.org/wiki/Decumanus_Maximus.com>. $<$ http://en.wikipedia.org/wiki/Augur.com>.

Wynn, Graeme. Vancouver and Its Region. Vancouver: UBC, 1992

Young, F. "Graveyards and Social Structure." Rural Sociology. 25 (1960): 447. 